\title{
Pulmonary Arterial Hypertension
}

\section{Evangelos D. Michelakis and Stephen L. Archer}

Introduction and History of the Pulmonary Circulation . . . . . . . . . . . . . . . . . 2203

Definition of Pulmonary Hypertension. . . . . . . . . . 2204

Classification of Pulmonary Arterial Hypertension and Association with Other Diseases .......... 2204

Prevalence and Natural History of Pulmonary Arterial Hypertension . . . . . . . . . . . . . . . . . . . . 2206

The Changing Epidemiology of Pulmonary

Arterial Hypertension . . . . . . . . . . . . . . . . . 2207

The Mysteries of the Pulmonary Circulation. . . . . . 2207

The Development of the Pulmonary Circulation. . . . 2208
Vascular Diversity Within the Pulmonary Circulation . . . . . . . . . . . . . . . . . 2208

Vascular Biology of Pulmonary Arterial Hypertension . . . . . . . . . . . . . . . . . 2211

Clinical Recognition of Pulmonary Arterial Hypertension . . . . . . . . . . . . . . . . . . . 2217 Comorbidities with Pulmonary Arterial Hypertension . . . . . . . . . . . . . . . . . . 2227 Management of Pulmonary Arterial Hypertension. . . 2230 An Evidence-Based Approach to the Patient with Pulmonary Arterial Hypertension. . . . . . . . . . . . 2238

\section{Introduction and History of the Pulmonary Circulation}

The first description of the circulation of blood through the lungs has been attributed to Ibn Nafis (1210-1288). ${ }^{1}$ The concept was rediscovered by Michael Servetus, a Spanish physician during the Renaissance (1511-1553) and recorded, oddly enough, in two pages of his religious treatise, Christianismi Restitutio (1553). ${ }^{2}$ The definitive exposition of the pulmonary circulation was made by William Harvey in DeMotu Cordis (1628). ${ }^{3}$ The first observation of the pulmonary capillaries was first reported by Marcellus Malpighi (1661). ${ }^{4}$ Heart catheterization in humans, driven by a desire to obtain the perfect mixed venous specimen and measure cardiac output, was first performed in 1929 by the German urologist Forssmann, ${ }^{5}$ using a ureteral catheter to access his own right atrium. Over a decade later, Cournand and Richards at Columbia University in New York subsequently used right heart catheterization to record pulmonary artery pressure (PAP) in patients with shock and secondary forms of pulmonary hypertension (PHT). For these accomplishments, which were inspired by an interest in the pulmonary circulation and PHT related to mitral stenosis, Forssmann, Cournand, and Richards received the Nobel Prize in 1956.

Pathologic findings consistent with primary PHT were first noted in autopsy specimens as a form of arterial sclerosis by Romberg ${ }^{6}$ and Monckeberg ${ }^{7}$ over a century ago. However, the first diagnosis of primary PHT in a living human was not made until 1951, by Dresdale et al. ${ }^{8}$ Over the past 50 years it has become clear that primary PHT is largely a disease of the pulmonary circulation, and the pathology is focused in the small pulmonary arteries, which are characterized by intimal fibrosis, medial hypertrophy, adventitial proliferation, obliteration of small arteries, and, on occasion, vasculitis or changes in the walls of the pulmonary veins. ${ }^{9}$ In addition, there are angioproliferative lesions, called plexiform lesions, which are uniquely found in pulmonary arterial hypertension (PAH) and not in other forms of PHT.

In utero, the pulmonary circulation is largely bypassed, as oxygenation is the responsibility of the placenta. The fetal right ventricle, relative to the adult ventricle, is hypertrophied, and the arteries in this high pressure-low flow circuit have thickened media and adventitia. At birth there is a transition to a high-flow, low-resistance circuit designed for gas exchange, and the right ventricle becomes a thin-walled, afterload-intolerant pump. The adult pulmonary circulation accommodates the entire right heart cardiac output at $20 \%$ the pressure and resistance of the systemic vasculature. The pulmonary circulation is composed of large, extrapulmonary, "conduit" arteries, which anatomically and embryologically resemble systemic arteries, and small, muscular intrapulmonary arteries, which control regional distribution of pulmonary blood flow and largely determine pulmonary vascular resistance (PVR). These arteries perfuse an extensive thin-walled, metabolically active, capillary bed where gas exchange occurs. Blood then courses to the left atrium via the venous circulation, which has active tone and which, as it approaches the left atrium, acquires a sleeve of cardiac myocytes. ${ }^{10}$ The normal physiologic function of the pulmonary veins is uncertain, although they may be involved in coordinating venous flow with atrial function. In disease, the pulmonary veins can be a source of ectopy, which leads to atrial fibrillation. ${ }^{11}$ 


\section{Definition of Pulmonary Hypertension}

Pulmonary hypertension is a condition defined as an increase of the mean PAP to more than $25 \mathrm{~mm} \mathrm{Hg}$ at rest or $30 \mathrm{mmHg}$ with exercise. This definition was used in the National Institutes of Health (NIH) registry of patients with primary $\mathrm{PHT}^{12}$ a form of $\mathrm{PAH}$ in which the etiology is unknown and the pathology is focused in the arterial portion of the pulmonary circulation. Although this chapter focuses on PAH, the most common forms of PHT are "passive," relating to left ventricular dysfunction with increased left ventricular end-diastolic pressure due to myocardial or valve disease. In this pathology there is usually relatively minor pulmonary vascular pathology, although some patients with left heart failure or mitral stenosis have more severe PHT than would be predicted based on their left atrial pressure, suggesting a reactive form of PAH. The use of PAP as a means to diagnose PAH is flawed because it is not precise in anatomically localizing the cause of the hypertension. For example, the elevated PAP in left heart diseases is due to the elevated pulmonary capillary wedge pressure and the gradient between the PA diastolic pressure and the wedge pressure is minimal. In contrast, in PAH this gradient is more than 10 to $12 \mathrm{~mm} \mathrm{Hg}$, localizing the problem (obstruction) within the pulmonary circulation, proximal to the left atrium.

Pulmonary artery pressure increases slightly with age and normally increases with conditions that elevate cardiac output (e.g., exercise), even in healthy, young individuals. In healthy older men (ages 61 to 83 years), the mean PAP can increase to more than $40 \mathrm{~mm} \mathrm{Hg}$ during exercise. With exercise, PAP, wedge pressure and cardiac output are all elevated but PVR is relatively unchanged. Consequently, PVR (Table 105.1) is a better parameter with which to define pulmonary arterial pathology. Conversely, PAP may be minimally elevated in a patient with PAH and very low cardiac output; in such a case PVR is usually ele- vated at rest. In borderline cases, exercise can be used to elicit dramatic increases in PVR. The upper limit for PVR index [(PAP-wedge pressure $) /$ cardiac index] in normal subjects increases from approximately $2.8 \mathrm{~mm} \mathrm{Hg} / \mathrm{L} / \mathrm{min} / \mathrm{m} / 6$ to 10 years) to 3.2 (32 to 45 years) to 4.6 (60 to 83 years). ${ }^{13}$ Pulmonary vascular resistance must be measured in order to diagnose PAH.

The occurrence of PHT, whether as a primary disease or a complication of heart or airway disease (cor pulmonale) is an independent predictor of increased morbidity and mortality. This is because the impact on the function of the afterload-intolerant right ventricle is the same, regardless of the specific etiology of PHT. The function of the thin-walled adult right ventricle decreases abruptly even with small increases in its afterload, resulting in decreases in stroke volume and thus cardiac output. This is in sharp contrast to the left ventricle, which can compensate for much greater increases in afterload (Fig. 105.1).

\section{Classification of Pulmonary Arterial Hypertension and Association with Other Diseases (Table 105.2)}

Twenty-five years following the original meeting, the World Health Organization (WHO) sponsored the second International primary PHT meeting in Evian, France, where a new classification of PHT syndromes was adopted..$^{14}$ Importantly, primary PHT (both sporadic and familial) was grouped with several other forms of PHT that strongly resembled primary PHT under the rubric of pulmonary arterial hypertension. These "primary PHT-like" cases were associated with identifiable pathogenic stimuli or disease states, such as the use of anorectics, collagen vascular disease, infection with HIV, congenital systemic to pulmonary shunts, and persistent PHT of the newborn. This reclassification reflected the fact that the clinical presentation and the histologic picture

TABLE 105.1. Useful formulas for assessment of pulmonary hypertension

\begin{tabular}{|c|c|c|}
\hline Parameter & Formula & Normal Values \\
\hline $\begin{array}{l}\text { PVR } \\
\qquad \mathrm{mmHg} / \mathrm{L} / \mathrm{min} / \mathrm{m}\end{array}$ & PVR $($ Wood units $)=\left[\frac{P A_{\text {mean }}-P_{\text {wedge }}}{\text { Cardiac output }}\right]$ & $\begin{array}{l}\text { Age } 6-10 \text { years: } 2.8 ; \text { Age } 32-45 \text { years: } \\
\text { 3.2; Age }>60 \text { years: } 4.6^{13}\end{array}$ \\
\hline $\begin{array}{l}\text { PVR } \\
\text { dynes sec } \mathrm{cm}^{-5}\end{array}$ & $P V R\left(\right.$ dyne $\left.\sec \mathrm{cm}^{-5}\right)=\left[\frac{P A_{\text {mean }}-P_{\text {wedge }}}{\text { Cardiac output }}\right] \times 80$ & $\begin{array}{l}<60 \text { years: mean PAP: } 12 \pm 2 \mathrm{~mm} \mathrm{Hg} \\
\text { PVR: } 70 \pm 25 \\
>60 \text { vears: mean PAP: } 16 \pm 3 \mathrm{~mm} \mathrm{Hg}\end{array}$ \\
\hline $\begin{array}{l}\text { Total pulmonary } \\
\text { resistance (TPR) }\end{array}$ & $T P R($ Wood units $)=\left[\frac{P A_{\text {mean }}}{\text { Cardiac output }}\right]$ & PVR: $124 \pm 32$ \\
\hline $\begin{array}{l}\text { PAP mean (based on } \\
\quad \text { acceleration time, AT) }\end{array}$ & $\begin{array}{l}P A P_{\text {mean }}=79-(0.45 \times A T) \text { or } 90-(0.62 \times A T) \\
\text { Based on pulsed Doppler measurement in the main } \mathrm{PA}^{137,246}\end{array}$ & $121 \pm 27 \mathrm{~ms}^{135}, 134 \pm 20 \mathrm{~ms}^{246}$ \\
\hline PA Doppler & $\begin{array}{l}P A P=A T / R V E T^{247} \\
(\mathrm{RVET}=\text { right ventricular ejection time })\end{array}$ & $\begin{array}{l}>0.36 \\
\text { Doppler values in main PA of adults; } \\
\text { velocity } 70 \mathrm{~cm} / \mathrm{s} \text { and ET of } 320 \mathrm{~ms}\end{array}$ \\
\hline $\begin{array}{l}\text { PA systolic pressure } \\
\text { (TR velocity, } \mathrm{V}_{\text {TR }} \text { ) } \\
\text { (modified Bernoulli's } \\
\text { equation) }\end{array}$ & PA systolic pressure $=4 \times V_{T R}^{2}+R A$ pressure ${ }^{\star}$ & \\
\hline
\end{tabular}

\footnotetext{
*Estimated from JVP.
} 

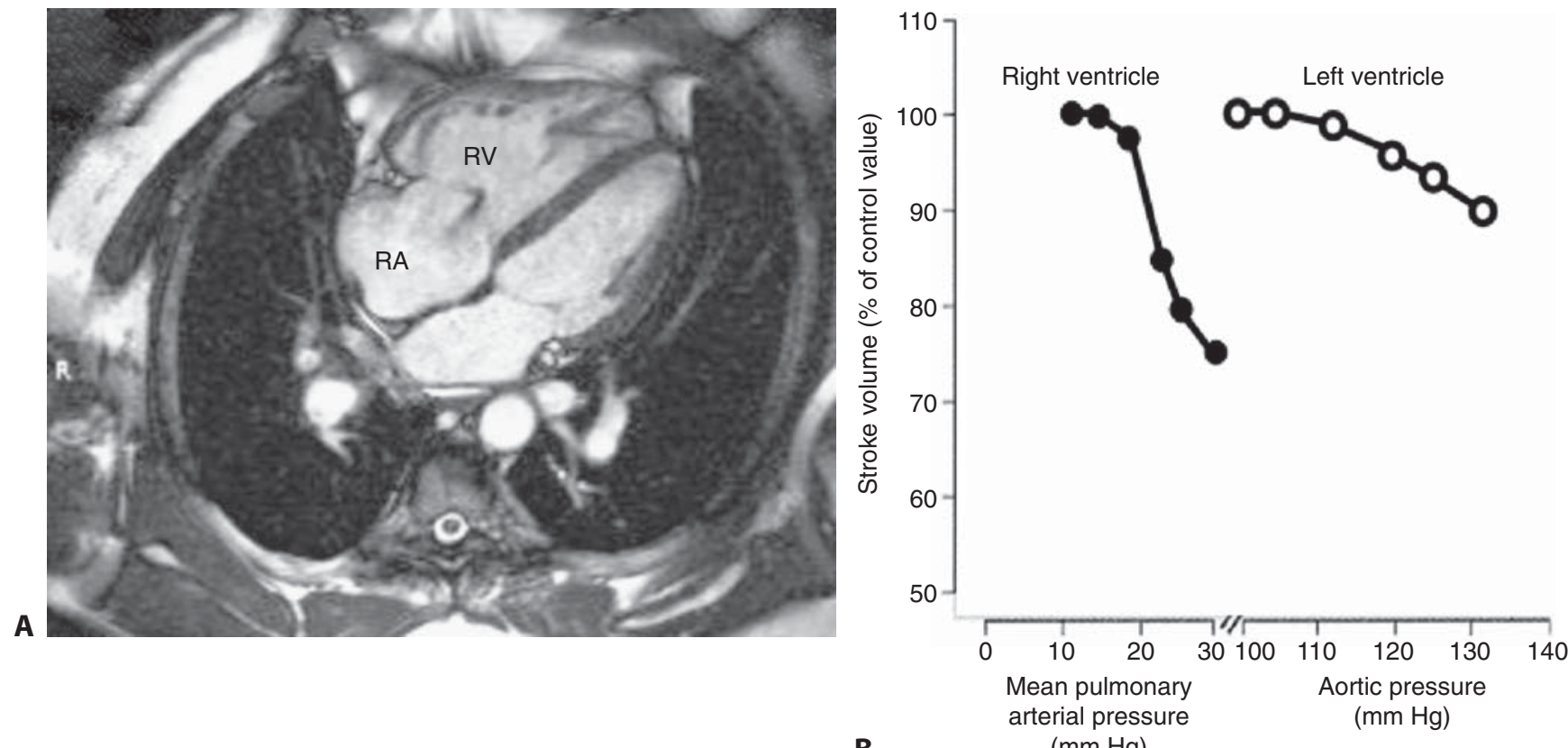

FIGURE 105.1. The right ventricle (RV) in pulmonary arterial hypertension (PAH). (A) A dilated RV is seen in this magnetic resonance (MR) angiography of a 55-year-old man with PAH. A dilated right atrium (RA) is also shown, and a central jet or regurgitation can be seen in the tricuspid valve in systole. The septum is flattened due to the pressure overload in the RV. (B) For the same increase in afterload, the function of the RV decreases much more compared to

B

that of the left ventricle (LV). The large resulting decrease in cardiac output that results with even small increases in the RV afterload [i.e., the pulmonary vascular resistance (PVR)] is responsible for many of the symptoms in PHT. The rapid deterioration of the RV function in PAH is also responsible for the much worse prognosis in patients with $\mathrm{PAH}$, compared to that of the patients with systemic hypertension.

TABLE 105.2. Revised clinical and classification of pulmonary hypertension (Venice, 2003)

\begin{tabular}{|c|c|}
\hline Classification & Specific etiology \\
\hline Pulmonary arterial hypertension & $\begin{array}{l}\text { 1. Idiopathic (iPAH) } \\
\text { 2. Familial (fPAH) } \\
\text { 3. PAH associated with: } \\
\text { Collagen vascular disease } \\
\text { Congenital systemic to pulmonary shunts } \\
\text { Portal hypertension } \\
\text { HIV infection } \\
\text { Drugs and toxins } \\
\text { Other (thyroid disorders, glycogen storage disease, Gaucher's disease, hereditary hemorrhagic } \\
\text { telangiectasia, hemoglobinopathies, myeloproliferative disorders, splenectomy) } \\
\text { 4. PAH associated with significant venous or capillary involvement } \\
\text { Pulmonary veno-occlusive disease (PVOD) } \\
\text { Pulmonary capillary hemangiomatosis (PCH) } \\
\text { 5. Persistent pulmonary hypertension of the newborn (PPHN) }\end{array}$ \\
\hline Pulmonary venous hypertension & $\begin{array}{l}\text { 1. Left-sided or ventricular heart disease } \\
\text { 2. Left-sided valvular disease }\end{array}$ \\
\hline PHT associated with hypoxemia & $\begin{array}{l}\text { 1. Chronic obstructive pulmonary disease } \\
\text { 2. Interstitial lung disease } \\
\text { 3. Sleep-disordered breathing } \\
\text { 4. Alveolar hypoventilation disorders } \\
\text { 5. Chronic exposure to high altitude } \\
\text { 6. Development abnormalities }\end{array}$ \\
\hline $\begin{array}{l}\text { Thromboembolic PHT caused by } \\
\text { chronic thromboembolism or } \\
\text { embolic disease }\end{array}$ & $\begin{array}{l}\text { 1. Thromboembolic obstruction of proximal pulmonary arteries } \\
\text { 2. Thromboembolic obstruction of distal pulmonary arteries } \\
\text { 3. Pulmonary embolism (tumor, parasites, foreign material) }\end{array}$ \\
\hline Miscellaneous & $\begin{array}{l}\text { Sarcoidosis, histiocytosis } \mathrm{x} \text {, lymphangiomatosis, compression of pulmonary vessels (adenopathy, } \\
\text { tumor, fibrosing mediastinitis) }\end{array}$ \\
\hline
\end{tabular}


TABLE 105.3. World Health Organization (WHO) functional classification of pulmonary hypertension

\begin{tabular}{cc}
\hline Functional class & Defining criteria \\
\hline I & Patients with PHT but without resulting \\
& limitation of physical activity Ordinary \\
& physical activity does not cause undue \\
& dyspnea or fatigue, chest pain, or syncope \\
& Patients with PHT who are comfortable at rest \\
II & but in whom ordinary levels of physical \\
& activity causes undue dyspnea or fatigue, \\
& chest pain, or near syncope \\
& Patients with PHT resulting in marked \\
& limitation of physical activity with minimal \\
& physical activity; they are often comfortable \\
III & at rest; less than ordinary activity causes \\
& undue dyspnea or fatigue, chest pain, or near \\
& syncope \\
& Patients with PHT with inability to carry our \\
& any physical activity without symptoms; \\
these patients manifest signs of right heart \\
failure; dyspnea and/or fatigue may even be \\
present at rest and increases with physical \\
activity
\end{tabular}

among different forms of PAH are indistinguishable, suggesting that the syndromes share pathogenetic mechanisms. Minor modifications to the Evian classification were proposed in the Third World Symposium of Pulmonary Arterial Hypertension that was held in Venice, Italy, in 2003. In this latest nomenclature (Table 105.2) the term primary PHT was replaced by idiopathic PAH (iPAH), which occurs in sporadic (sPAH) and familial forms (fPAH). The current WHO classification for defining functional class for PAH patients is shown in Table 105.3 (See also Fig. 105.2).

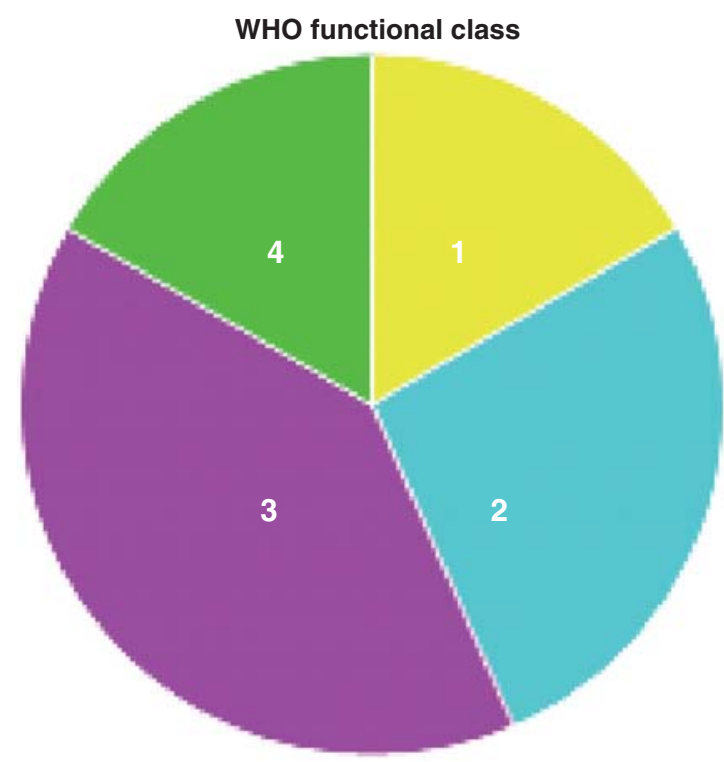

FIGURE 105.2. World Health Organization (WHO) functional classification of pulmonary hypertension.

\section{Prevalence and Natural History of Pulmonary Arterial Hypertension}

The prevalence, incidence, and mortality of PAH in the general population remain unknown. Early estimates identified PAH as a rare or "orphan" disease with a prevalence of 1 to 2 per million, based on data from limited cohorts in the United States, France, and Israel. ${ }^{15-17}$ These studies, which did not perform population surveillance, identified a very high mortality in PAH patients, often worse than that of metastatic breast cancer. For reasons discussed below, it is very likely that the prevalence of PAH is underestimated and the mortality overestimated, based on emerging data from centers that have earlier disease detection and offer improved therapies.

The largest primary pulmonary hypertension (PPH) natural history study was based on the NIH primary PHT registry, which followed 187 patients from 1981 to $1987 . .^{18}$ Primary PHT was defined as mean pulmonary artery (PA) pressure $>25 \mathrm{~mm} \mathrm{Hg}$ at rest (or $>30 \mathrm{~mm} \mathrm{Hg}$ with exercise) in the absence of secondary causes for PHT, a definition different from the current definition of PAH, which includes PHT due to more common diseases like collagen vascular disease, HIV infection, portal hypertension, congenital heart disease as PAH (Table 105.2). The mean age was $\sim 36$ years with a female to male ratio of $1.7: 1$. The mean right atrial pressure at diagnosis was $10 \pm 6 \mathrm{~mm} \mathrm{Hg}$ and mean PA pressure $60 \pm$ $18 \mathrm{~mm} \mathrm{Hg}$, suggesting that this cohort had very severe PHT. A subsequent survival study of patients from the NIH registry showed a median survival of 2.8 years, with survival rates at 1,3 , and 5 years were $68 \%, 48 \%$, and $34 \%$, respectively. Mortality increased with advanced New York Heart Association (NYHA) class, elevated right atrial or mean PA pressure, and decreased cardiac index. Similar data were reported from smaller cohorts from Israel, ${ }_{1}^{16}$ India, ${ }_{1}^{19}$ and Japan. ${ }^{20}$

An increase in the number of deaths in the U.S. attributed to iPAH has been reported. ${ }^{21}$ Analysis of cause of death data (based on death certificates) showed an ageadjusted increase in the number of deaths ascribed to iPAH in the U.S. from 1979 to 1996 (Fig. 105.3). The rate

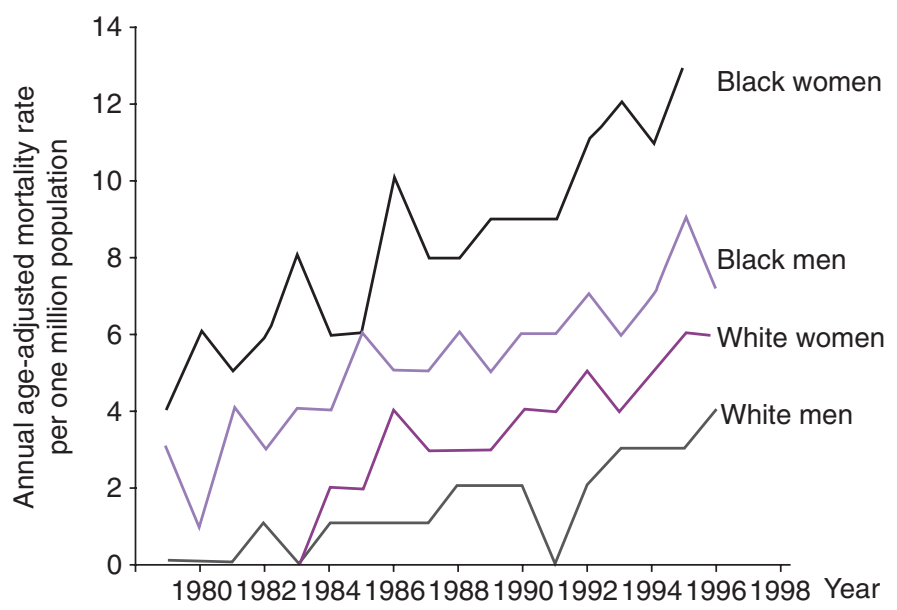

FIGURE 105.3. An increase in the incidence of idiopathic PAH (iPAH) has been documented recently, based on death certificate diagnoses in the United States. The increase has been higher in black men and black women. 
of the increase was greatest amongst African-American women. ${ }^{21}$ This increase could be due to a true increase in the incidence of deaths from iPAH (for example, due to the use of anorectic agents, which caused an outbreak of iPAH during that period), better case recognition (due to the increased access to noninvasive means of measuring PA pressure and the increased access to the specialized PAH clinics), or both.

Indeed, widespread access to noninvasive diagnostic techniques (e.g., Doppler echocardiography) has led to an increase in the number of patients who are diagnosed at earlier stages of the disease, sometimes even before the onset of symptoms. However, the isolated measurement of PA pressure without measurement of cardiac output and wedge pressure has led to many misdiagnoses of PHT. In addition, there has recently been a dramatic increase in the awareness of PAH due to a number of factors, including an increase in the interest of the pharmaceutical industry, the medical community (during 2004 there were several publications from the American College of Cardiology (ACC) and the American College of Chest Physicians (ACCP), offering for the first time guidelines and evidence-based recommendations) and public advocacy (with organized Web sites focusing on PAH: http://Www.phassociation.org and http://

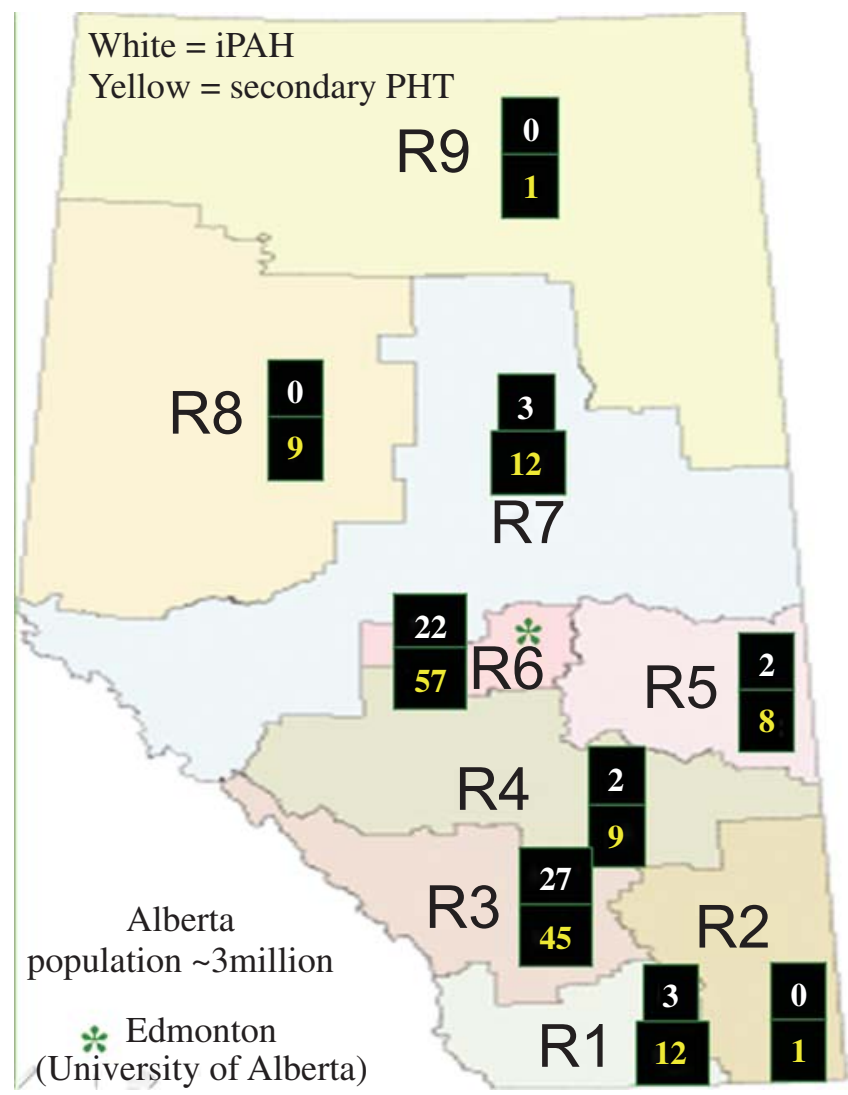

FIGURE 105.4. Pulmonary arterial hypertension in Alberta, Canada. (A) iPAH versus PHT over a 1-year period in Alberta (20022003). These numbers are based on hospital discharge diagnoses (each patient was counted once). A cohort of well-characterized consecutive PAH patients in the University of Alberta PAH program over the past 2 years suggests that PAH is more frequent that the National Institutes of Health $(\mathrm{NIH})$ registry suggested and PAH patients are now older and less sick (see Table 105.4).
TABLE 105.4. University of Alberta Pulmonary Hypertension (PHT) Program: PAH cases diagnosed (2002-2004)

\begin{tabular}{lc}
\hline Women (\%) & $26(65)$ \\
$\quad$ mean age: $49 y$ & $14(35)$ \\
Men $(\%)$ & \\
$\quad$ mean age: $58 y$ & \\
Etiology $(\%)$ & $24(60)$ \\
iPAH & $11(28)$ \\
Connective tissue disease & $2(5)$ \\
Congenital heart disease & $2(5)$ \\
Portal hypertension & \\
HIV
\end{tabular}

www.phcentral.org/talk/index.html). Patient empowerment has increased the number of self-referrals and referrals from general practitioners to PAH specialists. It is likely that the availability of oral therapies for PAH (such as Bosentan and sildenafil) has also enhanced the interest in making the diagnosis of PAH.

\section{The Changing Epidemiology of Pulmonary Arterial Hypertension}

Because of the lack of ongoing national databases and registries since the NIH registry closed, data on the current prevalence and natural history of PAH are lacking. However, anecdotal evidence suggests that the epidemiology has changed. For example, in the University of Alberta Pulmonary Hypertension Program (a tertiary care program serving a catchment population of 1.6 million) there have been 148 referrals for documented PHT over the past 2 years. From these, 40 had $\mathrm{PAH}$, which was a new diagnosis in $75 \%$ of cases (Fig. 105.4, see also Table 105.4). The female to male ratio is $\sim 2: 1$ and the mean age, in years, is 58 for men and 49 for women. Almost half of the patients are NYHA class I or II (Fig. 105.4). Although this is small and predominantly Caucasian cohort, it is consistent with anecdotal evidence that PAH is more common and more prevalent in older ages, and that current PAH cohorts are less sick than the original NIH cohort, which was predominantly young, female, and quite ill. Organized and independent, publicly funded, databases and registries are urgently needed to determine the true prevalence, incidence, and natural history of PAH, much like the NIH registry in the 1980s.

To understand $\mathrm{PAH}$ it is essential to review the unique features of the pulmonary circulation and its embryology.

\section{The Mysteries of the Pulmonary Circulation}

The pulmonary or "lesser" circulation has fascinated physiologists for over a century. Its many differences from the systemic vascular beds have only recently begun to be understood. For example, the pulmonary circulation is a lowpressure circulation with thin-walled arteries and it accommodates the whole cardiac output at a PA pressure of 
$<30 / 20 \mathrm{mmHg}$, in contrast to the higher-pressure systemic circulation $(120 / 80 \mathrm{~mm} \mathrm{Hg})$ with its thick, muscular arteries. The purpose of the two circulations is also different: $\mathrm{O}_{2}$ uptake for the pulmonary circulation, and $\mathrm{O}_{2}$ delivery for the systemic circulation. In this regard, the pulmonary circulation constricts in response to acute hypoxia (hypoxic pulmonary vasoconstriction, $\mathrm{HPV}^{22}$ ), which is the major mechanism to optimize ventilation-perfusion matching and thus $\mathrm{O}_{2}$ uptake; in contrast, the systemic circulation dilates in response to hypoxia, which optimizes $\mathrm{O}_{2}$ delivery. In addition, the pulmonary circulation develops in utero in a relatively hypoxic environment, compared to the systemic circulation. In utero, the uninflated lungs are bypassed by oxygenated blood coming from the placenta, which is preferentially shunted to the systemic vasculature through the fossa ovalis and the ductus arteriosus. The diseases that afflict the pulmonary circulation are also relatively unique. In adult life, systemic hypertension and atherosclerosis spare the pulmonary circulation, and. conversely, PAH usually occurs without substantial systemic vascular disease. However, systemic arterial vasospasm in the digits, which is a response to cold (Raynaud's phenomenon), is not uncommon in PAH (particularly in association with ingestion of anorexigens or collagen vascular diseases). The relative contribution of genetic versus environmental differences to these pulmonary-systemic arterial differences is unclear and perhaps both contribute. The systemic arteries and pulmonary arteries have different embryologic origins, but also experience markedly different local environments. For example, the small pulmonary arteries that control PVR are adjacent to the alveoli and experience much higher levels of ambient oxygen and much less shear stress than systemic arteries.

Understanding these differences will explain several important mechanisms in health and disease. For example, why is the pathology of PAH restricted to the pulmonary vessels, leaving all the systemic vessels intact? The answer to this question has important clinical implications since currently a major challenge in the therapy of PAH is the lack of selective treatments that lower PAP without causing systemic vasodilatation. The PAH patients tolerate systemic vasodilatation poorly because fixed and elevated levels of right ventricular afterload prevent compensatory increases in cardiac output in response to vasovagal stimuli or vasodilator therapies, promoting a vicious cycle of hypotension. Therapeutic targets unique to the pulmonary circulations have not yet been identified. However, accessing the pulmonary vasculature via the airway permits selective therapy of the pulmonary circulation for compounds that are not systemically absorbed [e.g., Iloprost ${ }^{\circledR}$, inhaled nitric oxide (iNO)].

The lung has two parallel circulations: the pulmonary arteries and the bronchial arteries. The bronchial arteries are thick-walled and muscular, and they supply blood to the bronchi and the wall of the large pulmonary arteries. In other words, they are vessels made to supply oxygen to support the lung's relatively minimal metabolic functions. In this regard bronchial arteries resemble systemic vessels. In contrast, the pulmonary arteries are involved in the central uptake of oxygen from the lungs. Hypoxic pulmonary vasoconstriction is a homeostatic response, intrinsic to the pulmonary arteries, that optimizes oxygenation by matching ventilation to perfusion. In $\mathrm{HPV}$, the small $(<300 \mu \mathrm{M})$ arteries "sense" even small decreases in the local alveolar $\mathrm{PO}_{2}$ and constrict to divert the blood to better ventilated areas, preventing the delivery of suboptimally oxygenated blood to the body; conversely, all systemic arteries vasodilate, thereby optimizing systemic $\mathrm{O}_{2}$ transport. The resistance pulmonary arteries, together with carotid body and airway neuroepithelial bodies, constitute the body's specialized $\mathrm{O}_{2}$ sensing system, the function of which is optimization of $\mathrm{O}_{2}$ uptake. Interestingly, these tissues share common mechanisms to transduce changes in $\mathrm{PO}_{2}$ into changes in arterial tone, ventilation, and airflow. $^{22}$

\section{The Development of the Pulmonary Circulation}

Hypoxic pulmonary vasoconstriction is strongest in the small, fourth- to seventh-division pulmonary arteries that are surrounded by alveoli; conversely proximal, extrapulmonary arteries do not contract, and may even dilate in response to hypoxia (Fig. 105.5C). These differences may be genetically programmed because the proximal pulmonary arteries have a different embryologic origin from the small intrapulmonary arteries. ${ }^{23}$ The proximal pulmonary arteries are derived from the truncus arteriosus, which divides into the aorta and pulmonary trunk by 8 weeks of human gestation, by growth of the spiral aorticopulmonary septum. This occurs via angiogenesis, which is the branching of new vessels from preexisting ones. ${ }^{24}$ In contrast, the small intraparenchymal pulmonary arteries are derived from the sixth branchial arch arteries, the most caudal of the brachial arteries, by 7 weeks' gestation in humans. ${ }^{24}$ This occurs via vasculogenesis, which is the development of blood lakes in the mesenchyme. Recent evidence suggests that these arteries originate from a strand of endothelial precursors that connect the ventral wall of the dorsal aortae to the pulmonary trunk. ${ }^{25}$ Distinct endothelial precursor cells have recently been identified in human embryos ${ }^{26}$ (Fig. 105.5A). A survival advantage to these endothelial cells is offered by a variety of survival and antiapoptotic factors, and it appears that insulin growth factor plays a central role very early in the process. ${ }^{26}$ Both the angiogenesis (for the proximal pulmonary arteries) and the vasculogenesis (for the distal pulmonary arteries) are elegantly coordinated, and finally the two developing vascular segments are connected by a fusion process ${ }^{24}$ (Fig. 105.5).

\section{Vascular Diversity Within the Pulmonary Circulation}

The different embryonic origins of vascular cells within the fetal lung may account for some of the endothelial and smooth muscle heterogeneity that characterizes the adult lung. For example, endothelial cells from the proximal arteries have a different phenotype compared to endothelial cells from distal pulmonary arteries. ${ }^{27}$ The differences between these two types of endothelial cells are maintained even in culture, emphasizing their genetic basis. ${ }^{27}$ Similarly, smooth muscle cells (SMCs) from the distal and proximal pulmonary arteries have different phenotypes and functional properties. 

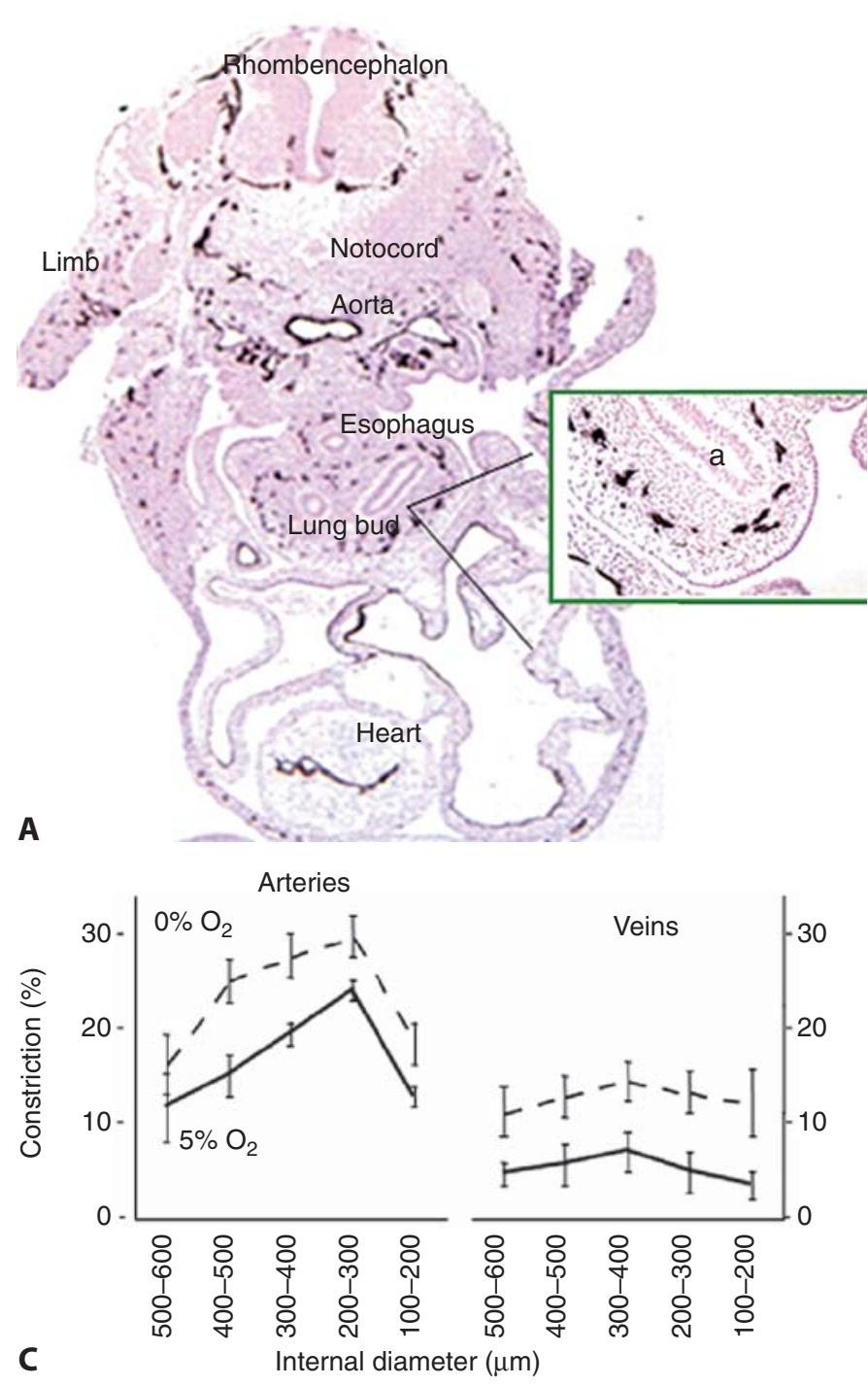

First, distal pulmonary artery SMCs (PASMCs) contract in response to hypoxia in vitro, whereas the cells from proximal pulmonary arteries dilate, like the SMCs from systemic arteries. ${ }^{28}$ Perhaps this reflects the fact that the SMCs of small pulmonary arteries express relatively more oxygensensitive Kv channels (particularly Kv1.5 and Kv2.1), whereas proximal PASMCs express more calcium-activated $\mathrm{K}^{+}$channels (KCa). ${ }^{29,30}$ This finding is important because these redoxand oxygen-sensitive Kv channels, such as Kv1.5, have been directly implicated in the initiation of HPV. ${ }^{31}$ Inhibition of these channels leads to depolarization of the SMCs, opening of the voltage-gated L-type calcium channels, influx of calcium, and contraction. The full manifestation of HPV is supported by calcium release from intracellular stores as well as by calcium sensitization of the contractile apparatus by rho kinase. ${ }^{22}$

Hypoxic pulmonary vasoconstriction occurs even at mild levels of alveolar hypoxia, and at these levels of physiologic hypoxia, animals and patients do not develop seizures or arrhythmias /which would be expected if these channels were similarly inhibited in the brain and the heart, where they are also expressed). The restriction of HPV to certain

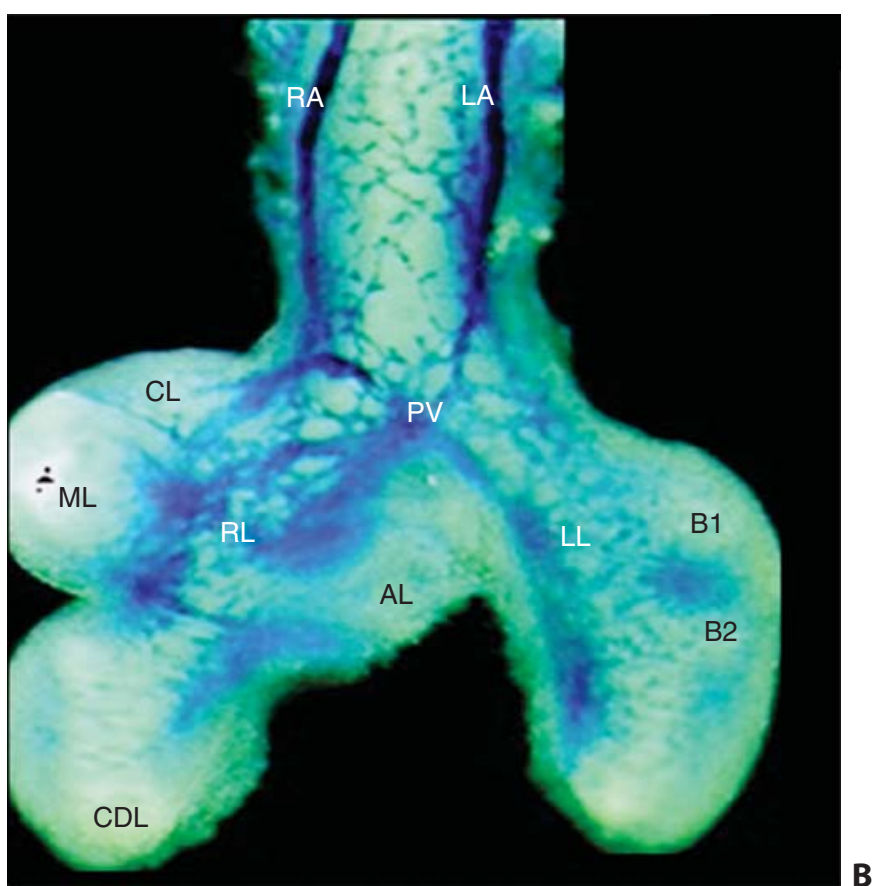

FIGURE 105.5. Embryology might explain the diversity within the pulmonary circulation in response to hypoxia (see text). (A) Horizontal section of a 4-week embryo demonstrates precursor endothelial cells (ECs) (black) as inner linings of the heart and great vessels and in and around several developing organs. Higher magnification of a lung bud demonstrates a single layer of EC organized around the developing airway (a). (B) Tie-1-Lac Z transgenic mice embryo (11.5 days) shows that the left and right pulmonary arteries are now completed (via a fusion process) and run as a unit, alongside the trachea. (C) Most of the constrictor response to acute hypoxia within the pulmonary circulation occurs in the small and medium-sized pulmonary arteries.

portions of the pulmonary circulation thus might be due to tissue heterogeneity among expressed $\mathrm{K}^{+}$channels between pulmonary and systemic vascular beds (e.g., splice variants). This restricted localization of the hypoxic vascular response could also be due to the presence of unique sensors for hypoxia in the distal pulmonary arteries. It is the sensor, which, in response to hypoxia, alters the production of a mediator that regulates the function of $\mathrm{O}_{2}$-sensitive $\mathrm{K}^{+}$channels. The sensor of hypoxia in the pulmonary arteries appears to be the SMCs' mitochondrial electron transport chain, $22,32,33$ or possibly another vascular redox enzyme, reduced nicotinamide adenine dinucleotide phosphate (NADPH) oxidase. ${ }^{34}$ This sensor changes the production of reactive oxygen species (ROSs) in response to mild hypoxia, and these ROSs serve as diffusible second messengers, changing the gating and opening of certain Kv channels, such as Kv1.5 and Kv2.122 (Fig. 105.6). In hypoxia, altered mitochondrial-derived ROS production leads to Kv channel inhibition and vasoconstriction. Although the identity of the pulmonary vascular oxygen sensor remains controversial, and there is disagreement as to whether hypoxia increases or decreases ROS, mitochondria are vascular $\mathrm{O}_{2}$ sensors in the pulmonary arteries, as 
well as in a variety of other oxygen-sensitive vascular tissues, including the ductus arteriosus and the carotid body. ${ }^{22}$ The mitochondria of the small pulmonary arteries are functionally distinctly different from the mitochondria of the systemic vessels $^{35}$ (Fig. 105.7).

\section{Clinical Implications}

Although some of these concepts have been introduced only during the past few years, their clinical implications have already become apparent. Kv1.5, which is involved in the initiation of $\mathrm{HPV}$, is selectively downregulated in both animal models of PAH and humans with $\mathrm{PPH} .{ }^{36-38}$ This downregulation leads to depolarization and the activation of the voltage-gated calcium channels in the PASMCs. This likely explains the beneficial effects of L-type calcium channel blockers (such as nifedipine) in some patients with PAH. ${ }^{39}$ These mechanisms can also explain why drugs that open $\mathrm{K}^{+}$channels (e.g., inhaled $\mathrm{NO}$ and sildenafil) are beneficial in PAH. In the future, perhaps therapeutic strategies can be devised to exploit mitochondrial diversity to create therapies that are selective for the pulmonary circulation. The mitochondria are promising targets for PAH therapy because they not only regulate vascular tone but also are major determinants of rates of apoptosis in the vascular wall. Induction of apoptosis in the media of remodeled pulmonary arteries in PAH might be an effective and selective therapeutic strategy. In experimental $\mathrm{PAH}$, it appears that mitochondrial function is abnormal (as manifest by a hyperpolarized mitochondrial membrane potential and altered ROS production), and this leads to inappropriately low rates of apoptosis and enhanced SMC proliferation. ${ }^{38}$ Strategies that induce mitochondria-dependent apoptosis may prove to be effective and selective treatments. Dichloroacetate (an inhibitor of the

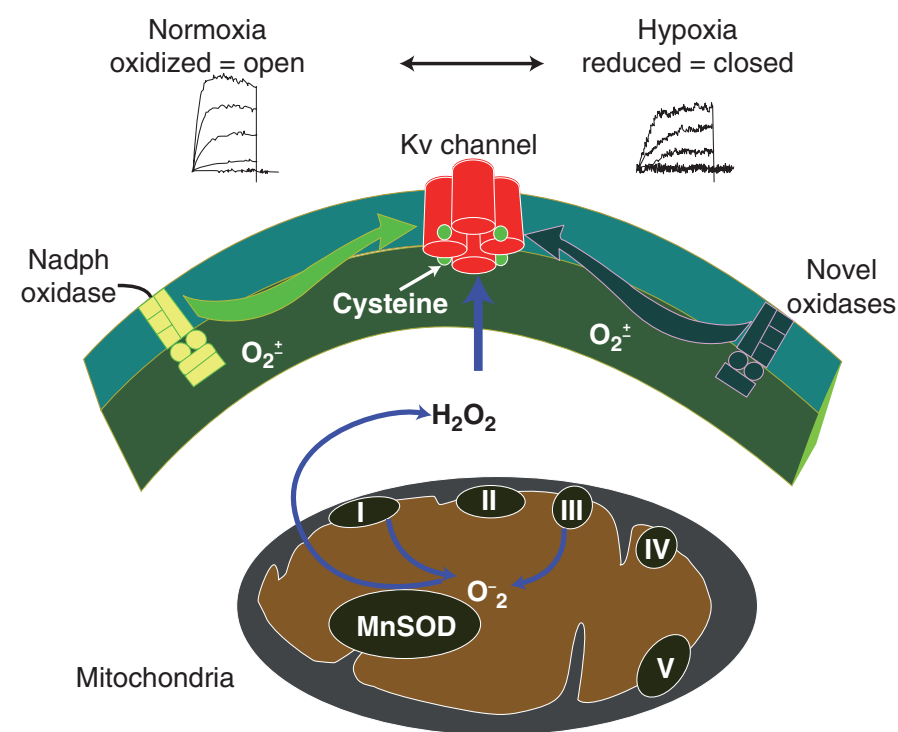

FIGURE 105.6. A model for oxygen sensing in the pulmonary circulation. In hypoxia the sensors (mitochondria) change the production of the mediator (activated oxygen species, AOS) and regulate the function of the effectors $\left(\mathrm{K}^{+}\right.$channels). Alternate sensors include the reduced nicotinamide adenine dinucleotide phosphate (NADPH) oxidase and novel oxidases.
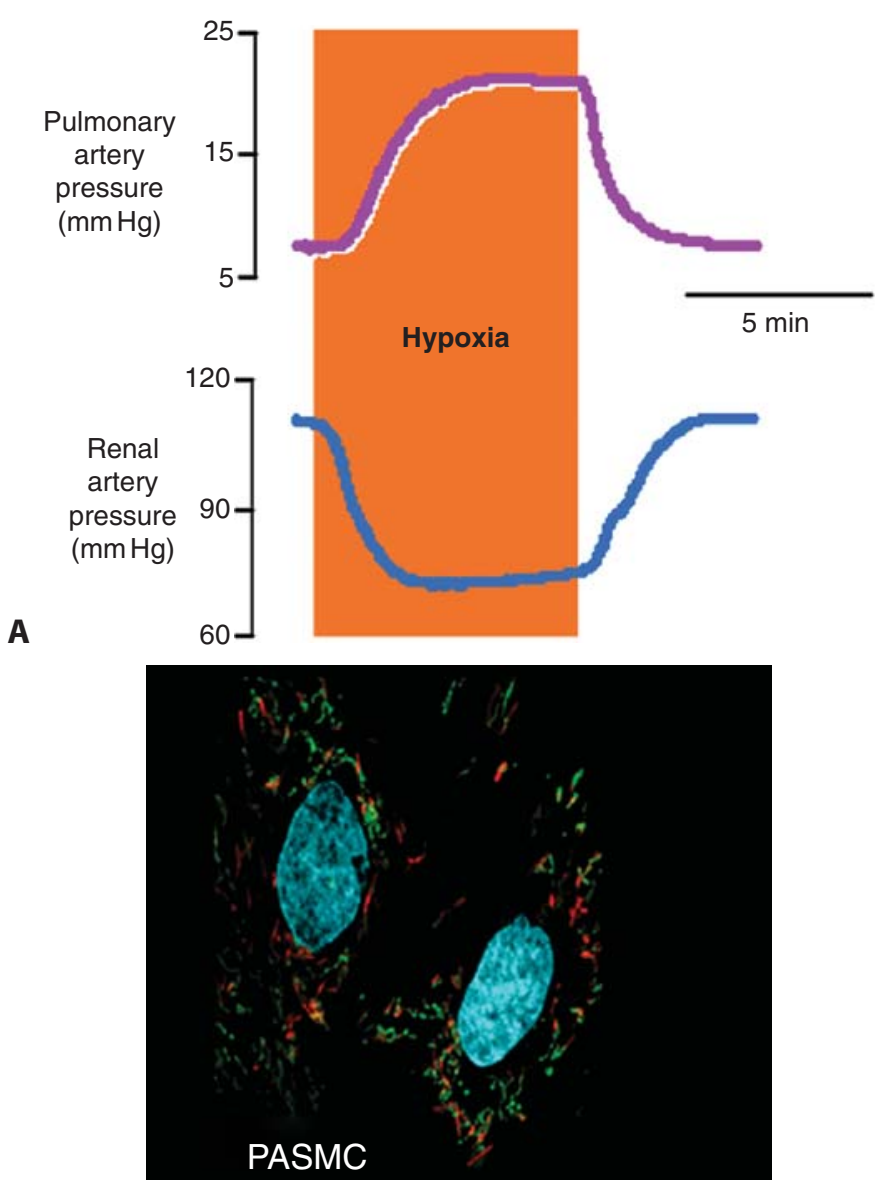

B

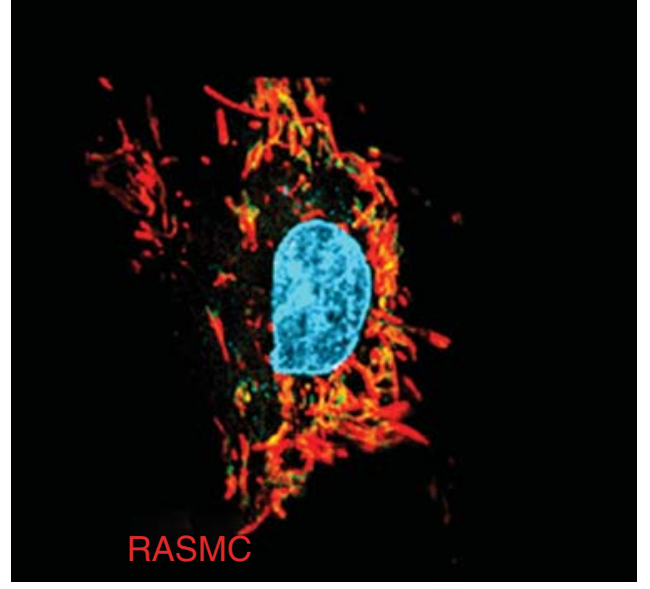

FIGURE 105.7. Mitochondrial diversity in the vasculature. (A) The opposing effects of the pulmonary and the renal circulation to hypoxia are at least in part due to differences in the oxygen sensor, that is, the mitochondria. The traces shown here are from isolated rat lungs and kidney perfused in series. (B) The pulmonary artery smooth muscle cell (PASMC) mitochondria are more depolarized (as shown by the TMRM fluorescence and confocal microscopy) compared to the renal artery smooth muscle cell (RASMC) mitochondria, although they are imaged under identical condition.

mitochondrial pyruvate dehydrogenase kinase, which has been used orally in human with congenital lactic acidosis| induces vascular apoptosis and reverses PAH in rats, without affecting the systemic vessels. ${ }^{38}$ Inhaled gene therapy with a 
dominant-negative construct that inhibits the inhibitor of apoptosis protein survivin also induces mitochondriadependent apoptosis and reverses PHT in animals. ${ }^{40}$

\section{Vascular Biology of Pulmonary Arterial Hypertension}

\section{Histopathology}

Pulmonary arteries in PAH are characterized by intimal fibrosis, medial hypertrophy, adventitial proliferation, obliteration of small arteries, in situ thrombosis, and, on occasion, vasculitis or changes in the walls of the pulmonary veins $^{41}$ (Fig. 105.8). A fascinating, focal vascular structure, the plexiform lesion, is found in many cases of PAH and is typically absent in secondary forms of PHT, due to hypoxia, cor pulmonale, left heart disease, and thromboembolism. Plexiform lesions are somewhat reminiscent of renal glomeruli, their many vascular channels being lined with endothelial cells rich in type-3 nitric oxide synthase (eNOS) ${ }_{1}^{42}$ factor VIII, vimentin, ${ }^{43}$ and the receptor for vascular endothelial growth factor (VEGF). ${ }^{44}$ Plexiform lesions may represent an angiogenic response to local ischemia or hypoxia, as occurs with the creation of collateral vessels associated with obstructed arteries in other vascular beds. Certainly, computerized three-dimensional reconstruction of vessels in $\mathrm{PAH}$ demonstrate that plexogenic lesions occur distal to obstructive vascular lesions. ${ }^{44}$

Studying PAH pulmonary arteries with either a plexiform lesion or intimal or medial hypertrophy, one is impressed by the increased cellularity in the vascular wall. The increased cellularity may represent infiltrating inflammatory cells (in some cases), but in most cases it reflects excessive cell proliferation or suppressed apoptosis. The therapeutic potential of reversing the imbalance between proliferation and apoptosis within the pulmonary artery wall is a very new area of research in PAH and has already produced some attractive experimental treatments for $\mathrm{PAH}$, as will be discussed below.

\section{Mechanisms of Pulmonary Arterial Hypertension}

The challenge for any pathogenetic theory of PAH is to account for the entire spectrum of the disease, that is, pulmonary artery vasoconstriction, obstructive vascular remodeling, and thrombosis in situ. However, PAH is likely a syndrome, not a disease, consisting of several conditions that share similar features but result from diverse etiologic stimuli. It is also likely that classic PAH is the end stage of multiple mechanisms and phenotypes, one or more of which might be an initiating mechanism, whereas others follow and exacerbate the condition. A "multiple hit hypothesis" is increasingly being accepted as the leading theory to explain the complexity, relative rarity, and pulmonary vascular selectivity of PAH. Much like cancer, a susceptible patient with a genetic predisposition [e.g., due to mutations of the bone morphogenetic protein receptor-2 (BMPR-2) or gene polymorphisms] appears to require additional environmental insults (like an anorectic drug or a viral infection) before PAH is manifested. ${ }^{9}$
The many abnormalities that have been described in PAH can be grouped into two large thematic categories: (1) abnormalities that contribute to an imbalance between vasoconstrictors and vasodilators and thus promote vasoconstriction, and (2) abnormalities that contribute to an imbalance between proliferation and apoptosis and thereby promote proliferative remodeling. Specific cellular and biochemical abnormalities have been described in $\mathrm{PAH}$ at all levels of the vasculature, from the blood (e.g., platelets) and endothelial cells through the SMCs, fibroblasts, and inflammatory cells. In this discussion we emphasize the studies that have used patients or human tissues.

While the mechanisms that we discuss below, alone or in combination, can explain most of the features of $\mathrm{PAH}$, no mechanisms so far can adequately explain perhaps the biggest mystery of this challenging disease: Why are the vascular abnormalities in PAH restricted to the pulmonary circulation? What is it that predisposes the pulmonary arteries or protects the systemic arteries from this disease?

\section{The Endothelium}

At the late stages of PAH the pulmonary artery endothelium is highly abnormal. ${ }^{45}$ Because PAH is usually detected only in the late stages of the disease, studies of the endothelial function in patients with early PAH are lacking. The final result of the endothelial dysfunction is an imbalance of endothelial-derived vasoactive factors, with an increase in the vasoconstrictors/vasodilator balance.

Both iPAH and secondary PHT patients excrete elevated levels of a thromboxane $\mathrm{A}_{2}$ metabolite and reduced amounts of a prostacyclin metabolite. ${ }^{46}$ Thromboxane $A_{2}$ is a potent vasoconstrictor and stimulus for platelet aggregation, whereas prostacyclin is an antiproliferative, antiaggregatory, vasodilator endothelial product. The fact that this platelet-endothelial abnormality occurs in both iPAH and secondary PHT suggests it is not the cause of iPAH. Nonetheless, this observation has had rich therapeutic value, as is discussed later.

It is also postulated that there is an excess of the constrictor endothelin-1 (ET-1) and a deficiency of the vasodilator NO in iPAH. The idea of a NO deficiency in $\mathrm{PAH}$, the conventional wisdom, relates to the observed decrease in expression of endothelial nitric oxide synthase (eNOS) in the lungs of a few iPAH subjects. ${ }^{47}$ However, NOS function was not measured in this immunohistochemistry study. Conversely, lung NO production, which admittedly may not reflect only pulmonary vascular NO production, is actually enhanced ${ }^{48}$ or preserved in $\mathrm{PAH}^{49}$ Similarly, iPAH patients have higher urinary cyclic guanosine monophosphate (cGMP) concentrations than asthmatic patients or healthy controls. ${ }^{50}$ Since most blood vessels respond to elevation of tone with a homeostatic increase in NO production, NO deficiency in PAH might represent a failure of this pathway in the late stages of the disease. Alternatively, certain patients with endothelial dysfunction or an abnormal eNOS variant may be predisposed to certain forms of PAH. Depressed NO production may contribute to the susceptibility to anorexigen-induced PAH. ${ }^{51}$

Endothelin-1 (ET-1) is a potent peptide vasoconstrictor and mitogen. ET-1 levels are increased in experimental ${ }^{52}$ and human PAH. ${ }^{53,54}$ The high levels of ET-1 in arterial compared 

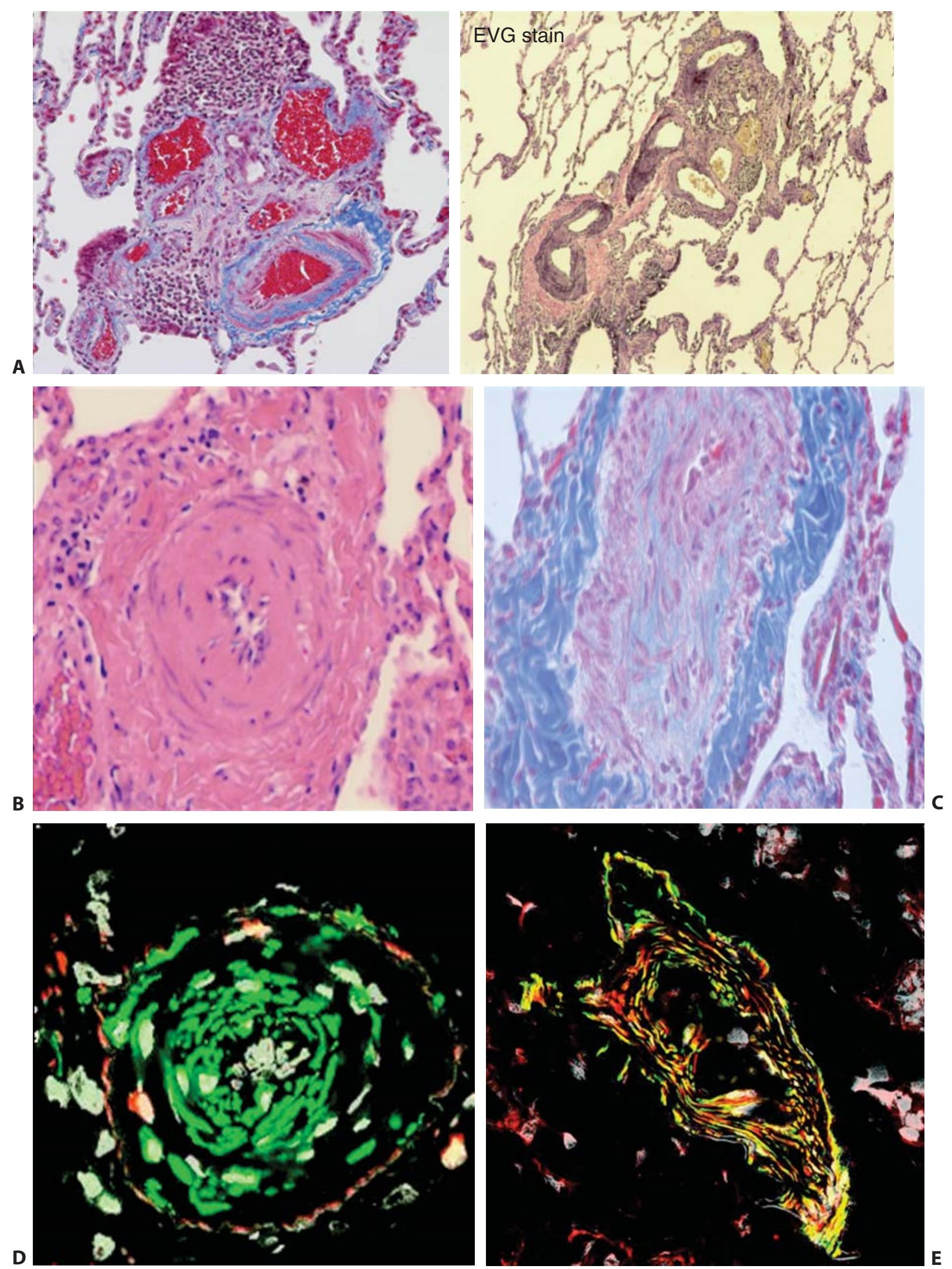

FIGURE 105.8. Idiopathic PAH pathology. All of these sections are obtained from the lungs of a 34-year-old-man with iPAH who underwent transplantation. The characteristic plexogenic (A), medial (B), and intimal (C) hypertrophy lesions are shown (EVG, elastic van Giessen stain). Fluorescence immunohistochemistry (D) and confo-

cal microscopy (E) show medial hypertrophy (smooth muscle actin—green) and survivin or phosphodiesterase 5 (red) expression in the media and adventitia of the remodeled small pulmonary arteries. 
with venous plasma in PAH and the increased expression in pulmonary arteries suggest that ET-1 contributes to the increased PVR in iPAH. Increased ET-1 levels also occur in other diseases, such as congestive heart failure. However, elevation of ET-1 levels does not necessarily mean that antagonism of the pathway is beneficial. In congestive heart failure the endothelin receptor antagonists have been ineffective. ${ }^{55,56}$ The mitogenic action of ET-1 in the PASMCs occurs via the endothelin A (ETA) receptor, whereas the endothelin B (ETB) receptor is thought to mediate the clearance of ET-1 from the pulmonary circulation and cause NO-mediated vasodilatation.

Another vasodilator that has more recently been proposed to play a significant role in PAH is the neurotransmitter vasoactive intestinal peptide (VIP), which is a potent pulmonary vasodilator that also inhibits the proliferation of SMCs and decreases platelet aggregation. The VIP receptors are linked to adenylate cyclase and eventually lead to activation of both cyclic adenosine monophosphate (cAMP) and cGMP. Both low serum concentration and low expression of VIP have been reported in iPAH pulmonary arteries, and inhalation of VIP in eight iPAH patients resulted in acute improvement in hemodynamics. ${ }^{57}$

Disordered production of vasoactive mediators is not the only endothelial abnormality in PAH. The endothelial cells also form plexiform lesions. These plexiform lesions, which are seen in several types of PAH (but not in secondary forms of $\mathrm{PHT}$ ), have an abnormal proliferative phenotype. Lee et $\mathrm{al}^{58}$ assessed whether the proliferation of endothelial cells in plexiform lesions in iPAH is the result of a monoclonal expansion, as occurs in neoplasia, or is polyclonal, typical of normal proliferation. They studied the methylation pattern of the human androgen receptor gene in endothelial cells microdissected from plexiform lesions, and showed that $77 \%$ of endothelial lesions were monoclonal, whereas in secondary PHT $100 \%$ of the endothelial lesions (not plexiform lesions) were polyclonal. This intriguing hypothesis, that $\mathrm{PAH}$ is somewhat of a "neoplastic" condition, remains controversial but merits further assessment. Recent rodent studies confirm this hypothesis, by the finding that a potent inhibitor of apoptosis that was previously thought to be exclusively found in cancer cells, survivin, is selectively expressed in the PA wall in patients with PAH but not normal controls $^{40}$ (Fig. 105.8).

\section{The Smooth Muscle Cell}

\section{$\mathrm{K}^{+}$Channel Dysregulation}

$\mathrm{K}^{+}$channels are transmembrane spanning proteins that contain a pore with great selectivity for $\mathrm{K}^{+} .{ }^{9}$ They are tonically active in vascular SMCs, allowing a slow efflux of $\mathrm{K}^{+}$ along its intracellular/extracellular concentration gradient of 145/5 mM. There are several $\mathrm{K}^{+}$channel types: voltage-gated $(\mathrm{Kv})$, inward rectifier $\left(\mathrm{K}_{\mathrm{ir}}\right)$, and calcium-sensitive $\left(\mathrm{K}_{\mathrm{Ca}}\right)$. $\mathrm{Kv}$ channels have a voltage sensor and both respond to and help to establish membrane potential. Inhibition of $\mathrm{Kv}$ channels results in accumulation of positively charged $\mathrm{K}^{+}$ions within the cell, thereby raising the membrane potential to more positive levels (depolarization), which activates the voltagegated, L-type calcium channels. Calcium then enters the cell, via the L-type, voltage-gated calcium channels, which are inhibited by nifedipine, activating the contractile apparatus, thus leading to vasoconstriction. Indeed, acute hypoxia appears to initiate HPV by inhibition of $\mathrm{Kv}$ channel in the PASMCs. ${ }^{60,61}$ The intracellular calcium increase also activates a number of mechanisms that result in cell proliferation. ${ }^{62}$ Intracellular $\mathrm{K}^{+}$causes a tonic inhibition of several caspases. The decreased intracellular $\mathrm{K}^{+}$that follows $\mathrm{K}^{+}$ channel opening inhibits caspases, thereby activates apoptosis. ${ }^{63}$ Thus a PAH PASMC that is relatively deficient in $\mathrm{K}^{+}$ channels, whether the basis is genetic or acquired $\left(\mathrm{K}^{+}\right.$channel inhibition by hypoxia or anorexigens), would be depolarized, with increased levels of intracellular $\mathrm{Ca}^{2+}$ and $\mathrm{K}^{+}$. This ionic environment places the cell in a contracted, proliferative, antiapoptotic state. In the presence of appropriate stimuli or growth factors, the vasoconstriction and the proliferation within the vascular wall likely contributes to the PA remodeling seen in PAH.

There is currently a search for the molecular identity of the $\mathrm{K}^{+}$channels involved in HPV and PAH. There are nine families of $\mathrm{Kv}$ families (Kv1-9), each with many members (i.e., Kv1.1 to Kv1.7). ${ }^{59}$ In humans with iPAH, Kv1.5 messenger RNA (mRNA) levels are reduced in PASMCs, and this is circumstantially associated with membrane depolarization and elevation of cytosolic $\mathrm{Ca}^{2+} \cdot{ }^{36,64}$ Less is known about Kv2.1, although it is involved in setting membrane potential in rat PASMCs. ${ }^{31}$ It is fascinating that the anorexigens that caused several epidemics of PAH during the past 30 years $^{65}$ inhibit $\mathrm{K}^{+}$current and depolarize PASMCs, leading to pulmonary vasoconstriction. They appear to do this by inhibiting both Kv1.5 and Kv2.1. ${ }^{66}$ channels whose expression is also selectively downregulated in experimental PAH. ${ }^{67}$ Interestingly, reversal of this "ionic remodeling," whether indirectly by drugs ${ }^{67}$ or directly by $\mathrm{K}^{+}$channel gene therapy, ${ }^{37}$ improves the hemodynamic and remodeling abnormalities in experimental PHT. Taken together these data suggest that the selective downregulation of Kv channels might play a role in the pathogenesis of $\mathrm{PAH}$; in other words, $\mathrm{PAH}$ might be a form of a Kv channelopathy. There is clearly a precedent for ion channelopathies causing human disease, including chloride channel mutations causing cystic fibrosis and mutation of $\mathrm{K}^{+}$and $\mathrm{Na}^{+}$channels causing the long QT syndrome that results in sudden cardiac death. The Kv channel hypothesis requires further investigation.

\section{SURVIVIN}

Survivin, a member of the mammalian "inhibitor of apoptosis" family, ${ }^{68}$ is known to be expressed in most cancers but not in most normal adult cell types. ${ }^{69}$ The cell cycle-dependent expression of the survivin gene in mitosis suggests a role for survivin in promoting cell proliferation. However, recent data point to a more selective role of survivin in antagonizing mitochondrial-dependent apoptosis, ${ }^{69}$ and a mitochondrial pool of survivin has recently been identified in cancer cells. ${ }^{70}$ Survivin is expressed in remodeled resistance PAs, but not normal PAs, from PAH patients and rats with monocrotaline (MCT)-induced $\mathrm{PAH}$, a widely used model of $\mathrm{PAH}^{40}$ Inhaled adenoviral gene therapy with a dominant-negative construct that inhibits endogenous survivin reverses established MCT-PAH. The therapeutic effect of inhibition of survivin is achieved by induction of mitochondria-dependent apoptosis in PASMCs. Interest- 
ingly, this mechanism is also associated with activation of Kv channels. ${ }^{40}$

Survivin mutations, similar to those observed in oncogenic transformation, ${ }^{71}$ might occur in some patients with $\mathrm{PAH}$, resulting in spontaneous survivin expression, although this is entirely speculative. Voelkel et al. ${ }^{72}$ have exposed fascinating similarities between cancer and $\mathrm{PAH}$, by showing that the proliferating cells in the neointimal plexogenic $\mathrm{PAH}$ lesions are monoclonal. Alternatively, survivin expression may be induced following endothelial damage, which is likely a critical early event in the pathogenesis of PAH. ${ }^{45,73}$ Endothelial damage would allow direct exposure of PASMCs to circulating growth factors that are known to induce survivin expression. In addition to facilitating the PASMC transition to a proliferative state, survivin inhibits apoptosis by hyperpolarizing mitochondria. This will result in less cytochrome c and $\mathrm{H}_{2} \mathrm{O}_{2}$ in the cytoplasm, thereby inhibiting $\mathrm{Kv}$ channels. The resultant increase in the intracellular $\mathrm{K}^{+}$ further suppresses apoptosis and, by depolarizing the cell membrane, increases the opening of the voltage-gated $\mathrm{Ca}^{2+}$ channels, thereby enhancing $\mathrm{Ca}^{2+}$ influx, causing vasoconstriction and amplification of proliferative signal pathways.

\section{Platelets}

Several groups have hypothesized that serotonin (5-hydroxytryptamine, 5-HT) may be important in the development of PAH. ${ }^{74-77}$ The majority of the circulating $5-\mathrm{HT}$ is produced by the gastrointestinal tract chromaffin cells and pulmonary neuroepithelial bodies and is stored in the platelet dense granules. A key piece of evidence for the involvement of serotonin is the finding that plasma serotonin levels are increased in iPAH patients versus controls, whereas platelets from iPAH patients have decreased serotonin concentrations. ${ }^{75}$ Serotonin released during in vitro platelet aggregation is also exaggerated in iPAH patients relative to controls. Moreover, these abnormalities persist after heart-lung transplantation, suggesting that this platelet abnormality is not secondary to the $\mathrm{PHT}^{75}$

\section{THE 5-HT TRANSPORTER}

The classical action of the anorexigens is to cause serotonin release and prevent the reuptake of serotonin. In addition, anorexigens are actively taken up into the cells by means of the 5-HT transporter (5-HTT). It has been shown that there is overexpression of 5-HTT in PASMCs from patients with $\mathrm{PAH}$, and as a result their PASMCs grow abnormally rapidly in response to serotonin or serum stimulation. ${ }^{78} 5$-HTT expression is also increased in the platelets and lungs from PAH patients versus controls. ${ }^{78} 5$-HTT overexpression is predominantly evident in the media of the hypertrophied pulmonary arteries. ${ }^{78} 5$-HTT is encoded by a single gene in chromosome 17q11.2. The L-allelic variant of the 5-HTT gene promoter, which induces a greater rate of 5-HTT gene transcription than the $\mathrm{S}$ allele, has been reported, by one group, to be associated with 5-HTT overexpression and increased PASMC growth. The L allele was present in homozygous form in $65 \%$ of French PAH patients but in only $27 \%$ of controls. Since this report is from a single country and since ethnicity is important in such polymorphisms, independent confirmation in a different population is needed. Mice over- expressing the 5-HTT gene exhibit spontaneous PHT in normoxia and exaggerated PHT in hypoxia. ${ }^{79}$ These data suggest that 5-HTT activity might play a key role in the pathogenesis of PASMC proliferation in PAH and that a 5-HTT polymorphism confers susceptibility to $\mathrm{PAH}^{78}$ The serotonin hypothesis provides another genetic basis for a PAH-susceptible genotype, in addition to mutations in BMPR2.

\section{THE 5-HT RECEPTORS}

Activation of 5-HT 1B receptors elicits vasoconstriction in human small pulmonary arteries ${ }^{80}$ by activating $G_{i}$ signaling, which inhibits adenylate-cyclase and decreases cAMP levels. In the chronic hypoxic model of PHT, mice lacking 5-HT1B receptors develop less vascular remodeling and have no right ventricular hypertrophy compared to the wild-type controls. ${ }^{81}$ Similarly, mice lacking the 5-HT2B receptor, which is the receptor activated by nor-dexfenfluramine, the active metabolite of dexfenfluramine, do not develop chronic hypoxic PHT. ${ }^{82}$ Both 5-HT1B and 5-HT2B receptor expression is also increased in PAH. ${ }^{82}$

Much of the evidence linking 5-HT and PAH comes from the fact that the anorexigens cause 5-HT release. However, a link among $\mathrm{K}^{+}$channels, anorexigens, and 5-HT has been proposed. The anorexigens block Kv channels in platelet progenitor cells, megakaryocytes. ${ }^{83} \mathrm{Kv}$ channel inhibition in platelets leads to serotonin release. ${ }^{83}$ Furthermore, fenfluramine reduces Kv1.5 mRNA levels by $50 \%$ in PASMCs from normotensive patients, ${ }^{84}$ suggesting that inhibited gene transcription and expression of Kv channels may play an important role in anorexigen-PAH. These data suggest that one of the reasons that 5-HT might be increased in PAH is the lack of Kv channels in platelets or pulmonary endothelial cells.

\section{The Extracellular Matrix}

Vascular remodeling is a prominent feature of $\mathrm{PAH}$ with muscularization of normally non- or partially muscularized peripheral arteries. The muscularization relates to differentiation of pericytes, medial hypertrophy, as well as proliferation and distal migration of PASMC. However, in PAH there is also increased production of extracellular matrix (collagen, elastin, fibronectin, and tenascin-c). Like the procoagulant state in $\mathrm{PAH}$, altered mitogenesis in $\mathrm{PAH}$ appears to be a secondary response to an initial injury. Rabinovitch ${ }^{85,86}$ has suggested that endothelial abnormalities, early in the course of PAH, permit extravasation of blood factors that stimulate SMC production of a vascular serine elastase. This results in the liberation of matrix-bound mitogens, such as basic fibroblast growth factor (FGF-2), and also enhances matrix degradation by activating other matrix metalloproteinases (MMPs). The MMPs can lead to the production of a mitogenic cofactor, tenascin. Tenascin binds to its $\alpha-\beta_{3}$ integrin receptors, leading to phosphorylation of growth factor receptors and SMC proliferation. When MMPs are inhibited, tenascin levels fall and apoptosis ensues. ${ }^{86}$ Direct inhibition of MMP2 and serine elastases leads to activation of apoptosis and suppression of proliferation in the media, and thus regression of medial hypertrophy. ${ }^{86}$ Although MMPs were conventionally thought to be solely important in remodeling, we have recently learned they can also affect vascular tone. MMP-2 and MMP-9 can activate platelets, ${ }^{87}$ while intravascular 
MMP-2 can enhance formation of vasoconstrictors, including a novel form of endothelin, and inhibit the action of endogenous vasodilators. ${ }^{88}$ The inhibition of MMPs, if selectively targeted, could be an appealing therapeutic target for causing regression of PAH.

\section{INFLAMMATION}

Inflammatory mechanisms have been implicated in several animal models of PAH (like the monocrotaline model) and human $\mathrm{PAH}$ associated with collagen vascular diseases or HIV infection. ${ }^{89}$ Immunosuppressive therapy, using cyclophosphamide and corticosteroids, has been reported to significantly improve PAH in patients with systemic lupus erythematosus. ${ }^{90,91}$ However, this is just anecdotal evidence from case reports. A potential role of inflammation in $\mathrm{PAH}$ is also supported by the prevalence of antinuclear antibodies and increased circulating levels of proinflammatory cytokines [interleukin-1 (IL-1), IL-6] in PAH patients. Furthermore, the presence of a large number of inflammatory cells and expression of chemokines, like RANTES and fractaline, has been described in and around the plexogenic lesions in PAH. $^{92}$

\section{Hypoxia Inducible Factor (HIF-I $\alpha$ )}

Hypoxia inducible factor- $1 \alpha$ is a master gene that controls the transcription of many genes that are activated by hypoxia. Rats with haploinsufficiency for HIF-1 $\alpha$, exposure to chronic hypoxia, manifest-delayed or reduced polycythemia, right ventricular hypertrophy, PHT, and pulmonary vascular remodeling have greater weight loss compared with wildtype littermates. ${ }^{93,94}$ Interestingly, this partial deficiency of HIF-1 $\alpha$ is also sufficient to impair hypoxia-induced depolarization and reduction of $\mathrm{K}^{+}$current, ${ }^{94}$ again tying the PASMC $\mathrm{K}^{+}$channels to PHT. The pathophysiologic role of HIF- $1 \alpha$ in nonhypoxic PAH is unknown, but it is likely that this pathway is important, as discussed next.

\section{ANGIOGENESIS}

Hypoxic activation of HIF-1 $\alpha$ also results in increased production of VEGF and increased expression of its receptors, Flk and Flt. ${ }^{95}$ Disordered angiogenesis has been described in $\mathrm{PAH}$ and has been implicated in the formation of plexogenic lesions. In this regard, it is noteworthy that most $\mathrm{PAH}$ patients have systemic hypoxemia and reduced alveolar diffusion capacity, even though their alveolar $\mathrm{PO}_{2}$ is normal. Increased levels of VEGF and increased expression of Flt as well as HIF- $1 \alpha$ and $-1 \beta$ have been described in these lesions; on the other hand, plexogenic lesions have decreased levels of essential factors for angiogenesis including phosphoinositide-3-kinase, AKT, and src. ${ }^{96}$ These findings have led to the hypothesis that the plexogenic lesions are not a primary abnormality in PAH but rather a secondary phenomenon, caused by a disordered angiogenesis in response to local tissue hypoxia, distal to the obliterated pulmonary arteries. $^{96}$

\section{Genetics}

Most cases of PAH appear to be sporadic, but $6 \%$ to $12 \%$ of cases are inherited in an autosomal dominant manner with incomplete penetrance. ${ }^{97}$ The disease may skip generations and might affect only a few siblings in a generation. Thus the actual proportion of familial cases may be underestimated. Although clinical and pathologic features are the same in sporadic and familial forms, familial PAH displays genetic anticipation and onset at decreasing ages in subsequent generations. Loyd et al. ${ }^{98}$ reported a successive decrease in age of death from $\mathrm{PAH}$ over three generations in one kindred, from $46 \pm 15$ to $36 \pm 13$ to $24 \pm 11$ years. This phenomenon has been observed in fragile $\mathrm{X}$ syndrome and several dominantly inherited diseases like myotonic dystrophy and Huntington's disease. The occurrence of genetic anticipation suggests that the molecular basis of familial $\mathrm{PAH}$, similarly to myotonic dystrophy, may involve expansion of a trinucleotide repeat, ${ }^{99}$ although this has not been yet shown in iPAH or fPAH. The gene for familial $\mathrm{PAH}$, previously known as $P P H 1$, was localized on 2q33 chromosome using genetic linkage analysis. ${ }^{97,100,101}$ A positional candidate approach led to the identification of $B M P R 2$ as one of the genes causing familial $\mathrm{PPH} .{ }^{102,103}$ Heterogeneous germline mutations in BMPR2 have been identified in up to $60 \%$ of several kindreds with fPAH. Interestingly, mutations in this gene have been observed in a minority of sporadic $\mathrm{PAH}$ patients $(26 \%)$, suggesting BMPR2 may contribute to the pathogenesis of iPAH occasionally. ${ }^{104}$

The BMPs are a family of secreted growth factors that are part of the transforming growth factor- $\beta$ (TGF- $\beta$ ) superfamily. Originally described as the molecules that induce ectopic bone and cartilage formation when implanted subcutaneously, ${ }_{1}^{105}$ they are now known to be important regulators of mammalian development. ${ }^{106}$ For example, BMP-4 plays a critical role in embryonic lung development. ${ }^{107}$ Transforming growth factor- $\beta$ superfamily members interact with two classes of transmembrane receptor, serine-threonine kinases type I and II receptors. ${ }^{108}$ Type II receptors have constitutively active cytoplasmic kinase domains, but they are unable to activate downstream signals in the absence of a type I receptor. Furthermore, several TGF- $\beta$ family members can use the same receptors as the BMPs, adding significant plasticity to the regulation of the downstream responses. ${ }^{108}$ This plasticity is further enhanced by the fact that a variety of downstream signaling pathways, following the binding of BMPs to BMP receptors I and II, are activated in a cell-specific manner. ${ }^{108}$ An important signaling system is the Smad system, which includes the BMPR-activated Smads (Smad-1, -5, and -8) and the common mediator Smad (Smad-4). ${ }^{109}$ The activated Smad-1, -5, -8-Smad-4 complex enters the nucleus to regulate a number of DNA binding transcription factors and cofactors that are required to initiate specific transcriptional responses. ${ }^{109}$ The Smads were originally named after a gene called "mothers against decapentaplegic (dpp),"110 an upstream gene that controls the function of $d p p$, a gene of Drosophila melanogaster that encodes a grow th factor that belongs to the TGF- $\beta$ superfamily that plays a central role in multiple cell-cell developmental signaling events. Overall, activation of the BMPR-2 pathway leads to suppression of several transcription factors, favoring apoptosis.

Homozygous deletion of the BMPR2 in vivo is associated with embryonic lethality. ${ }^{111}$ Over 40 different germline mutations in the BMPR2 gene have been described in both 
familial and $\mathrm{PAH}$ cases and include missense and frameshift mutations. ${ }^{108}$ Although it is known that at least some of the described mutations result in loss of function of the BMPR2 gene product, ${ }^{112}$ it is not known how this loss of function leads to the development of PAH. Recently, PASMCs from patients with iPAH, but not secondary PHT, were shown to exhibit enhanced growth responses to TGF- $\beta_{1}$ and BMPs. ${ }^{113}$ Recent work with a conditional knockout of BMPR2 (using a smooth muscle specific, dominant negative strategy) shows that when the BMPR2 mutation is activated after birth, mice developed PHT, right ventricular hypertrophy, and have increased medial hypertrophy of the PA, all without increase in systemic arterial pressure. ${ }^{114}$ Nonetheless many questions remain regarding the "sufficiency" of BMPR2 mutations to cause PAH. Moreover, the mechanism by which mutations in a ubiquitously expressed receptor might result in the highly restricted pattern of disease pathology seen in patients with PAH is unclear. It remains uncertain whether BMPR2 mutations result in disease by inhibiting a normal rate of apoptosis or whether something else stimulates a need for apoptosis, which cannot be supported when BMPR2 is dysfunctional. Alternatively, one can speculate that since BMPR2 mutations alter the function of many transcription factors, they may work by several mechanisms, each relating to altered transcription of relevant genes, such as Kv channels, ET-1 or the 5-HTT.

\section{Is THere A Link?}

Is there a link between these diverse abnormalities? It is apparent that most of these abnormalities result in enhanced vasoconstriction, impaired apoptosis, or accelerated proliferation of the vascular cells. It is becoming clear that not all mechanisms might be operational at a given stage of the disease or in a given patient. For example, endothelial damage is likely an early event in $\mathrm{PAH}$, whereas increased proliferation/suppressed apoptosis of the SMC is a late event. Whereas one patient might be prone to increased proliferation in the vascular wall because of a $B M P R$ mutation, susceptibility in another might relate to an abnormal 5-HTT or dysfunctional $\mathrm{K}^{+}$channel. A multiple hit hypothesis has been proposed for $\mathrm{PAH}^{9}$ (Fig. 105.9). In this theory, one or more environmental insults have to occur on a predisposed genetic background because of one or more gene abnormalities. Perhaps the pathogenesis of PAH is too complex to be explained by a single unifying theory.

While the discovery of BMPR2 mutations may explain some forms of familial PAH and may predispose to PAH in animals, it appears that the majority of iPAH is not due to these mutations. A mechanism such as the loss or inhibition of $\mathrm{K}^{+}$channels (whether genetically or by anorexigens) could unify the 5-HT and the Kv channel theories and, even if not the initiator of $\mathrm{PAH}$, explain much of the phenotype. Similar "channelopathy" could afflict the platelets or the megakaryocytes. In this scenario the PASMCs would be predisposed to constriction and proliferation and would have impaired apoptosis, whereas the platelets would secrete excess 5-HT, thereby reinforcing SMC contraction and proliferation. The increased expression of the inhibitor of apoptosis survivin significantly suppresses $\mathrm{K}^{+}$current. Moreover, the idea that $\mathrm{K}^{+}$channels might be central to the pathogenesis of PAH is supported by the observation that experimental therapies promoting the function and expression of $\mathrm{K}^{+}$channels have been effective in several animal PAH models. In other words, apoptosis resistance and proliferation in the pulmonary vascular wall may occur due to dysregulation in the BMPR-2 pathway, 5-HT, survivin, and the Kv channels, alone or in combination.

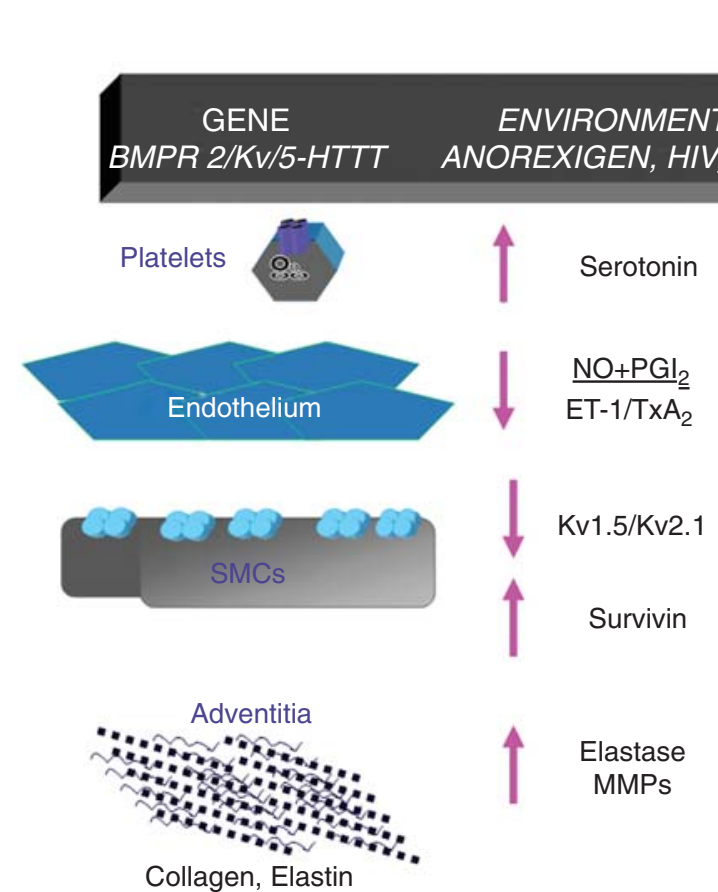

Collagen, Elastin
FIGURE 105.9. A schematic for the proposed multiple hit hypothesis in PAH. 


\section{Clinical Recognition of Pulmonary Arterial Hypertension}

\section{Symptoms (Table 105.5)}

Pulmonary arterial hypertension is an uncommon condition, and its symptoms are nonspecific. Therefore, patients often have symptoms for months or years before a correct diagnosis is made, especially in iPAH, where the lack of associated conditions does not provide additional clues. In the NIH registry, the average time from onset of symptoms to diagnosis of PHT was 2.5 years. ${ }^{18}$ Although symptoms of PHT do not directly reflect PAP, patients usually remain asymptomatic until PAP has doubled. ${ }^{115}$

The earliest and most common symptom of PAH is dyspnea. In the NIH registry, $60 \%$ of the patients had dyspnea as a presenting symptom, although $98 \%$ had dyspnea by the time they were enrolled in the registry. ${ }^{18}$ The causes of dyspnea in PAH are diverse, varying somewhat according to the etiology of the syndrome. Dyspnea is found in the majority of pulmonary hypertensive syndromes, with the notable exception of sleep apnea. In most cases, dyspnea appears to relate more to altered lung mechanics and reflex activation than to hypoxemia. In PAH there is often a respiratory alkalosis with mild hypoxemia. In these patients, dyspnea may relate to increased J-receptor activity, possibly a result of decreased vascular and therefore lung compliance. Hypoxemia may also lead to dyspnea in patients with PAH due to intracardiac shunting (e.g., Eisenmenger's syndrome). Interstitial lung disease, with reduced lung compliance and hypoxemia, is another cause of dyspnea and is common in patients with $\mathrm{PAH}$ due to connective tissue diseases (e.g., mixed connective tissue disease, scleroderma, CREST syndrome).

Like dyspnea, fatigue is a common and nonspecific symptom in these patients. Fatigue may reflect reduced cardiac output and impaired oxygen delivery to the tissues. In addition, PVR increases dramatically with exercise in patients with PAH, unlike normal individuals. Dyspnea and fatigue occur with similar frequency regardless of the cause of the PHT.
Syncope and near syncope can occur in severe $\mathrm{PAH}$, particularly with exertion. During exercise, the obstructed or obliterated pulmonary vascular bed may be unable to correct for a fall in systemic vascular resistance by accommodating adequate increases in cardiac output, culminating in reduced cerebral blood flow and syncope.

Chest pain is not unusual in PAH and may be described by the patient as sharp and pleuritic or as a dull ache. The dull chest ache noted by some patients with PHT is suggestive of angina. Potential mechanisms include right ventricular ischemia and distention of the pulmonary arteries.

A somewhat unusual symptom of PHT is hoarseness (Ortner's syndrome). Hoarseness results when the left recurrent laryngeal nerve, which passes between the aorta and the pulmonary artery, is compressed by the enlarged pulmonary artery. ${ }^{115,116}$

Hemoptysis also occurs in many types of PHT. It has been reported that in the capillary bed of patients with PHT there are microaneurysms that may be susceptible to rupture, resulting in hemoptysis. ${ }^{115}$ Hemoptysis is a frequent cause of morbidity and mortality in Eisenmenger's syndrome, accounting for $15 \%$ of deaths in one study. ${ }^{117}$

\section{Physical Examination}

Like the history, the findings on physical examination in PHT are often nonspecific. A number of patients with PHT have an entirely normal physical examination. Furthermore, the physical examination rarely allows quantification of the severity of PHT until the terminal stages of the disease, when right heart failure appears. The physical findings of PHT reflect the presence of an enlarged, noncompliant right ventricle $(\mathrm{RV})$ and insufficiency of the tricuspid or pulmonic valves. The most common clinical signs and their mechanism are shown in Table 105.5.

Although a loud pulmonic component of the second heart sound is common in patients with PHT, as the hypertension becomes more severe the interval between closure of the aortic and pulmonic valves may decrease so that the valves close almost simultaneously, eliminating the value of this sign. However, if a second heart sound is heard at the apex

TABLE 105.5. Signs and symptoms of pulmonary hypertension

\begin{tabular}{ll}
\hline Sign & Mechanism \\
\hline Accentuated component of $\mathrm{S}_{2}$ & Increased force of P-valve closure \\
Early systolic click of the pulmonary valve & Sudden interruption of P-valve closure \\
Midsystolic ejection murmur & Turbulence in P-valve outflow \\
Diastolic murmur & P-valve regurgitation \\
Holosystolic murmur increasing with inspiration & Tricuspid regurgitation \\
Increased jugular a wave & Increased RV filling pressure \\
Left parasternal lift and right-sided $S_{3}$ & RV hypertrophy and failure \\
Edema, ascites, hepatomegaly & RV failure \\
\hline Symptom & Mechanism \\
\hline Dyspnea, fatigue & Decreased cardiac output \\
Chest pain & RV ischemia, PA dilatation \\
Syncope & Decreased cardiac output, arrhythmias \\
Hoarseness (Ortner's syndrome) & Compression of the laryngeal nerve by the dilated PA \\
\hline
\end{tabular}


(where the aortic component is not audible in normal hearts) it almost always is due to a loud $\mathrm{P}_{2}$ and suggests severe PAH.

The Graham-Steele murmur of pulmonic valve insufficiency occasionally accompanies severe PHT. This diastolic murmur is usually best heard in the left second or third inner space near the sternum. Pulmonary insufficiency may be distinguished from aortic insufficiency by observing the response to the Valsalva maneuver. The pulmonary regurgitation murmur usually returns to pre-Valsalva intensity within several beats, whereas the aortic regurgitation murmur usually takes longer to return to its intensity. The time delay occurs because the blood excluded from the thorax by the Valsalva maneuver must first traverse the pulmonary circulation before reaching the aorta and augmenting the murmur. In some PHT patients a diastolic murmur that enhances with inspiration occurs. This right-sided "Austin Flint murmur" is due to functional tricuspid stenosis due to valve closure caused by severe pulmonic insufficiency. ${ }^{118}$ Although echocardiographic evidence of mild tricuspid and pulmonic regurgitation is prevalent even in normal individuals, audible or hemodynamically significant insufficiency is rare. However, pulmonic insufficiency can also occur fairly commonly in patients with fluid overload related to renal failure, which also reflects transient $\mathrm{PHT}^{119}$

The blowing systolic murmur of tricuspid regurgitation is best heard over the lower right sternal border and may briefly enhance with inspiration (Carvallo's sign). The right-sided third heart sound occurs primarily once the RV has decompensated from chronic pressure overload, and is usually accompanied by a murmur of tricuspid regurgitation.

\section{Clinical and Laboratory Assessment (Table 105.6)}

Diagnostic testing in PHT may serve three purposes: (1) documentation and quantification of $\mathrm{PHT}_{\text {; }}(2)$ defining the etiology, particularly differentiating between PAH and secondary PHT; and (3) assessment of prognosis. A major emphasis is detecting conditions that have a specific treatable cause of the PHT (notably mitral regurgitation or stenosis and thromboembolic PHT).

Our approach to the patient with presumed PHT is to establish its presence, preferably by a noninvasive test, such as echocardiography. If the pressure is elevated or cannot be accurately measured, then a right heart catheterization is performed. A typical case is presented in Figure 105.10.

Once a diagnosis of PHT is established, the next goal is to determine the etiology. The following tests should be obtained in all patients in whom the cause of PHT is not evident: electrocardiogram (ECG), chest radiograph, arterial blood gases, complete blood count, electrolytes and liver function tests, pulmonary function tests (PFTs), ventilation/ perfusion lung scan, serology for rheumatic diseases (e.g., fluorescent antinuclear antibody, FANA), serology for HIV, ventilation perfusion (V/Q) scan, and an echocardiogram with Doppler assessment of PA acceleration time and tricuspid regurgitation velocity as well as an echo-contrast study, to exclude shunting. This relatively inexpensive and safe battery of tests can detect patients with chronic lung disease, valvular heart disease, left ventricular dysfunction, most intracardiac shunts, thromboembolic disease, LV dysfunction, and PAH due to HIV, liver disease/portal hypertension, or connective tissue disease. In patients with abnormal PFTs or inconclusive V/Q scan, a chest computed tomography (CT) is also performed in order to exclude or confirm pulmonary fibrosis or thromboembolic disease.

A right heart catheterization is performed in essentially all patients with evidence for $\mathrm{PAH}$, for the following reasons: (1) to confirm the presence and magnitude of PHT and establish an objective baseline for future therapies; and (2) to determine or confirm the type of $\mathrm{PAH}$ (e.g., to make the diagnosis of $\mathrm{PAH}$ a gradient between the mean wedge pressure and the pulmonary artery diastolic pressure of more

TABLE 105.6. Comparison of invasive and noninvasive tests in three forms of pulmonary hypertension

\begin{tabular}{|c|c|c|c|c|c|}
\hline & $\begin{array}{c}\text { NIH iPAH } \\
\text { registry }^{18}\end{array}$ & iPAH ${ }^{248}$ & Thromboembolic $^{248}$ & Thromboembolic 449,250 & Cor pulmonale ${ }^{25}$ \\
\hline \multicolumn{6}{|c|}{ Pulmonary function tests (\% predicted) } \\
\hline $\mathrm{FEV}_{1}$ & $83 \pm 17$ & $79 \pm 8$ & $75 \pm 9$ & $\mathrm{~N} / \mathrm{A}$ & $33 \pm 14$ \\
\hline TLC & 89 & $87 \pm 12$ & $96 \pm 12$ & $\mathrm{~N} / \mathrm{A}$ & $105 \pm 15$ \\
\hline DLCO & 82 & $59 \pm 22$ & $60 \pm 19$ & $75-107$ & \\
\hline \multicolumn{6}{|l|}{ Arterial blood gases $(\mathrm{mm} \mathrm{Hg})$} \\
\hline $\mathrm{PO}_{2}$ & $70 \pm 2$ & $65 \pm 12$ & $62 \pm 8$ & $<80$ in $80 \%$ & $59 \pm 8$ \\
\hline $\mathrm{PCO}_{2}$ & $30 \pm 6$ & $31 \pm 5$ & $32 \pm 5$ & $24-37$ & $46 \pm 8$ \\
\hline Mean PAP & $61 \pm 20$ & $57 \pm 15$ & $48 \pm 16$ & $49 \pm 9$ & $24 \pm 5$ \\
\hline Wedge pressure & $9 \pm 4$ & $7 \pm 4$ & $7 \pm 4$ & $9 \pm 3$ & $9 \pm 3$ \\
\hline \multicolumn{6}{|l|}{ Ventilation/perfusion scan } \\
\hline Low probability or normal & $97 \%$ & 100 & 0 & 0 & $\mathrm{~N} / \mathrm{A}$ \\
\hline High probability & $0.6 \%$ & 0 & 100 & 100 & N/A \\
\hline \multicolumn{6}{|l|}{ Pulmonary angiography $(\%)$} \\
\hline Positive for proximal thrombi & 0 & 0 & 100 & 100 & $\mathrm{~N} / \mathrm{A}$ \\
\hline Deaths from angiography & 0 & 0 & 0 & 0 & $\mathrm{~N} / \mathrm{A}$ \\
\hline
\end{tabular}

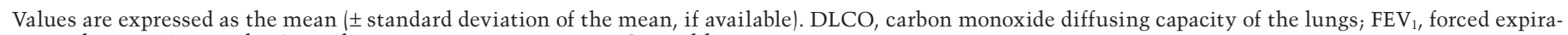
tory volume in 1 second; PAP, pulmonary artery pressure; TLC, total lung capacity. 


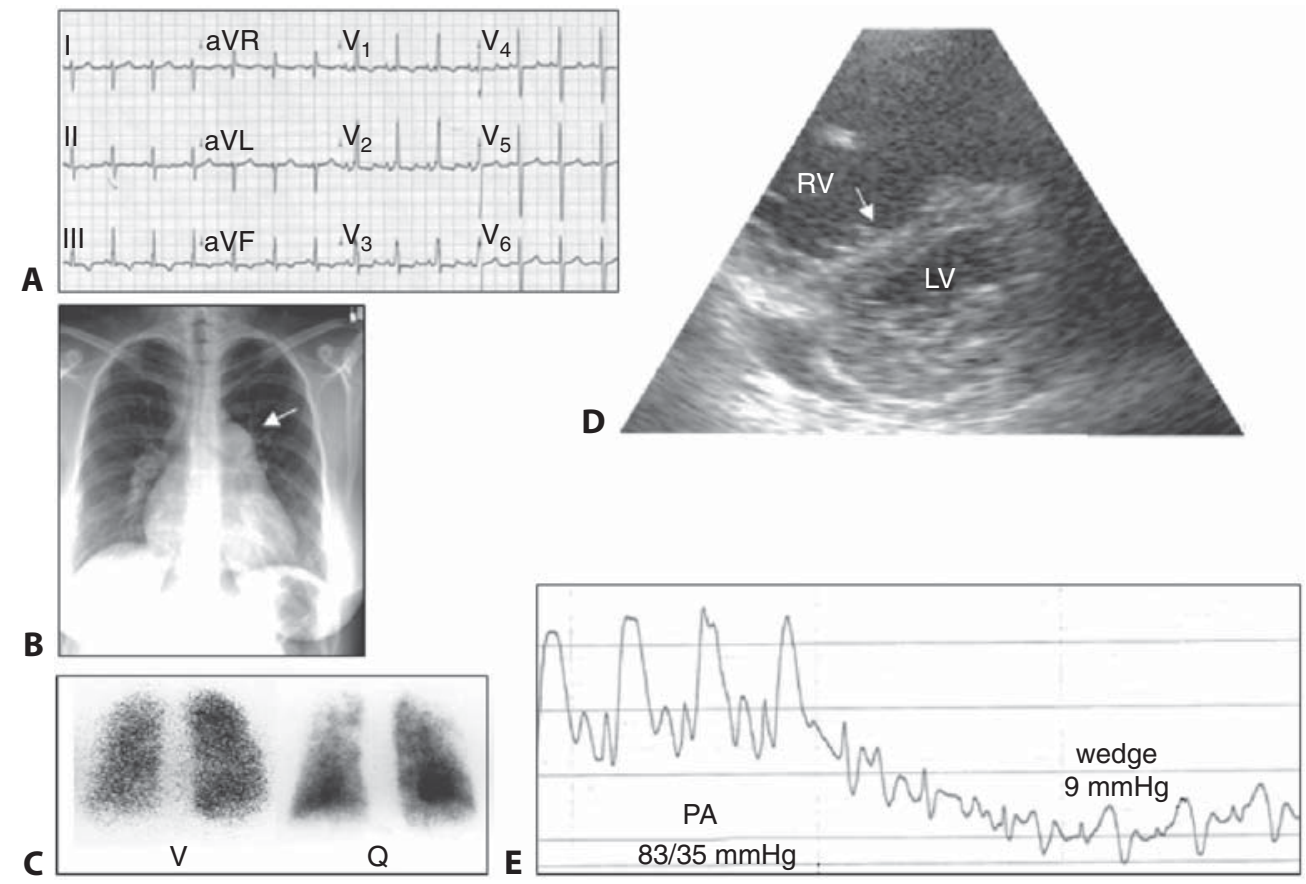

FIGURE 105.10. A classic iPAH case. A 32-year-old woman presents at the University of Alberta with fatigue and dyspnea on exertion of 1 year's duration. Her jugular venous pressure (JVP) is $11 \mathrm{~cm}$ $\mathrm{H}_{2} \mathrm{O}$; there is a loud $\mathrm{P}_{2}$, and pulmonic flow murmur. There is mild peripheral edema. Her electrocardiogram (ECG) (A) shows right axis deviation and right ventricular hypertrophy. Her chest x-ray (B) shows cardiomegaly and no evidence of pulmonary venous hypertension. There is evidence of proximal pulmonary artery dilatation (arrow) and pruning of the peripheral pulmonary arteries. A ventilation/perfusion (V/Q) scan (C) shows low probability of a pulmonary embolism but shows a characteristic "moth-eaten" abnormality in the perfusion image. A transthoracic echocardiogram (D) excludes left ventricular (LV) and valvular disease. A contrast study rules out intracardiac shunts but does show right ventricular dilatation. The systolic flattening of the septum (arrow) is diagnostic of right ventricular (RV) pressure overload. This suggests severe $\mathrm{PAH}$ and the estimated systolic PA pressure by Doppler is $\sim 90 \mathrm{~mm} \mathrm{Hg}$. A right heart catheterization confirms the diagnosis and the severity of PAH. The gradient of $26 \mathrm{mmHg}$ between the diastolic pulmonary artery pressure (PAP) and the wedge pressure confirms that the problem is intrinsic to the pulmonary arteries, that is, that the patient has PAH (E). There was a $22 \%$ decrease in the pulmonary vascular resistance (PVR) by a maximal dose of inhaled nitric oxide (NO) $(80 \mathrm{ppm})$ and a $25 \%$ decrease in the PVR, 50 minutes after a single dose of sildenafil (75 mg po). Because the PVR decreased by $>20 \%$, this patient is considered a "responder" to pulmonary vasodilators. The patient was started on $\mathrm{Ca}^{2+}$ blockers, but she could not tolerate even moderate doses of nifedipine because of peripheral edema, dizziness, and hypotension. Although she responded very well to a single dose of sildenafil, she could not afford to pay for sildenafil (50 mg po t.i.d. $=$ CDN $\$ 500 /$ month). She was started on Bosentan $125 \mathrm{mg}$ po b.i.d. She continued to deteriorate, and 3 months later her 6-minute walk had decreased from $290 \mathrm{~m}$ to $250 \mathrm{~m}$. She was started on continuous intravenous epoprostenol and a workup for heart-lung transplantation was initiated. Her condition has been stable for the following 12 months (class II), and her average 6minute walk performance is $350 \mathrm{~m}$. She has yearly right heart catheterizations and echocardiograms. She attends the multidisciplinary PAH clinic every 3 months where she also sees a dietitian and a psychologist. than 10 to $12 \mathrm{mmHg}$ has to be established); and (3) to determine the response to acute vasodilators (e.g., iNO), since this is associated with prognosis and might guide choice of therapies (see below).

After the diagnosis of PAH is established and before the initiation of any treatment, a good assessment of the baseline functional class has to be established. The baseline functional class not only predicts prognosis but also guides immediate and future treatments. In addition to the NYHA functional class, quantitative assessment of functional performance can be achieved with $\mathrm{maxVO}_{2}$ testing, or, if that is not possible, the 6-minute walk test. The 6-minute walk test has emerged as one of the most important end points in clinical trials over the past few years. It is simply the distance the patient covers during a 6-minute walk period on a standard corridor with standardized supervision. The 6-minute walk is a very strong predictor of survival in PAH. ${ }^{120}$ The ability of this simple test to predict survival likely comes from the fact that it reflects cardiac output and more specifically the ability to increase cardiac output during mild exercise. This in turn reflects the performance of the right ventricle. In clinical practice one is impressed by the frequent dissociation between PVR and functional class and the better correlation with 6-minute walk and functional class. This is because, for reasons that we do not yet understand, the response of the right ventricle to the same increase in its afterload varies significantly among patients. A simple index of the compensation of the right ventricular condition is the 
right atrial pressure. The jugular venous pressure and 6minute walk should be documented at each visit.

More recently, a simple test that is currently available as a point-of-care test is emerging as another index of right ventricular size and function: the brain natriuretic peptide (BNP) levels. Levels of BNP, a peptide released from the ventricles during stretch or ischemia, correlate well with hemodynamics and also predict survival in patients with $\mathrm{PAH}{ }^{121}$ There are two assays available, and the advantage of the point of care assay that measures BNP itself (Triage-BNP test $\AA^{\circledR}$, Biosite, San Diego, CA; normal values are $<100 \mathrm{pg} / \mathrm{mL}$ ) over the automated proBNP assay is its convenience (it can be done in the clinic) and its relative independence from confounding effects with age or mild to moderate impairment of renal function. Measurement of BNP may prove a useful means to judge the success of therapy or provide early warning of right ventricular decompensation.

\section{Chest X-Ray}

Central pulmonary artery enlargement and enlargement of the right ventricle are important clues to the presence of severe PAH (see case report in Fig. 105.10). "Pruning" of the peripheral pulmonary arteries is a classic sign, which reflects vascular obliteration of the small arteries in the periphery of the lungs. Understanding of this important finding becomes easier if one looks at the MR angiography with gadolinium from the same patient, where the obliteration of the peripheral pulmonary arteries is directly shown (Fig. 105.11). Other radiographic signs of PHT include right heart enlargement (filling in of the retrosternal space on the lateral view) and PA enlargement, measured as the diameter of descending right pulmonary artery (normal values are $12.1 \pm 1.2 \mathrm{~mm}$ ). The absence of signs of secondary hypertension also can be documented with a chest x-ray; for example, the presence of septal thickening or pleural effusions suggests venous hypertension

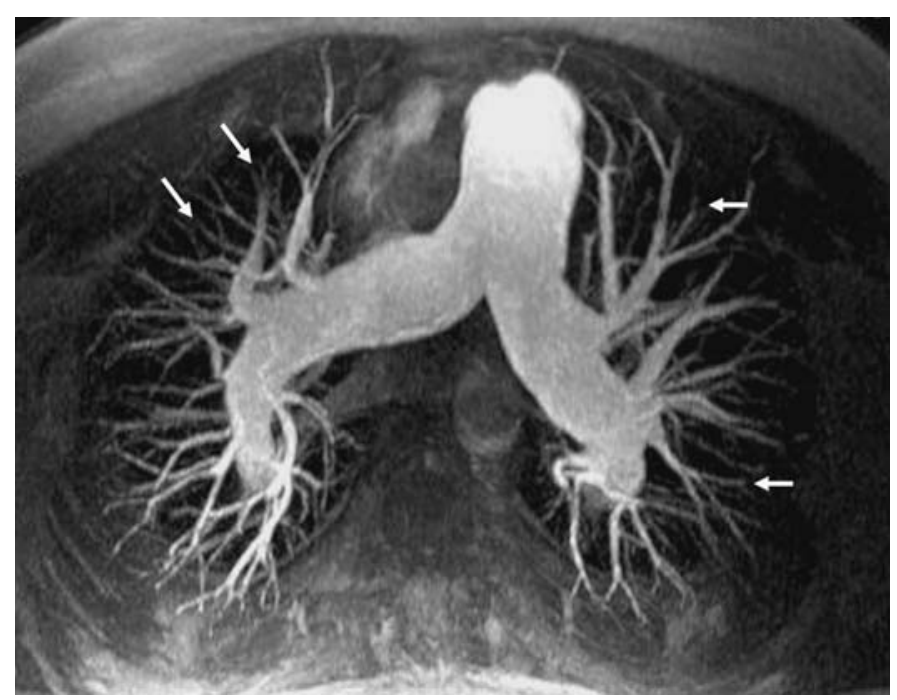

FIGURE 105.11. Noninvasive pulmonary gadolinium MR angiography of a 32-year-old woman with iPAH. Note the obliteration of the distal pulmonary arteries (arrows), a finding that explains the "pruning" seen in the periphery of the lung fields in the x-rays of patients with severe PAH. to left ventricular dysfunction, veno-occlusive disease, or pulmonary capillary hemangiomatosis.

\section{Electrocardiography}

Electrocardiography is a specific but insensitive means of diagnosing RV hypertrophy (RVH), and for this reason, even though it is simple, it is not a good screening test. Nonetheless, by the time they are detected, most PAH patients have clear-cut RVH and right axis deviation (Fig. 105.10). Lehtonen and Sutinen ${ }^{122}$ compared four sets of ECG criteria for diagnosing RVH in patients whose RV thickness was measured at autopsy. Hearts were considered normal if the total weight was less than $250 \mathrm{~g}$, the RV less than $65 \mathrm{~g}$, and the combined LV plus septum (S) weight less than $190 \mathrm{~g}$ (ratio of LV + S/RV, 2.3-3.3). By combining aspects of the four sets of ECG criteria, they achieved a diagnostic sensitivity of $63 \%$ and a specificity of $96 \%$. These combined criteria included right axis deviation greater than $110, \mathrm{R}$ wave equal to or greater than $\mathrm{S}$ wave (in $\mathrm{V}_{1}$ or $\mathrm{V}_{2}$ ), $\mathrm{R}$ wave equal to or less than $\mathrm{S}$ wave in lead $\mathrm{V}_{6}$, and the calculated value $A R: P L$ of 0.7 , where $A$ is the maximum R-wave amplitude in leads $\mathrm{V}_{1}$ or $\mathrm{V}_{2}, R$ is the maximal $\mathrm{S}$-wave amplitude in leads $\mathrm{I}$ or $\mathrm{V}_{6}$, and $P L$ is the minimal S-wave amplitude in leads $\mathrm{I}$ or $\mathrm{V}_{6}$. This set of criteria was quite specific, despite the presence of LV hypertrophy and myocardial infarction in the study population. A limitation of this study is that the autopsy was restricted to patients dying from respiratory failure, and perhaps these criteria might not be applicable in other causes of PHT. For example, the chest size is enlarged in patients with chronic airway disease and influences the voltage and the axis in ECG.

The ECG criteria for RVH become less specific in the presence of right bundle branch block, posterior myocardial infarction, left posterior hemiblock, and Wolff-ParkinsonWhite syndrome with a posteroseptal accessory pathway. These conditions, rare in PAH except for the right bundle branch block, may cause right axis deviation or a predominant $R$ in lead $V_{1}$, similar to the findings in RVH. Fortunately, there are often clues that permit differentiation of $\mathrm{RVH}$ from these conditions. Posterior infarction usually involves associated inferior infarction. One should be cautious in making a diagnosis of $\mathrm{RVH}$ in patients with inferior $\mathrm{Q}$ waves and dominant $\mathrm{R}$ waves in $\mathrm{V}_{1}$. Furthermore, patients with RVH typically have right atrial (RA) enlargement (known as P-pulmonale), diagnosed based on the presence of asymmetrical peaked $\mathrm{P}$ waves greater than $2.5 \mathrm{~mm}$ in amplitude in any lead. Therefore, if one is attempting to distinguish between a posterior hemiblock and RVH, the presence of atrial hypertrophy would militate in favor of the diagnosis of hypertrophy.

\section{Pulmonary Function Tests}

Pulmonary function tests are often abnormal in patients with PHT. The abnormality of lung function may be the cause of the PHT, as in chronic obstructive pulmonary disease, or vice versa (see Table 105.6). For example, patients with thromboembolic and iPAH often have mild restrictive or obstructive patterns noted on spirometry. Diffusing capacity for carbon monoxide (DLCO) is typically low in $\mathrm{PAH}$, more so in patients with scleroderma. 

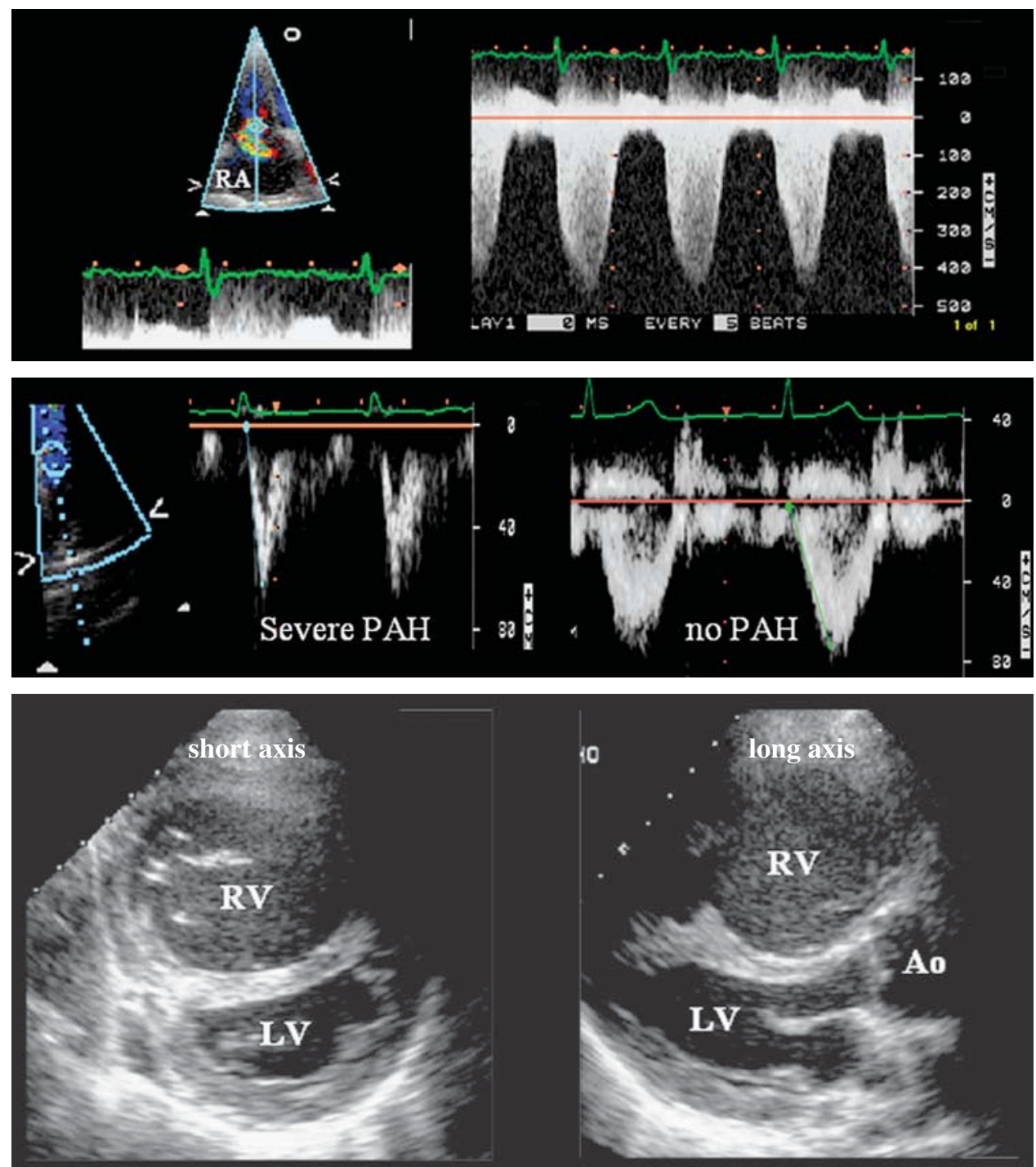

FIGURE 105.12. Echocardiography findings in PAH. Classic examples of continuous and pulsed Doppler as well as $2 \mathrm{D}$ imaging are shown.

\section{Echocardiography (Fig. 105.12)}

There are a number of excellent articles and chapters reviewing the use of echocardiography in the detection and quantification of PHT. ${ }^{123,124}$ If the image quality is adequate and one integrates anatomic data (RV chamber size and thickness, mitral valve anatomy|, physiologic measurements (Doppler measurement of valve insufficiency and shunts), and a few simple calculations of pulmonary artery pressures, the echocardiogram is a reliable test for suggesting the presence of PHT. The likelihood of finding and estimating the severity of PHT is directly proportional to the diligence of the sonographer and the experience of the physician who interprets the study.

\section{M-Mode Echocardiogram}

Although the M-mode echocardiogram is less widely used since the advent of two-dimensional echocardiography, it is occasionally a useful modality in the diagnosis of PHT. The M-mode signs of PHT are indirect measurements that predominantly reflect the rigid, noncompliant nature of the diseased pulmonary vasculature. A characteristic sign of PHT is the absence of an " $\mathrm{A}$ " dip on the M mode of the pulmonic valve. ${ }^{125}$ The A dip, which occurs when atrial systole causes a bulging or partial opening of the pulmonic valve, is present only in patients in sinus rhythm. The sensitivity and specificity of this sign are relatively low. ${ }^{126}$

A second sign of PHT is the transient midsystolic closure of the pulmonic valve. The reasons for the premature closure of the pulmonic valve in PHT include the reduced capacitance of the pulmonary vascular bed and a prominent flow reversal within the hypertensive pulmonary artery. ${ }^{127}$ Reflection of the systolic wave front may be enhanced in the hypertensive pulmonary vasculature, resulting in deceleration of midsystolic flow. This M-mode sign of PHT is related to the finding on pulsed Doppler of a transient, early systolic pulmonary arterial flow deceleration. The notched morphology 
on $\mathrm{M}$ mode is fairly specific but is insensitive as a test for PHT and has been reported in patients with normal PAP who have idiopathic dilatation of the pulmonary artery. ${ }^{128}$

The adult right ventricle is roughly one third the thickness of the LV. Right ventricle hypertrophy can be measured using the M-mode echocardiogram or the electronic calipers on the two-dimensional image. Care must be taken to ensure that the M-mode cursor avoids the papillary muscles and the RV muscular bands. The RV can be measured from many acoustic windows, but it is optimally measured from a medially angulated parasternal or subcostal window at the level of the tips of the tricuspid valve leaflets, using a $5-\mathrm{MHz}$ transducer. ${ }^{129}$ With this technique, Gottdiener et al. ${ }^{130}$ found that normal subjects have an RV wall thickness of $\leq 4 \mathrm{~mm}$.

\section{Two-Dimensional ECHOCARDIOGRAPHY}

The RV has a complex geometric shape. Unlike the somewhat ellipsoid configuration of the LV, the RV is crescentic and is not readily described by simple geometric equations. Even measurement of wall thickness is difficult owing to the trabeculation, which can result in significant variation in wall thickness within a relatively small sample volume.

Goerke and Carlsson ${ }^{131}$ have shown that Simpson's rule can be used to calculate volumes of ventricular casts in a similar model. Starling et al. ${ }^{132}$ showed that RV volume could be calculated as area times length of the right ventricle, but the appropriate subcostal views could be obtained only in $64 \%$ of patients.

The end-systolic configuration of the ventricular septum is a useful indirect measurement of the relative pressures in the LV and RV. ${ }^{133}$ As RV systolic pressure increases, there is a gradual change in septal configuration from convex (bulging toward the right ventricle) to flat, and finally to concave (indented toward the left ventricle) (Fig. 105.12). Twodimensional estimates of RV mass are difficult, and a threedimensional technique, specifically magnetic resonance imaging (MRI), is preferred to accurately measure RV mass.

Pericardial effusion is a common but nonspecific finding in chronic severe PHT. In one study, largely comprising patients with thromboembolic PHT, $41 \%$ had small or medium-sized effusions, none of which was symptomatic. The likelihood of effusion was increased in those patients with the highest RA pressure or PAP. ${ }^{134}$

\section{Pulsed Doppler (Fig. 105.12, Table 105.1)}

Pulsed Doppler measurement of pulmonary artery flow velocity in the main PA is an extremely useful qualitative and quantitative technique for measuring PA pressure, and, unlike estimates based on tricuspid regurgitation velocity, is available in virtually all patients. In PHT, the peak velocity of the Doppler envelope decreases and the time to peak velocity (measured from the onset of flow) or acceleration time (PAAT) shortens. In severe PHT there may be "notching" or early systolic deceleration, which, like the premature partial closure of the pulmonic valve on $\mathrm{M}$ mode, reflects the velocity waves and cancellation by reverse flow. This is due to the noncompliant nature of the distal vascular bed in PHT. The normal pulmonary artery flow velocity is $81 \pm 17 \mathrm{~cm} / \mathrm{s}$ and occurs with a PAAT of $121 \pm 27$ seconds. ${ }^{135}$ A typical Doppler signal in patients with $\mathrm{PHT}$ is often of triangular shape rather than the normal broad shield shape seen in normotensive patients, and the PAAT is shortened. ${ }^{136}$ Although there is a fair correlation between acceleration time and pulmonary artery systolic pressure, Mahan et al. ${ }^{137}$ found a better correlation between PAAT and mean PAP. They used a regression equation to develop the following formula predictive of mean PAP: mean PA pressure $=79-0.45 \times$ PAAT. Other groups have confirmed this relationship, albeit with modified regression equations (Table 105.1). This technique is somewhat heart rate dependent, but it correlates well with mean PAP in patients with heart rates between 60 and 100. It is useful to express the PAAT as a ratio with the systolic ejection time (SET), which also shortens in PHT. A PAAT/SET <0.36 reliably indicates PHT. These same Doppler parameters are useful in assessment of rodent models of PHT. ${ }^{38,40}$

\section{Continuous Wave Doppler (Fig. 105.12)}

Continuous wave Doppler measurement of tricuspid regurgitation velocities permits accurate, noninvasive measurement of systolic PAP, even in many normal individuals. Tricuspid regurgitation is extremely common, and increases in prevalence and severity as PAP increases. Berger et al. ${ }^{138}$ found tricuspid regurgitation in 39 of 49 patients with systolic pressures less than $35 \mathrm{~mm} \mathrm{Hg}$ and in 26 of 27 patients with pressures greater than $50 \mathrm{~mm} \mathrm{Hg}$. They noted an excellent correlation between Doppler and catheter estimates of pulmonary artery systolic pressure $(r=0.97)$.

Guided by color flow Doppler, the continuous wave Doppler must be positioned parallel to the regurgitant jet to accurately measure peak tricuspid regurgitation velocity. However, the jets are often eccentric and small, which results in incomplete envelopes that underestimate PAP; PAP is calculated using the modified Bernoulli equation. Systolic PAP can be estimated as four times the square of the systolic tricuspid valve plus the RA pressure (the pressure into which the tricuspid regurgitation is ejected) (Table 105.1). Yock and Popp $^{139}$ used this modified Bernoulli's equation to estimate RV systolic pressures in patients with clinical signs of PHT. In their study, tricuspid regurgitation velocity could be measured in 54 of 62 patients. There was a good correlation between the pressures obtained by catheter and by Doppler. The utility of the tricuspid regurgitation jet in evaluating pulmonary systolic pressure has been well validated. ${ }^{140}$ It is apparent that accurate estimation of PAP relies on knowledge of the RA pressure. RA pressure can be estimated at the bedside by measuring the jugular venous pulse (JVP). Unfortunately, this is difficult in some patients, and sonographers, who perform most studies, are usually not trained to measure JVP. The RA pressure is approximated by the perpendicular height of the JVP above the sternal angle plus the estimated distance from the middle RA to the sternal angle $(\sim 5 \mathrm{~cm}$ in an average-sized adult). This estimated atrial pressure in $\mathrm{cm}$ $\mathrm{H}_{2} \mathrm{O}$ can be converted to $\mathrm{mm} \mathrm{Hg}$ by dividing by 1.3 .

The diameter of the proximal inferior vena cava is more readily measured by the sonographer and can be used to estimate RA pressure. At normal RA pressures, the vena cava decreases in size 50\% with normal inspiration (inspiratory pressures of 0 to $5 \mathrm{~mm} \mathrm{Hg}$. ${ }^{141}$ Much higher inspiratory pressures are required to achieve the same degree of collapse in patients with elevated RA pressure. There is a good relationship between RA pressure and the inspiratory pressure required to alter caval size, but this requires the use of 
sonospirometry. ${ }^{142}$ Measurement of caval diameter $2 \mathrm{~cm}$ proximal to the RA junction at rest and with respiratory maneuvers, such as a sniff, permits approximation of right atrial pressure. ${ }^{142}$ As a rule, an inferior vena cava that is more than $2 \mathrm{~cm}$ in diameter and that collapses by less than $50 \%$ when the patient sniffs is "plethoric" and usually reflects an RA pressure $>10 \mathrm{mmHg}$. Conversely, cavae that are under $2 \mathrm{~cm}$ that collapse by $>50 \%$ with spontaneous respiration reflect normal atrial pressures (1 to $6 \mathrm{~mm} \mathrm{Hg}$ ).

In clinical practice, due to time constraints on sonographers, jet eccentricity, inaccurate estimation of RA pressure, and poor acoustic windows, the ability to accurately predict PAP using tricuspid regurgitation (TR) velocity is substantially less than the $90 \%$ reported in select research cohorts, even if one enhances the tricuspid regurgitation jet with injection of contrast material. Consequently measurement of RVH on a two-dimensional echocardiogram and PAAT, using pulsed Doppler, should also be used in assessing possible PHT.

A
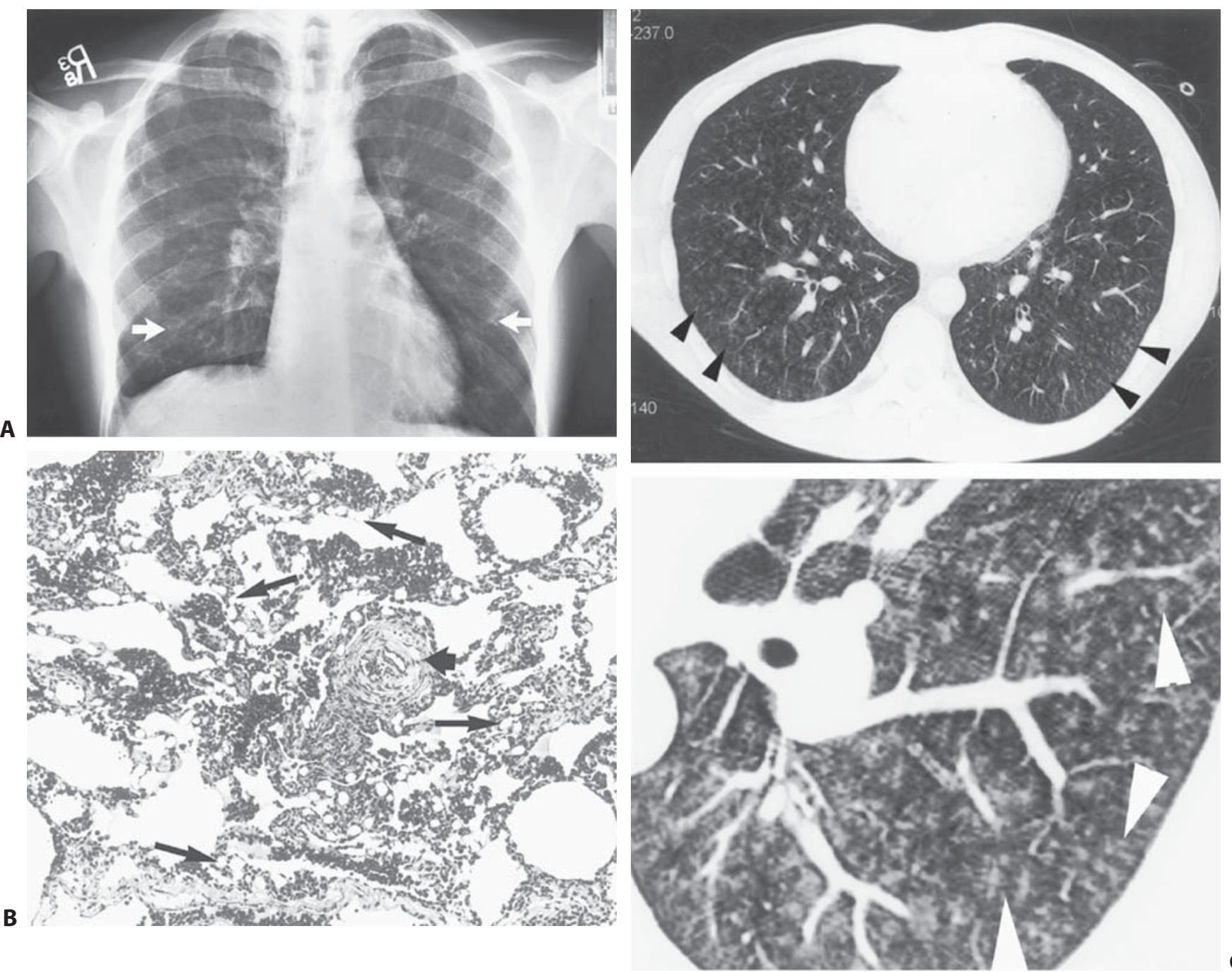

\section{C}

FIGURE 105.13. Pulmonary capillary hemangiomatosis. (A) Illdefined nodular irregularities representing the nodular capillary proliferation are shown (arrows) in the chest x-ray. (B) Open lung biopsy shows diffuse alveolar septal involvement by a proliferation of small thin-walled vessels (long arrows). Thickening of the wall and narrowing of the lumen of a pulmonary artery are due to fibro-
High-resolution CT is a significant aid in excluding occult parenchymal lung disease, pulmonary fibrosis, or chronic pulmonary embolism in possible $\mathrm{PAH}$ patients. Of patients with biopsy-proven interstitial fibrosis, 10\% may have normal chest radiographs, and for these patients CT scans are a more sensitive technique. ${ }^{143}$ Contrast-enhanced, multislice CT (16 or, more recently, 64 slice), can detect central chronic thromboembolic with a specificity of $85 \%$ to $90 \%$ and sensitivity of $90 \% .{ }^{144}$ Computed tomography scanning is also helpful in differentiating $\mathrm{PAH}$ due to veno-occlusive disease from iPAH. The presence of ground-glass opacities (particularly with a centrilobular distribution), septal lines, and adenopathy are indicative of pulmonary veno-occlusive disease in PAH patients (Fig. 105.13).

Multislice and electron beam CT was used to compare the pulmonary vascular and parenchymal characteristics of the lung in $31 \mathrm{PAH}$ patients with Eisenmenger's syndrome

\section{Computed Tomography}

plasias (short arrow). (C) Axial computed tomography (CT) shows subtle innumerable micronodular densities in the centrilobular regions (arrowheads) surrounded by normal parenchyma are observed (top). A magnified image of the left lower lung demonstrates the micronodular ill-defined centrilobular densities (arrowheads) separated by relatively spared normal parenchyma (bottom). 
versus 13 iPAH patients. ${ }^{145}$ In Eisenmenger's patients the proximal PAs were consistently enlarged and $13 \%$ of patients were aneurysmal, which caused bronchial compression and atelectasis. Thromboses were uniformly present on CT, although they were large in only $29 \%$ of patients. Mural calcific deposits occurred in $26 \%$ of these patients. In addition, Eisenmenger's patients often had pulmonary infarction, intrapulmonary hemorrhage, bronchial collateral vessels, and neovascularization. In contrast, iPAH patients had consistent enlargement of proximal PAs on CT, but no aneurysms, thromboses, infarcts, or neovascularity ${ }^{145}$ However, like Eisenmenger's patients, extensive mural calcific deposits were found in $23 \%$ of $\mathrm{PAH}$ patients and they too had bronchial collaterals. ${ }^{145}$

\section{Ventilation Perfusion Scans (Fig. 105.14)}

$\mathrm{V} / \mathrm{Q}$ scans are widely used in assessment of patients with PHT to exclude thromboembolic PHT. Hull et al. ${ }^{146}$ compared the relative roles of V/Q scans, objective testing for venous thrombosis, and pulmonary angiography in 305 consecutive patients with suspected acute pulmonary embolism. This classic study proved that a segmental or larger unmatched perfusion defect was associated with an $86 \%$ frequency of pulmonary embolism (and thus could be considered "high probability"); however, the common clinical practice of excluding a diagnosis of pulmonary embolism based on the finding of a matched defect (perfusion and ventilation scans abnormal in the same area) was incorrect. Segmental and subsegmental matched low-probability V/Q abnormalities were associated with $36 \%$ and $25 \%$ incidence of angiographically confirmed embolism, respectively. Fortunately, virtually all patients with chronic thromboembolic PHT have one or more high-probability defects on their V/Q scan.

Patients with iPAH often have diffuse, inhomogeneous, or "moth-eaten" perfusion scans that are interpreted as being low probability. This reflects loss of small arteries in PAH. There have been a handful of reports of death within minutes of injecting the albumin macroaggregates, which are the small particles $(75 \mathrm{~mm})$ that are labeled with technetium. ${ }^{147}$ These complications have usually occurred in patients with severe PHT and may represent the inability of a severely obstructed vascular bed to deal with a shower of microemboli. With the advent of 64-slice CT scanning, capable of sub-1-mm resolution, the role of V/Q scans will diminish. In a recent meta-analysis, based on 12 studies of $\mathrm{CT}$ and $\mathrm{V} / \mathrm{Q}$ scanning in suspected pulmonary embolism, CT was found to have a sensitivity and specificity of $86 \%$ [95\% confidence interval (CI), 80-92\%], and 94\% (95\% CI, 91-96\%), respectively. ${ }^{148} \mathrm{~V} / \mathrm{Q}$ scanning had a much lower sensitivity of $39.0 \%$ $(95 \% \mathrm{CI}, 37-41 \%)$, although specificity was also high at $97 \%$ (95\% CI, 96-98\%). ${ }^{148}$ Thus, CT is the technique of choice to exclude pulmonary embolism, although a positive $\mathrm{V} / \mathrm{Q}$ scan (high probability) is sufficient to predict pulmonary embolism.

The challenge with "possible $\mathrm{PAH}^{\prime}$ patients is not to exclude acute pulmonary embolism, which can usually be done based on the presentation; rather, it is to actively exclude the diagnosis of chronic thromboembolic PHT because the latter has a specific and often curative surgical therapy-pulmonary thromboendarterectomy. In a center with high volumes, such as University of California-San Diego, results are excellent. In a series of 1100 patients with chronic pulmonary thromboembolism treated with thromboendarterectomy, survival was $94.2 \%$ and PVR was decreased by 547 dynes $\times \sec \times \mathrm{cm}^{-5} .149$

\section{Pulmonary Angiography}

Pulmonary angiography is primarily used to evaluate the possibility that the pulmonary hypertensive patient has chronic pulmonary emboli. In addition, angiography is a useful test to diagnose peripheral pulmonary artery stenoses, arteriovenous fistulas, and obliterative pulmonary vascular disease. In the University of Alberta PAH program, due to the use of V/Q CT scanning and MRI, conventional pulmonary angiography has not been required in characterizing any of the last consecutive 160 PHT patients. In patients

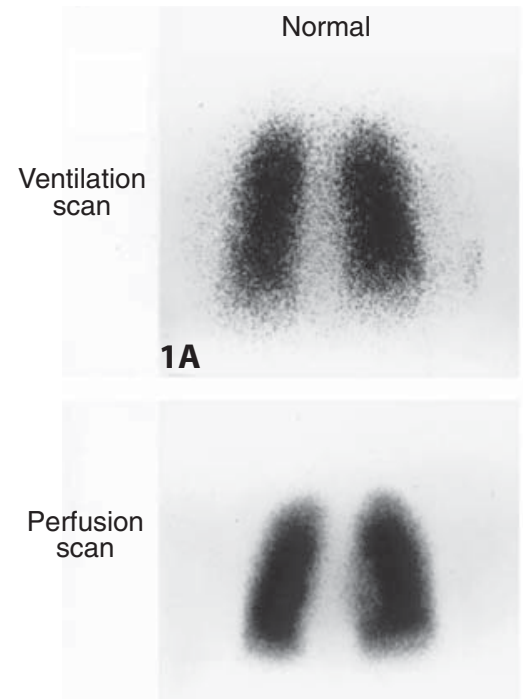

1B

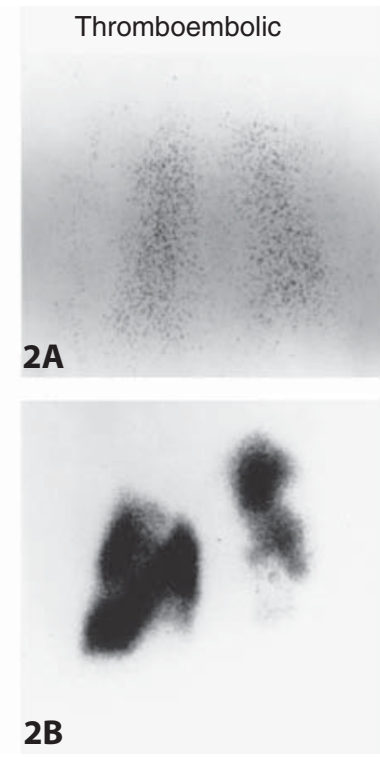

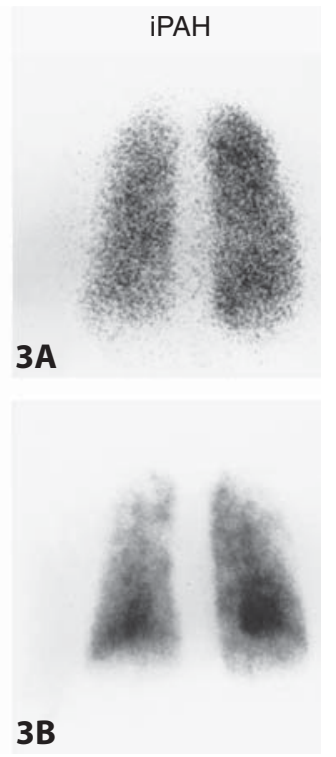

FIGURE 105.14. V/Q scanning in pulmonary hypertension (PHT). Note the "moth-eaten" pattern of perfusion in iPAH. 
being assessed for chronic PHT, pulmonary angiography should be reserved for those with equivocal CT scans.

Pulmonary angiography typically involves placement of a catheter in the pulmonary artery using the Seldinger technique. Unless the femoral veins and inferior vena cava are shown to be free of thrombus, it is best to use an antecubital or internal jugular route for vascular access to avoid embolization. Pulmonary angiography can be performed in PHT patients with minimal morbidity and mortality. The incremental risk of injection of contrast beyond the risk of placing a catheter merely to measure pressures is relatively small. The patients most at risk for complications are those with $\mathrm{RV}$ end diastolic pressures greater than $20 \mathrm{~mm} \mathrm{Hg}$ or those with overt evidence of right heart failure, and in these patients the technique should be used cautiously.

Whereas conventional angiography images the large vessels, an alternative angiographic technique, wedge angiography, can be used to study the microvasculature. This technique is primarily employed to assess the anatomy of the small vessels and capillary bed. Small amounts of contrast are injected distal to the inflated balloon while the catheter is "wedged," and magnified angiograms are obtained. In normal subjects the subsegmental vessel is plump and smooth, and there is a distal blush produced by the microcirculation. Narrowing of the vessel or reduction in the size of the microvascular bed occurs with progressive PAH. ${ }^{150}$ Findings on wedge angiography correlate fairly well with histologic assessment of the pulmonary vasculature obtained at lung biopsy. ${ }^{151}$

The literature contains many reports of deaths caused by pulmonary angiography, especially in patients with PHT. Advances in catheter design, use of nonionic contrast agents, and the advent of selective angiography have all contributed to improved safety. Nicod et al. ${ }^{152}$ analyzed the safety of pulmonary angiography in 67 patients with moderate to severe primary or thromboembolic PHT. These authors observed no significant complications but noted occasional transient episodes of hypotension, cough, and flushing. Supplemental oxygen to avoid hypoxemia and careful attention to analgesia are critical to safe pulmonary angiography.

The Prospective Investigation of Pulmonary Embolism Diagnosis (PIOPED) multicenter cooperative trial reported the safety and utility of pulmonary angiography in patients with acute pulmonary embolism. ${ }^{153}$ The 1111 pulmonary angiograms were performed with ionic contrast injected at 20 to $35 \mathrm{~mL} / \mathrm{s}$ for a total volume of 40 to $50 \mathrm{~mL}$. The mortality rate from pulmonary angiography was $0.5 \%$, with major, nonfatal complications in $1 \%$ and minor complications in $5 \%$ of patients. Mean PAP did not differ in those with major, minor, or no complications. A review of complications of pulmonary angiography revealed several incidents of cardiac perforation, which were attributed to the use of older, rigid catheters.

\section{Cardiac Catheterization}

Catheterization of the pulmonary artery remains the gold standard for determination of PAP, and, despite a plethora of available noninvasive techniques, is usually required to firmly establish a diagnosis of PAH. The goals of right heart catheterization include measurement of pressure, flow, and resistance. In addition, the catheter is used to establish the type of PHT.

One can generally consider PHT as being the result of vascular obstruction, as in thromboembolic and iPAH, or a passive response to elevated LV end-diastolic pressure, as in congestive cardiomyopathy. In patients with $\mathrm{PAH}$, there is a large gradient between the pulmonary diastolic pressure and the wedge pressure $(>12 \mathrm{~mm} \mathrm{Hg})$. This may be due to fixed vascular obstruction in a narrowed and partially obliterated vascular bed or may be due, in part, to increased pulmonary vascular tone. Based on studies of vasodilator therapy in patients with iPAH, which consistently show only $<20 \%$ of them responding to vasodilators /defined as a $20 \%$ or greater fall in PAP in response to inhaled NO or IV prostacyclin), it appears that the majority of $\mathrm{PAH}$ patients have fixed anatomic vascular disease as the sole cause of their transpulmonary gradient. Even responders have a significant component of their PVR elevation as a consequence of vascular remodeling.

In patients with left ventricular failure, pulmonary artery diastolic and wedge pressures are elevated to similar levels. In these patients, the total pulmonary resistance, which does not take into account the left atrial pressure, may be elevated but PVR is not increased (Table 105.1). The right heart catheterization readily distinguishes these forms of hypertension, and thus aids in achieving a specific mechanistic diagnosis.

Additional studies may be necessary if there is a suspicion of intracardiac shunting or valvular disease. In any patient with a question of shunting, we perform oximetry in all right heart chambers to localize and quantify the shunt.

Right heart catheterization carries some risks in patients with PHT. The risks of right heart catheterization can be divided into three categories: (1) risks related to obtaining vascular access (e.g., vasovagal reactions); (2) risks of having a catheter in the heart (pulmonary artery rupture, arrhythmia); and (3) risks of administering medications (e.g., negative inotropic effects, systemic vasodilatation with hypotension). Pulmonary hypertensive patients may be intolerant to vasovagal reactions that may occur during attempted vascular access. When systemic vasodilatation occurs, whether due to a drug or reflex, the dysfunctional RV and obstructed pulmonary vascular bed may not support the normal increase in left heart output that accompanies systemic vasodilatation. Therefore, a simple vasovagal reaction may lead to a fatal cycle of bradycardia, hypotension, acidosis, and death. However, it is noteworthy that there were no deaths during diagnostic catheterization in the NIH registry study, in which 187 patients, mostly class III and IV, underwent right heart catheterization. ${ }^{12}$

\section{Acute Vasodilator Testing-iNO}

Since the observation that patients who respond to acute pulmonary vasodilators with a $>20 \%$ decrease in their PVR have better prognosis and a high chance of responding to high doses of oral calcium channel blockers chronically, ${ }^{39}$ acute vasodilator testing has became a critical part of the $\mathrm{PAH}$ patient management. Although earlier studies used intravenous epoprostenol $(2 \mathrm{mg} / \mathrm{kg} / \mathrm{min}$, increase by this amount every 30 minutes, until effect is observed or adverse effects occur) or adenosine $(50 \mathrm{mg} / \mathrm{kg} / \mathrm{min}$, increase by this 

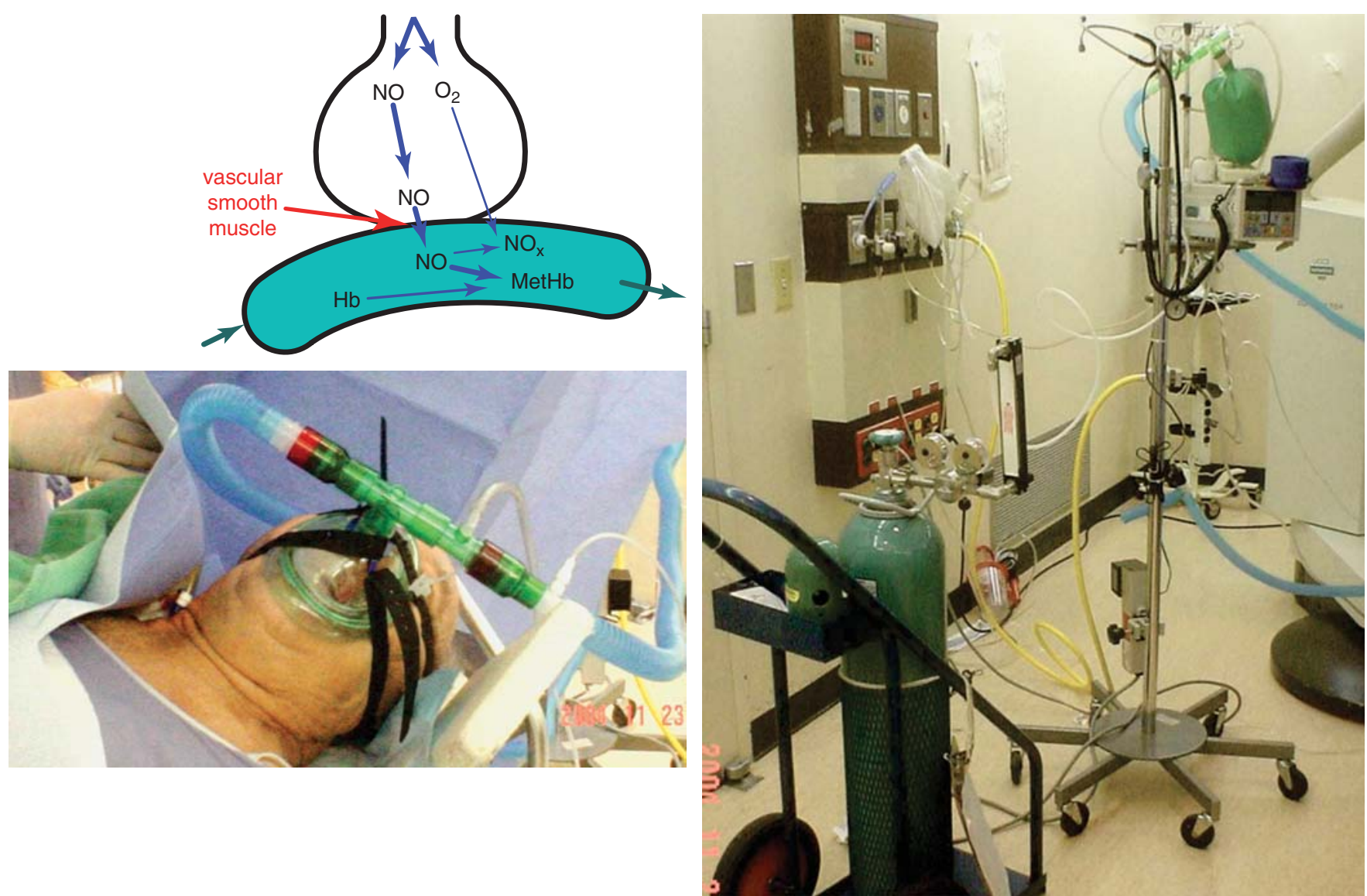

hemoglobin, the systemic effects of iNO are minimal.

amount every 2 to 3 minutes until effect is observed or adverse effects occur), iNO has recently become the vasodilator of choice. The inhaled route of administration offers a high degree of selectivity, and the effect disappears almost instantaneously with cessation of inhalation. A special mask and a device for the controlled delivery of the gas are required (Fig. 105.15), although iNO is not hard to administer. Unfortunately, the recent increases in its price make iNO relatively expensive. In our center, we begin the delivery of iNO at $5 \mathrm{ppm}$ and then we increase to $10,20,40$, and $80 \mathrm{ppm}$ (maximal dose) every 5 minutes. Calculation of the PVR before and after the maximal dose is important. With the recent introduction of therapies that, in addition to vasodilator effects, have antiproliferative properties as well (epoprostenol, endothelin receptor antagonists, sildenafil), the usefulness of vasodilator testing in terms of selecting future therapy has become less clear. For example, in scleroderma, prognosis and response to epoprostenol are not associated with acute vasodilator response. ${ }^{154}$ Nevertheless, the response to acute vasodilator testing remains an important means by which to determine the prognosis of PAH patients, even before treatments are initiated.

\section{Magnetic Resonance Imaging}

Magnetic resonance imaging facilitates reproducible, noninvasive volumetric flow measurement in the major pulmo- nary arteries and RV. There are many advantages of MRI, including the avoidance of intravenous contrast, its entirely noninvasive nature, and the high probability of obtaining an adequate image, even in patients with lung disease. Although scan times remain significantly longer than those for CT scanning, the technique facilitates measurement of chamber dimension, RV mass, and increasingly of pressure and flow in the right heart. Bogren et al. ${ }^{155}$ used MRI to evaluate pulmonary arterial compliance (vascular distensibility) in normal individuals and patients with PHT. Compliance, measured as the change in pulmonary artery volume resulting from an observed change in pressure, was considerable less in patients with PHT (8\%) than in controls $(23 \%)$. Furthermore, patients with PHT had a larger retrograde flow volume $(26 \%)$ than normals $(2 \%)$. This exaggerated reversal of pulmonary flow may explain the systolic closure ("notching") of the pulmonic valve in PHT. Recently, MRI has been used to track regression of RV hypertrophy in two small trials of the phosphodiesterase- 5 inhibitor sildenafil and the endothelin receptor inhibitor Bosentan for PAH. ${ }^{156,157}$ Magnetic resonance imaging can also be used to generate pressure volume relationships to define RV contractility. These techniques reveal that chronic $\mathrm{RV}$ pressure overload is associated with reduced RV pump function despite enhanced RV myocardial contractility in PHT patients. ${ }^{158}$ The interesting approach of simultaneous catheterization, using special catheters and MRI, holds clinical promise. Three- 
dimensional ultrafast dynamic contrast-enhanced MRI has been used to quantify regional lung perfusion in PHT and normal individuals on a pixel-by-pixel basis. ${ }^{159}$ This may be helpful, when coupled with gadolinium-enhanced MRI angiography, in assessing regression of pulmonary vascular disease (Fig. 105.11). Gadolinium-enhanced pulmonary MRI can reliably detect chronic PHT (based on the combination of dilated central PAs (diameter $>28 \mathrm{~mm}$ ) and abnormal proximal-to-distal tapering of the PAs). ${ }^{160}$ In addition, MRI can be used noninvasively to measure PA systolic and diastolic pressures. It is likely that the comprehensive "one-stop" MRI facilitating serial anatomic and functional assessment will become the gold standard for PAH patients. ${ }^{161}$

\section{Lung Biopsy}

Biopsy of the lung parenchyma, either transbronchially via the fiberoptic bronchoscope or by open thoracotomy, is a critically important diagnostic tool in the approach to patients with a variety of diffuse lung diseases. However, lung biopsy plays a less important role in the diagnosis of PHT in most clinical settings. A clinical diagnosis of iPAH can be established with reasonable certainty clinically. Indeed, pathology data from the NIH registry demonstrated that no other diagnosis was made pathologically in patients entered into the registry when lung tissue became available for review. In cases where the etiology is less certain, such as patients with significant elevations in PAP associated with moderately abnormal lung function tests or evidence of interstitial disease by chest radiograph or high-resolution computerized scans of the chest, or patients with serologic abnormalities or other clinical signs that are suggestive of a vasculitis, lung biopsy may be highly useful in establishing a diagnosis and guiding therapy. Transbronchial lung biopsy is not advocated in patients with PHT, since the small size of the specimen generally precludes establishing a definitive diagnosis, and the risk of hemorrhage from hypertensive pulmonary vessels is increased. Open lung biopsy via a minithoracotomy had been considered the approach of choice; however, the risks of this procedure are increased in patients with pulmonary vascular disease, and such cases should be performed by experienced surgeons supported by a cardiovascular anesthetist. Thoracoscopic lung biopsy, which is less invasive and provides adequate tissue for diagnosis, is the preferred approach when a histologic diagnosis is deemed necessary.

To recap, evaluation of PAH can be accurately accomplished by noninvasive techniques (echocardiography, multislice CT, and MRI). Consequently, lung biopsy and pulmonary angiography are rarely required and even V/Q scanning is becoming less necessary; however, the role of right heart catheterization remains critical.

\section{Comorbidities with Pulmonary Arterial Hypertension}

\section{Connective Tissue Disease}

Several connective tissue disease (CTDs) are complicated by $\mathrm{PAH}$ and they include systemic sclerosis, mixed connective tissue disease, systemic lupus erythematosus, and, rarely, rheumatoid arthritis, dermatomyositis, and Sjögren's syndrome. The strongest association is with scleroderma, ${ }^{162,163}$ and $\mathrm{PAH}$ is the leading cause of mortality in patients with scleroderma. ${ }^{164}$ In a prospective study using a catheterization-based diagnosis of $\mathrm{PAH}, \sim 12 \%$ of the patients with scleroderma $(n=722)$ were found to have PAH. ${ }^{154}$ The mean age of the patients with PAH in this study was 66 years and the female-to-male ratio was $4: 1$. Because patients with scleroderma also suffer from pulmonary fibrosis, the assessment of dyspnea and the cause of PHT (hypoxic PHT due to lung disease versus PAH) can be very difficult. A significant decrease in DLCO $(<55 \%)$ usually suggests the presence of $\mathrm{PAH}$ in these patients. It is also important to make sure that their PHT is not secondary to left ventricular dysfunction, particularly diastolic dysfunction, which may complicate scleroderma. For all these reasons the threshold for right heart catheterization should be relatively low, since this is often the only test that will definitively determine the extent and the cause of PHT.

Despite the fact that their histology and hemodynamics are similar to that of iPAH in recent trials, patients with $\mathrm{PAH}$ and scleroderma have worse prognosis compared with iPAH patients. In a study conducted between 1998 and 2002, their 3 -year mortality was $56 \%,{ }^{154}$ illustrating that the prognosis remains poor despite modern treatments, and perhaps challenging the notion that mechanisms of disease are homogeneous among the various forms of PAH. Interestingly, in contrast to the patients with $\mathrm{PAH}$, the response to acute vasodilators in patients with scleroderma is not associated with improved survival. ${ }^{154}$

\section{Congenital Heart Disease}

The high flow and the increased shear stress through the pulmonary circulation in congenital heart disease syndromes with significant left to right shunts, particularly if the shunt is at high pressure, causes endothelial damage and initiates proliferative remodeling in the pulmonary vessels. The histology, which can be graded using the validated Heath-Edwards classification, is indistinguishable from that of iPAH and includes medial and intimal hypertrophy, small vessel obliteration, thrombosis, and plexiform lesions. As the PA pressure rises and exceeds systemic arterial pressure, the shunt reverses and Eisenmenger's syndrome is established. The development of PAH is much more common in ventricular septal defects than atrial septal defects. ${ }^{165,166}$ If the ventricular septal defect is bigger than $1.5 \mathrm{~cm}$, there is a $50 \%$ chance for $\mathrm{PAH}$, while fewer than $3 \%$ of patients with small defects develop PAH. ${ }^{167}$ The lower pressure shunts of atrial septal defect are less likely to cause $\mathrm{PAH}$, but even here there is diversity. Sinus venosus atrial septal defects are associated with a $16 \%$ chance for $\mathrm{PAH}$, whereas with ostium secundum defects the chance is less than $4 \% .{ }^{168}$ Patients with congenital heart disease and PAH have better prognosis than patients with iPAH. ${ }^{169}$ Nonetheless, these patients are more prone to manifest significant desaturation with exercise and to have polycythemia than are iPAH patients. They also may develop hemoptysis, due to the rupture of bronchial arteries. 


\section{Portal Hypertension}

While cirrhosis without portal hypertension is not associated with $\mathrm{PAH}$, patients referred for liver transplant with portal hypertension have a $3 \%$ to $4 \%$ incidence of $\mathrm{PAH} .{ }^{170,171}$ However, increased PA pressures, without elevated PVR, are found in up to $20 \%$ of this population. ${ }^{170}$ In most patients with cirrhosis, the associated increase in the cardiac output can cause elevated PAP, simply due to the increased flow in the pulmonary circulation. Thus, it is very important not to rely on indirect estimations of the PA pressures with tests like echocardiography, but proceed with right heart catheterization in patients with hepatic disease in whom $\mathrm{PAH}$ is suspected. The prognosis of patients with $\mathrm{PAH}$ and untreated portopulmonary hypertension is very poor, with an average survival of only 15 months after diagnosis. ${ }^{172}$ In a small cohort of 15 patients, significant improvement was reported with epoprostenol. ${ }^{173}$ The recognition and possible treatment of patients with portopulmonary hypertension prior to transplantation is critical because the perioperative mortality is very high. In a recent meta-analysis of patients undergoing liver transplantation, a mean PA pressure of more than $50 \mathrm{~mm} \mathrm{Hg}$ was associated with $100 \%$ perioperative mortality; for mean PA pressure of 35 to $50 \mathrm{~mm} \mathrm{Hg}$, the mortality was $50 \%$; the mortality was $0 \%$ for mean PA pressure of less than $35 \mathrm{~mm} \mathrm{Hg} .{ }^{174}$ In selected patients, liver transplantation has reversed the PAH. ${ }^{174}$ The role of the liver in the pathogenesis of PAH is intriguing. One of the common animal models of $\mathrm{PAH}$ is created by injecting rats with the toxin monocrotaline, derived from the plant Crotalaria spectabilis. Monocrotaline requires hepatic activation before the alkaloid is active and can induce PAH.

\section{Human Immunodeficiency Virus Infection}

The first case of PAH in a patient with AIDS was reported in $1987,{ }^{175}$ and the association between infection with HIV and PAH was recognized a few years later. ${ }^{176,177}$ In a cohort of -1200 HIV-infected patients, a $0.5 \%$ incidence of PAH was reported. The largest case control study so far has come from the Swiss HIV Cohort (3349 HIV patients followed over 5.5 years), which reported a cumulative incidence of $0.57 \% .^{178}$ Patients with HIV infection have a rate for PAH 6 to 12 times higher than the general population. With the introduction of highly active antiretroviral therapy over the past few years and the improved prognosis, the incidence of noninfectious complications in this population has been increasing. The mechanism of PAH in patients with HIV infection remains unknown. The virus, to date, has not been isolated for the pulmonary arteries, ${ }^{179}$ leading to the unconfirmed hypothesis that the disease is caused by activated mediators or cytokines that result from the infection or the immune reaction to the infection. ${ }^{180}$ The mortality of HIV-infected patients is significantly higher compared to the HIV-infected patients without PAH, although it is similar to that of $\mathrm{iPAH}$ patients. ${ }^{181,182}$ Univariate analysis indicates that a CD4 lymphocyte count of more than 212 cells $\mathrm{mm}^{3}$ and the use of combination antiretroviral therapy and epoprostenol infusion were associated with better survival. ${ }^{182}$

Interestingly, another retrovirus, human herpes virus 8 (HHV8), was isolated from 10 out of 16 patients with iPAH. ${ }^{183}$
This is intriguing because HHV8 causes Kaposi's sarcoma, a tumor with endothelial abnormalities that show impressive similarities with the plexogenic lesions in $\mathrm{iPAH}$.

\section{The Impact of Anorexigens}

The anorexigens aminorex, fenfluramine, and dexfenfluramine are modified amphetamines that enhance serotonin release and inhibit serotonin reuptake in the brain, resulting in appetite suppression and a $5 \%$ to $10 \%$ weight loss. Between 1967 and 1972, there was an outbreak of PAH in Europe related to the anorectic agent aminorex that resolved with withdrawal of the drug. ${ }^{184}$ A similar PAH epidemic ensued in the 1980s and 1990s with the use of fenfluramine and dexfenfluramine. Although use of these appetite suppressants for 3 months was associated with a 23 -fold increase in the risk of developing $\mathrm{PAH}$, the annual incidence of $\mathrm{PAH}$ in the population as a whole remained very low (1.7 per million). ${ }^{185}$ Only a small proportion of the patients exposed to anorexigen developed $\mathrm{PAH}$, suggesting a requirement for one or more predisposing conditions. Endothelial dysfunction, acquired or genetic, is almost certainly a predisposing factor. Patients with anorexigen-induced PAH tended to be older and frequently had known risk factors for endothelial dysfunction (cigarette use or obesity). ${ }^{186}$ Indeed, compared with iPAH patients, those with anorexigen-associated $\mathrm{PAH}$ have decreased lung NO production, and their PVR is inversely related to NO production. ${ }^{186}$ Despite repeated attempts, it was not possible to create an animal model of $\mathrm{PAH}$ by feeding different species with large amounts of the various anorexigens, again suggesting the need for genetic or other predisposing factors.

The conventional view of the toxicity related to these agents is that it relates to elevation of serotonin, and certainly the "carcinoid-like" valve disease, which ultimately led to their withdrawal, ${ }^{187}$ may relate to disordered serotonin metabolism. However, it has been shown that potassium channel inhibition and membrane depolarization partially accounts for the pulmonary ${ }^{83}$ and systemic vasoconstriction that these agents induce. ${ }^{188}$ Although only weak pulmonary vasoconstrictors are seen in normal lungs, inhibition of NO synthase exposes the constrictor potency of the anorexigens, ${ }^{83}$ which supports the notion that endothelial dysfunction predisposes to this form of PAH. It has been proposed that the anorexigens are in reality Kv channel blockers that cause their intended (appetite suppression) and their unintended (altered platelet function and increased vascular tone) effects through their control of membrane potential and cytosolic $\mathrm{Ca}^{2+}$ levels. ${ }^{83,188}$ Indeed, the anorexigens do inhibit heterologously expressed Kv1.5 ${ }^{189}$ and Kv2.1 channels, ${ }^{190}$ channels that control the membrane potential of PASMCs and whose expression is decreased in PAH.

\section{Veno-Occlusive Disease}

In this rare disease, obliterative fibrotic lesions are seen in pulmonary veins and venules. These lesions are characteristically patchy and result in focal increase in the wedge pressure. Because of the patchy nature of the disease, the wedge pressure might be increased in one pulmonary artery branch but not in another. When this disease is suspected, wedging 
the catheter in several pulmonary artery branches is recommended during right heart catheterization.

A CT scan may be helpful, showing septal thickening, ground glass opacities and a mosaic pattern of lung attenuation $^{191}$ (Fig. 105.13). The prognosis is poor, and early referral for lung transplantation is suggested. It is also important to identify pulmonary veno-occlusive disease early in the assessment of PAH because administration of prostacyclin can cause acute pulmonary edema in this syndrome (as is the case in patients with impaired pulmonary venous drainage, whether due to pulmonary capillary hemangiomatosis or anomalous pulmonary venous drainage). ${ }^{192}$

\section{Pulmonary Capillary Hemangiomatosis}

Pulmonary capillary hemangiomatosis $(\mathrm{PCH})$ is a rare cause of PAH that occurs predominantly in young adults. It was first recognized in 1978 by Wagenvoort et al ${ }^{193}$ The condition is characterized by invasion of the lung with cytologically normal capillaries, and it clinically manifests as PHT and impaired gas exchange. Histologically, there is a proliferation of capillary-like vessels on and within the alveolar wall. Pulmonary capillary hemangiomatosis can occur in familial forms, ${ }_{1}^{194}$ and its complications include hemothorax or clubbing. It is difficult to distinguish (without histology) from pulmonary veno-occlusive disease (PVOD). A typical bilateral diffuse reticular nodular pattern is seen in the chest $\mathrm{x}$ ray. The CT findings (bilateral diffuse, centrilobular, poorly defined nodular opacities reflecting the capillary proliferation) are similar to those of veno-occlusive disease and help differentiate these two conditions from $\mathrm{iPAH}^{195}$ (Fig. 105.13).

As of 1996, only 18 cases had been reported in the literature. ${ }^{196} \mathrm{~A}$ more recent review noted 35 cases, but the prognosis remained dismal (median survival was 3 years from the first clinical manifestation). ${ }^{197}$ Interestingly, there have been reports of improvement using interferon. ${ }^{197}$ Early recognition of pulmonary capillary hemangiomatosis is important because there are anecdotal reports of pulmonary edema occurring in response to epoprostenol. ${ }^{192}$ Early referral for lung transplantation is recommended.

\section{Persistent Pulmonary Hypertension of the Newborn}

Persistent pulmonary hypertension of the newborn (PPHN) is a complex syndrome with multiple causes, with an incidence of 0.43 to $6.8 / 1000$ live births. It occurs in both idiopathic and secondary forms (associated with meconium aspiration, respiratory distress syndrome, pulmonary hypoplasia, and congenital diaphragmatic hernia). It causes severe hypoxemia and has a $10 \%$ to $20 \%$ mortality. Survivors have high morbidity in the forms of neurodevelopmental impairment, cognitive delays, hearing loss, and a high rate of rehospitalization. Persistent pulmonary hypertension of the newborn is characterized by a failure of transition of the hypoxic fetal pulmonary circulation from a high resistancelow flow bed to a low resistance-high flow neonatal circulation. It results in heart failure and persistent hypoxemia due to impaired maturation, vasoconstriction, and obstruction of the pulmonary vascular bed. The mechanisms that cause
PPHN are uncertain, and it is likely that there are many etiologic factors, including impaired angiogenesis, downregulation of smooth muscle cell potassium channels, and elevated shear stress, ${ }^{198,199}$

Persistent pulmonary hypertension of the newborn can be fatal, and in severe cases mechanical ventilation/extracorporeal ventilation is required. In a landmark trial, 58 fullterm infants with PPHN were prospectively randomized to inhaled nitric oxide $(80 \mathrm{ppm})$ versus a control gas (nitrogen), mixed with oxygen from a ventilator. ${ }^{200}$ Inhaled nitric oxide increased oxygenation in only $7 \%$ (two of 28). Long-term therapy with inhaled nitric oxide sustained systemic iNO successfully and doubled systemic oxygenation in 16 of 30 PPHN infants $(53 \%)$, whereas with conventional therapy without oxygenation, $75 \%$ of the infants had initial improvement. Extracorporeal membrane oxygenation was required in $71 \%$ of the control group and $40 \%$ of the nitric oxide group $(p=.02) .{ }^{200}$ Although iNO has not been shown to decrease mortality in $\mathrm{PPH}$, the use of extracorporeal membrane oxygenation has continued to decline since this new standard of care has been accepted. Abrupt discontinuation of inhaled NO can cause a rebound PHT, which may be more severe than prior to treatment. Sildenafil is useful to facilitate weaning of iNO in some PPHN patients, and it avoids rebound PHT. Sildenafil may also be useful as an alternative therapy for PPHN; clinical trials to evaluate this potential therapy are ongoing.

\section{Hereditary Hemorrhagic Telangiectasia (Rendu-Osler-Weber Syndrome)}

Patients with Rendu-Osler-Weber syndrome may develop $\mathrm{PAH}$ that is histologically indistinguishable from iPAH. ${ }^{201}$ Hereditary hemorrhagic telangiectasia (HHT) is an autosomal dominant vascular dysplasia caused by mutations in two genes that encode the TGF- $\beta$ receptors endoglin and activin-receptor-like kinase 1 (ALK1). ${ }^{201}$ These patients have arteriovenous malformations (mostly nasal, hepatic, cerebral, and pulmonary) and sometimes these lesions result in significant shunts. In addition, these patients are anemic due to the nasal bleeds that are often very difficult to manage. The shunts and the anemia result in higher cardiac outputs and an increase in the pulmonary pressures, due to high flow. For this reason right heart catheterization should be performed in patients with HHT and suspected PHT in order to measure cardiac output and calculate PVR.

\section{Hemoglobinopathies}

Pulmonary hypertension of some degree has been reported in up to $75 \%$ of patients with $\beta$-thalassemia, but the diagnosis was made with echocardiography and not right heart catheterization. ${ }^{202}$ The high cardiac output that complicates anemia could, by causing high flow, elevate PA pressures without truly causing PAH (i.e., without increasing PVR). In a study of 34 patients with sickle cell anemia who underwent catheterization, 20 were found to have increased PA pressures. However, several of these patients had increased wedge pressures due to left ventricular diastolic dysfunction. In a study of 195 consecutive patients with sickle cell disease, PHT (defined as tricuspid regurgitant jet velocity of $>2.5 \mathrm{~m} /$ 
sec) was found to be an independent and strong index of mortality. ${ }^{203}$ The destruction of circulating NO by the free hemoglobin in the blood of patients with hemolytic anemias has been proposed to contribute to the development of PAH in these patients. ${ }^{204}$

\section{Thyroid Disease}

Both hyperthyroidism and hypothyroidism have been associated with PHT. In patients with severe hyperthyroidism, the large increases in cardiac output can cause PHT due to high flow in the pulmonary circulation. There are several reports in the literature in which treatment of the hyperthyroid crisis completely reversed the PHT. ${ }^{205,206}$

However, the association with hypothyroidism is more interesting than high-flow PHT, which explains most of the apparent hyperthyroid PHT. In a single-center cohort of 41 patients with $\mathrm{iPAH}$, nine patients were found to have hypothyroidism, which is significantly higher that the expected incidence in the general population. ${ }^{207}$ An autoimmune pathogenetic link between hypothyroidism and iPAH has been proposed. ${ }^{208}$ In this regard, the lung and the thyroid gland have the same embryologic origins..$^{25}$ Moreover, it is very interesting that the thyroid hormone has been shown to regulate the expression of Kv1.5 in the myocardium. Hypothyroid rats have decreased expression of Kv1.5 in their hearts. Exogenous triiodothyronine $\left(T_{3}\right)$ restores channel expression within 1 hour of treatment, a reflection of the very short half-life of Kv1.5, ${ }^{209}$ the $\mathrm{K}^{+}$channel that is downregulated and potentially involved in the pathogenesis of experimental and human PAH. The possibility that hypothyroid patients might also be deficient in pulmonary artery Kv1.5, predisposing them to develop PAH is an intriguing, but untested, hypothesis.

\section{Management of Pulmonary Arterial Hypertension}

It was not until 2004 that the first evidence-based practice guidelines were published and endorsed by the ACCP (see the July 2004 supplement of Chest, volume 126). Randomized controlled trials (RCTs) have only recently been performed for PAH treatments (Table 105.7), and still a number of recommended treatments lack support from RCTs. These treatments are discussed in General Measures, below. Following the discussion of specific Food and Drug Administration (FDA)-approved and experimental treatments currently in use, we discuss the approach to the patient with PAH and the treatment options according to the stage of the disease.

\section{General Measures}

Conditions that can exacerbate the pathophysiologic process, such as pregnancy, high altitude, and air travel, should be avoided if possible. Similarly, medications that can potentiate pulmonary vasoconstriction, such as sympathomimetics used for allergic symptoms, or vasoconstrictor prostaglandins used as abortifacients, should not be used. Since oral contraceptives may exacerbate PHT in susceptible patients by increasing their risk for a thromboembolic event, other methods of birth control should be utilized. Lastly, all patients with PAH should be immunized against influenza and pneumococcal pneumonia and evolving respiratory tract infections should be treated aggressively.

\section{Oxygen Therapy}

In addition to maximizing oxygen delivery, supplemental oxygen therapy reduces the component of PHT that is due to active HPV. Patients with an arterial $\mathrm{PO}_{2}$ of less than 55 torr at rest or an arterial oxygen saturation of less than $90 \%$ with ambulation, measured while breathing ambient air, are candidates for continuous home oxygen therapy. Oxygen is most effective in this setting when it is used continuously. ${ }^{210}$ However, despite mild hypoxemia, most PAH patients do not usually manifest hemodynamic improvement with supplemental oxygen therapy. In patients with PAH due to congenital heart disease and right-to-left shunting, arterial oxygenation does not usually improve with supplemental oxygen, although patients may experience some symptomatic relief with its use. In a recent controlled study of patients with Eisenmenger's syndrome, oxygen therapy did not alter hematologic parameters, quality of life, or survival. ${ }^{211}$

Diuretics are useful for the treatment of right heart failure, but aggressive diuresis should be avoided because it can compromise cardiac output by excessively reducing preload. Furosemide in doses of 40 to $160 \mathrm{mg}$ per day is usually sufficient for patients with mild to moderate degrees of right heart failure. Patients refractory to furosemide may require the addition of more potent diuretics, such as metolazone or bumetanide. The potassium-sparing aldosterone antagonists, such as spironolactone, are a useful adjunct to loop diuretics for patients with refractory edema or ascites. Serum potassium and sodium levels should be monitored frequently when these agents are used.

\section{Cardiac Glycosides}

The effectiveness of digitalis in patients with PAH has not been studied. Digitalis is sometimes used in the treatment of refractory right ventricular failure, particularly when this is associated with left ventricular dysfunction or atrial arrhythmias.

\section{Anticoagulants}

The role of anticoagulants in nonthromboembolic PHT is controversial. Patients with pulmonary vascular disease appear to be at increased risk for thromboembolic events because of their physical inactivity, right heart dilatation, and sluggish pulmonary blood flow. In addition, they develop small thrombi in situ within their diseased arteries. Sudden death due to pulmonary thromboembolism can occur and large thrombi are particularly common in patients with Eisenmenger's physiology. In both a retrospective ${ }^{212}$ and a prospective study, ${ }^{39}$ survival in $\mathrm{iPAH}$ was significantly enhanced in patients who received anticoagulant therapy. The prospective study showed that the patients who benefit the most from warfarin are the ones who do not respond to $\mathrm{Ca}^{2+}$ channel blockers. However, this study was not designed to assess the effects of anticoagulation, and the therapy was not randomly assigned nor assessed in a blinded manner. 


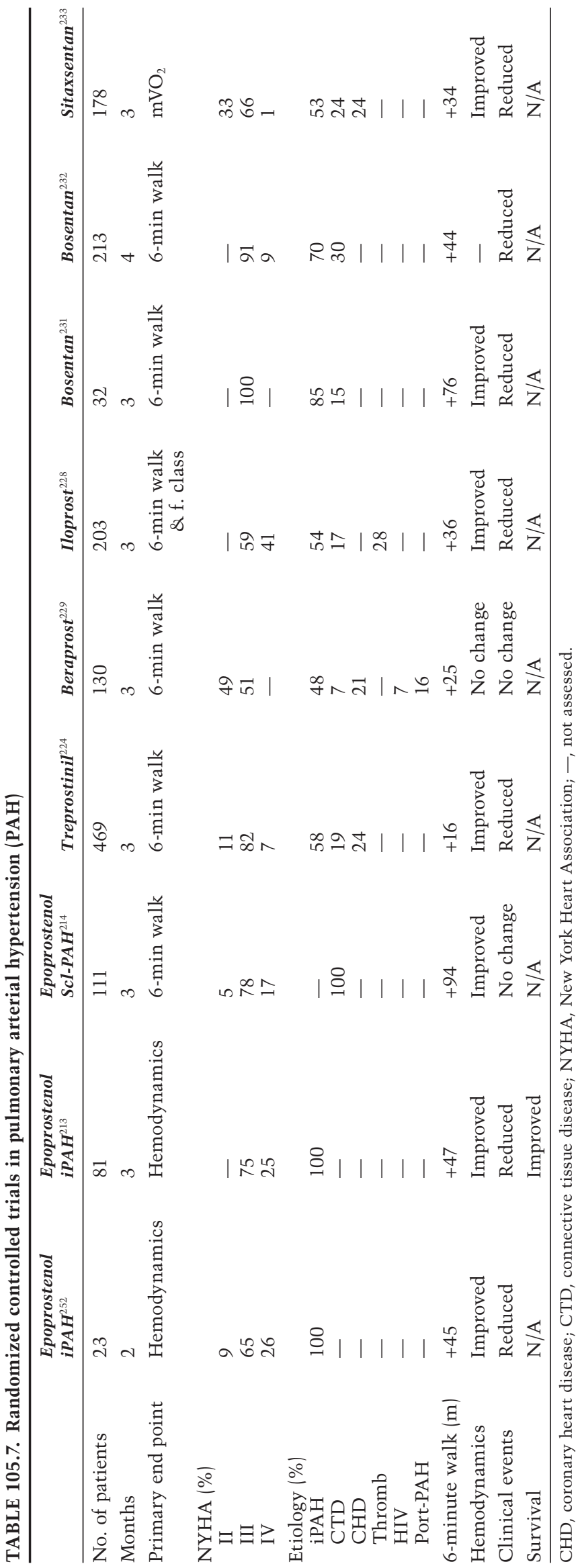


Thus, this study provides nondefinitive support only for the prescription of warfarin. Warfarin was used only in the presence of an abnormal V/Q scan, and it is therefore possible that these patients had simply a higher likelihood of survival. Adjusting anticoagulant medications may be particularly difficult in patients prone to altered drug metabolism due to hepatic congestion, and bleeding complications can occur even in the face of therapeutic degrees of anticoagulation. Some of the drugs currently completing phase III RCTs, like sitaxsentan, have a significant interaction with warfarin, requiring a significant decrease in the warfarin dose. Warfarin is the preferred drug, with the dose adjusted to achieve an INR of 1.5 to 2 . At this time, warfarin therapy is indicated in all patients with iPAH (recommendation: evidence level B). Some centers extrapolate the iPAH data on other subsets of $\mathrm{PAH}$, while others do not. The risk/benefit ratio for each patient has to be carefully considered. For example, some patients with PAH due to scleroderma or portal hypertension might be at increased risk of gastrointestinal bleeding due to esophagitis or varices, respectively. The role of low molecular weight heparin and new oral direct thrombin inhibitors (e.g., melagatran) in PAH is unknown.

\section{Calcium Channel Blockers}

Until recently, calcium channel blockers (CCBs) were the only option in the treatment of PAH. Rich et al. ${ }^{39}$ used high doses of CCBs in 64 patients with iPAH and followed them for 5 years. Seventeen patients $(27 \%)$ responded initially with an acute decrease in the PVR of $>20 \%$. After 5 years, $97 \%$ of these responders were alive, whereas only $55 \%$ of the nonresponders were alive (Fig. 105.16). Although this prospective trial was not placebo controlled, it remains one of the longest follow-up trials in PAH so far. Unfortunately, less than $20 \%$ of PAH patients respond to vasodilators acutely, and are therefore candidates for long-term CCB therapy. ${ }^{9}$ Furthermore, a number of these patients are unable to tolerate the

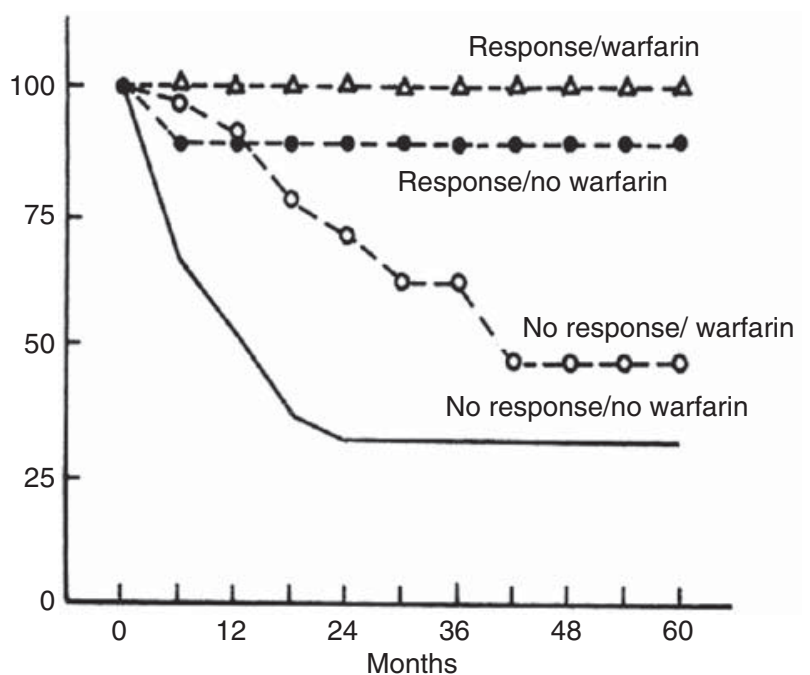

FIGURE 105.16. Response to acute vasodilators with $>20 \%$ decrease in the PVR at the time of diagnosis (i.e., "responders") and the use of warfarin are associated with much improved survival in a cohort of patients with iPAH, followed prospectively over 5 years.

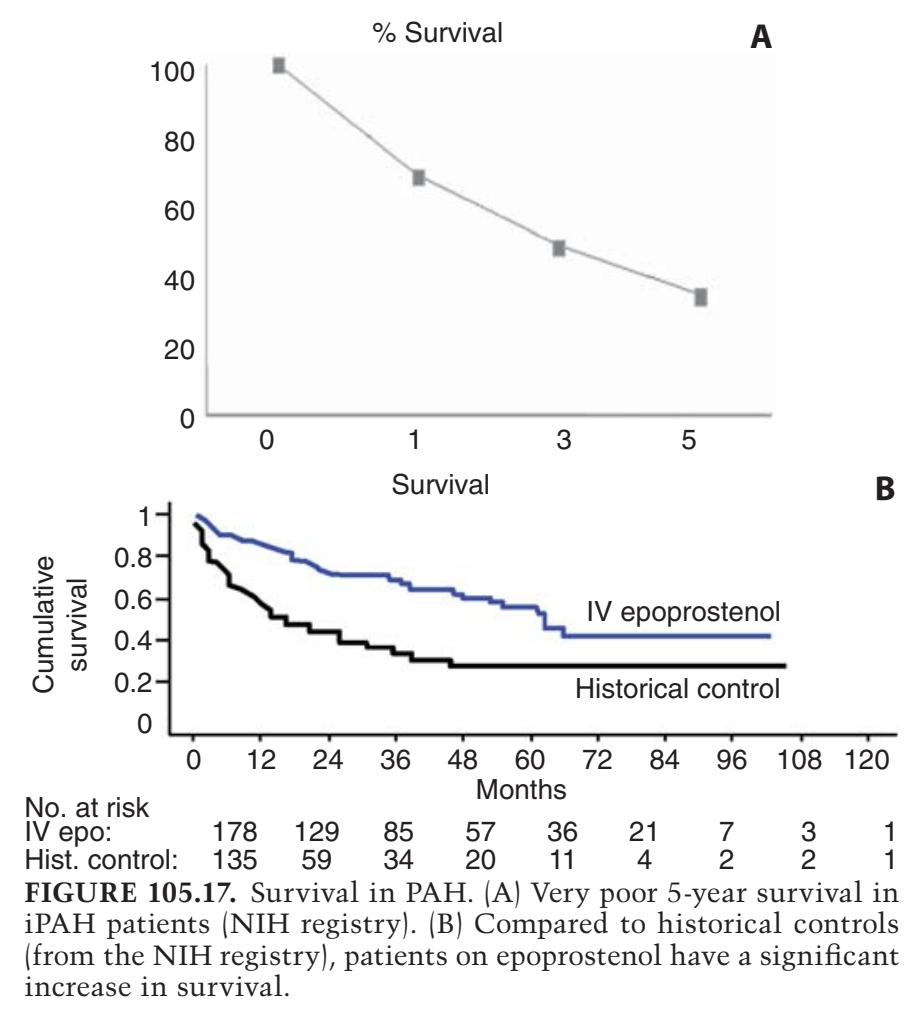

high doses required (e.g., nifedipine 180 to $240 \mathrm{mg}$ per day or an equivalent dose of a dihydropyridine), mainly because of systemic hypotension and peripheral edema.

\section{Prostanoids}

\section{EPOPROSTENOL}

Flolan ${ }^{\circledR}$ is the first treatment to show a substantial improvement in hemodynamics, functional capacity, and survival in patients with PAH (Fig. 105.17). In a landmark 3-month prospective open-label RCT, Flolan and conventional therapy ( $n=41)$ was compared to conventional therapy alone $(n=$ 40 ) in patients with iPAH NYHA class III or IV. ${ }^{213}$ The Flolan group showed greater improvement: mean pulmonary arterial pressure (mPAP) $-8 \%$ vs. $+3 \%$, PVR $-21 \%$ vs. $+9 \%$, and 6-minute walk $+47 \mathrm{~m}$ vs. $-64 \mathrm{~m}$. While eight patients died in the conventional treatment arm, there were no deaths in the Flolan group $(p<.003)$. A weakness of this study was that the baseline 6-minute walk performance in the Flolan group $(315 \mathrm{~m})$ was significantly better than that of the conventional treatment arm $(270 \mathrm{~m})$. The fact that the conventional group patients were sicker than the Flolan treatment group might have contributed to both the survival and the 6-minute walk differences. There were four episodes of sepsis and one of thrombosis attributed to the catheter in the Flolan group. In a similar RCT in PAH due to scleroderma, Flolan was shown to have similar beneficial effects in hemodynamics and functional capacity, but it did not improve survival. ${ }^{214}$

Several studies have shown that the beneficial effects of Flolan on both hemodynamics and functional class can be 
sustained for years. ${ }^{215-218}$ Survival with Flolan treatment at 1 , 2 , and 3 years was shown to be $88 \%, 76 \%$, and $63 \%$, respectively, significantly higher than the $59 \%, 46 \%$, and $35 \%$ reported from historical survival data ${ }^{218}$ (Fig. 105.15). Flolan was originally used as a bridge to transplantation, but it was soon realized that due to the substantial improvement, most patients were removed from transplant lists. Recently, four cases were reported in which long-term Flolan treatment was successfully tapered off and discontinued, replaced by the newly introduced oral therapies Bosentan and sildenafil. ${ }^{219}$ Although at this point these are exceptions, as combination therapies become more common it is likely that more patients might be able to be weaned off Flolan and maintained on oral therapies. On the other hand, some patients do not respond to Flolan and some criteria have been proposed to identify these patients early on and refer them for transplantation. Multivariate analysis in a long-term ( $>5$ years) follow-up study of 178 patients with iPAH NYHA class III or IV showed that poor long-term outcome is predicted by baseline NYHA class IV, baseline 6-minute walk $<250 \mathrm{~m}$, baseline right atrial pressure $>12 \mathrm{mmHg}$, and, paradoxically, with mPAP $<65 \mathrm{~mm} \mathrm{Hg}{ }^{220}$ In addition, poor outcome could be predicted if at 3 months after initiation of Flolan, the functional class had not improved and the total PVR had not increased by $30 \%$ or more. ${ }^{220}$

Due to its very short half life ( $<6$ minutes) and its instability in acidic $\mathrm{pH}$ and in room temperature, the drug has to be given intravenously via a pump and kept cold at all times with ice packs. Also, due to its effects on small veins, it can only be given through central venous, tunneled catheters. A dose is initiated at low levels $(1-2 \mathrm{ng} / \mathrm{kg} / \mathrm{min})$ and is slowly increased to a level just below the threshold for the many dose-dependent side effects; these include jaw pain, flushing, headache, diarrhea, an erythematous rash, and leg pains. The maximum dose tolerable varies significantly among patients. Excessive doses can lead acutely to hypotension and chronically to high-output cardiac failure. ${ }^{221}$

Interruption of the Flolan infusion may cause a rebound increase in PAP and systemic blood pressure. In experimental models this rebound hypertension is due to activation of the renin-angiotensin system and can be prevented by angiotensin II receptor blockade. ${ }^{222}$ Deaths have occurred when infusion catheters become disconnected or crimped. Patients having problems with the pump need to visit the emergency room immediately and be monitored until a new pump or a new access is established. Most patients carry an extra pump at all times. Lastly, perhaps the most serious side effect with long-term use is the catheter-related infections, from cellulitis to fatal sepsis. The cost of Flolan (over $\$ 100,000 /$ year) and the intrusive nature of administration have restricted its use to class IV patients and this leaves room for development of oral or inhaled therapies. In addition, the demands of Flolan therapy require a compliant patient. It is also noteworthy that this drug is not curative.

In patients with conventional congestive heart failure due to left heart disease, Flolan appears to be harmful. The Flolan International Randomized Survival Trial (FIRST), which assessed the effects of Flolan in 471 patients with class IIIb and IV congestive heart failure trial was terminated early because of a strong trend toward decreased survival in the patients treated with epoprostenol. ${ }^{223}$ In addition, chronic intravenous epoprostenol therapy did not improve in distance walked, quality of life, or morbid events. By extrapolation Flolan should not be used in forms of PHT associated with left ventricular dysfunction.

\section{Treprostinil}

Treprostinil is a prostacyclin analogue with a half-life of 3 hours, which is stable at room temperature. It has recently been introduced as an alternate to Flolan, and is delivered subcutaneously continuously via a pump. This pump is much smaller than the Flolan pump (like an insulin infusion pump-roughly the size of a pager) and there is no need for ice packs. The drug is offered premixed in a syringe and the patient does not have to prepare it sterilely every day as with Flolan. Because of the longer half-life, acute discontinuation of the drug is much less dangerous than it is with Flolan. Unfortunately, the efficacy of treprostinil is at best modest, and its use is limited by the often severe pain at the site of injection.

A large multicenter RCT trial on the use of treprostinil was recently reported, in which 470 patients were randomized to either treprostinil plus conventional therapy or placebo (continuous subcutaneous infusion of vehicle) plus conventional therapy for 12 weeks. ${ }^{224}$ There were significant differences in the design of this trial compared to the previous trial on epoprostenol. For the first time, class II patients were enrolled $(n=53)$, and patients with congenital heart disease and scleroderma were also enrolled. The primary end point was the 6-minute walk, which improved in the treprostinil group and did not change in the placebo arm (difference of $16 \mathrm{~m}, p<.006)$. The iPAH group improved by $19 \mathrm{~m}$. Several secondary end points including hemodynamics and quality of life indices improved. However, $85 \%$ of the patients reported infusion site pain. The $16-\mathrm{m}$ improvement in the 6-minute walk, although statistically significant, is likely to be clinically insignificant. This poor efficacy, at least compared to epoprostenol, might be explained by differences in the disease severity and PAH types enrolled. For example, the class II patients improved only by $2 \mathrm{~m}$ (whereas the patients in class III improved by $17 \mathrm{~m}$ and in class IV by $54 \mathrm{~m}$ ), and the patients with congenital heart disease did not improve at all.

\section{ILOPROST}

Iloprost is a prostacyclin analogue with a half-life of 25 minutes, available for IV, oral, and inhaled administration (Fig. 105.18). Iloprost is used in the treatment of PAH in Europe, and was approved in April 2005 in the United States. It is mostly delivered via the inhaled route, since this mode of delivery allows for selective effects on the resistance pulmonary arteries. These small PAs are surrounded by the alveoli, and some drugs, depending on their lung absorbance, can be delivered as an aerosol, with sparing of the systemic circulation, thereby limiting peripheral side effects. Unfortunately, multiple inhalations (six to nine per day) are required to achieve sustained clinical benefit, and each inhalation takes from 5 minutes (using ultrasonic nebulizers) to 15 minutes (using jet nebulizers). ${ }^{225}$

Following two promising open-label uncontrolled studies of Iloprost in PAH for 3 months ${ }^{226}$ and 1 year, ${ }^{227}$ a 3 -month 


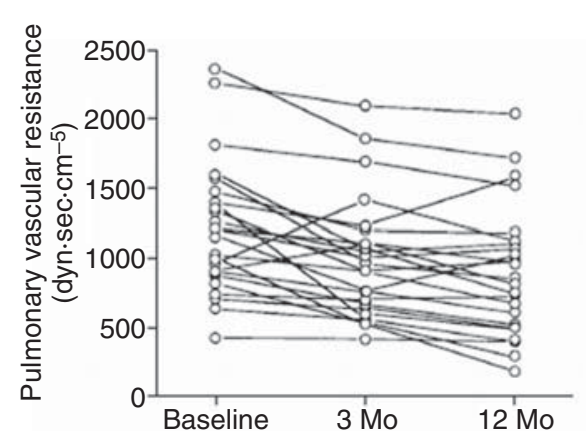

A

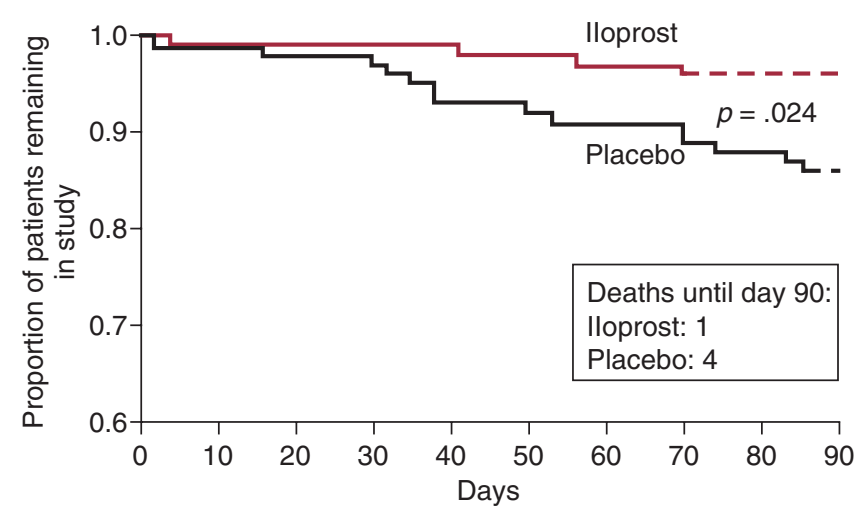

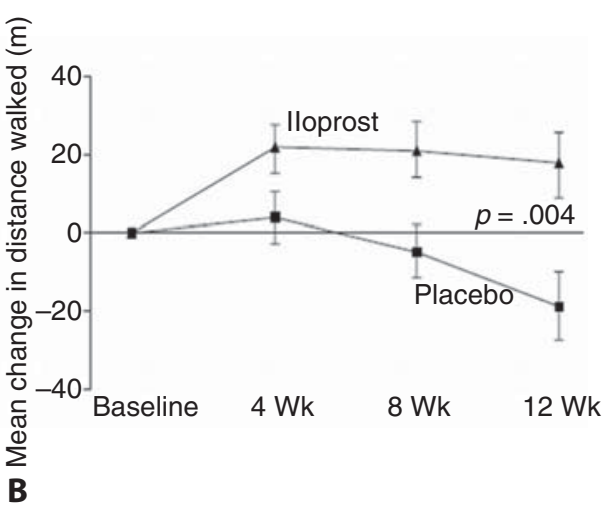

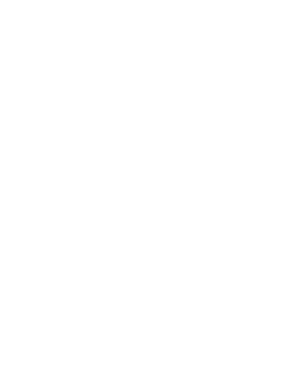

FIGURE 105.18. Iloprost in iPAH. (A) Sustained reduction of the PVR in patients taking Iloprost for 1 year. (B) Iloprost for 3 months leads to a significant improvement in the 6-minute walk and an increase in survival. double-blind placebo-controlled RCT was reported of 273 patients with class III to IV iPAH as well as PAH due to collagen vascular disease and inoperable thromboembolic disease. ${ }^{228}$ Iloprost $(2.5$ or $5 \mu \mathrm{g}$ ) six or nine times a day (max dose $45 \mu \mathrm{g} /$ dayl prolonged the 6 -minute walk by $36 \mathrm{~m}$ in the overall population relative to placebo $(p<.004)$. In the $\mathrm{iPAH}$ group, the improvement in the 6 -minute walk was $59 \mathrm{~m}$. There were also statistically significant improvements in NYHA functional class and quality-of-life indices. Importantly, statistically significant improvement was also seen in pulmonary hemodynamics. Interestingly, this improvement was unchanged when measured before and after Iloprost inhalation, suggesting some sustained positive effect on vascular remodeling, rather than reversible effects on pulmonary vascular tone. Iloprost did not improve survival (one death in the Iloprost group, four deaths on placebo, $p=$ NS). Only mild and transient side effects were reported.

\section{BERAPROST}

Beraprost is the first orally available prostacyclin analogue with a half-life of 40 minutes after oral administration. It has been used since 1995 in Japan for the treatment of iPAH, based on positive effects from several animal and small, open-label uncontrolled studies. To date, two large doubleblind, placebo-controlled RCTs have studied beraprost for 12 weeks $^{229}$ and for 1 year. ${ }^{230}$ In the 12 -week trial, 130 patients with NYHA class II and III with the full spectrum of PAH diseases were studied. The overall improvement in 6-minute walk was $25 \mathrm{~m}$; however, the iPAH patients improved by $45 \mathrm{~m}$. However, the 12 -month study showed that the small benefit in the 6-minute walk at 3 and 6 months $1+22 \mathrm{~m}$ and
$+31 \mathrm{~m}$ from baseline) was lost at 12 months. ${ }^{230}$ Tolerance was suspected, especially since the significant side effects improved after the early dose titration phase. Neither Beraprost study showed any significant improvement in hemodynamics or survival. Beraprost in now under evaluation at the European Agency for the Evaluation of Medicinal Products, and there are no plans for application to the FDA.

\section{Endothelin Receptor Inhibitors}

\section{BOSENTAN}

The first trial of Bosentan, a nonselective endothelin antagonist, aimed to study the safety of the drug on patients with severe PAH as well as explore its effects on functional capacity and hemodynamics. ${ }^{231}$ Eligible patients were those with NYHA class III and IV with iPAH and scleroderma-PAH in a double-blind, placebo-controlled manner. Interestingly, although class IV patients were eligible, they were not enrolled. Inclusion required patients to have been on stable standard treatment for a month prior to inclusion and not on epoprostenol. Thirty-two patients were randomized to Bosentan or placebo (2:1 ratio). Patients received Bosentan $62.5 \mathrm{mg}$ b.i.d. $\times 4$ weeks followed by $125 \mathrm{mg}$ b.i.d., for a total of 12 weeks. Bosentan caused a median increase of $50 \mathrm{~m}$ in the 6 minute walk from baseline, versus $-6 \mathrm{~m}$ in the placebo group. Bosentan increased the cardiac index (mean improvement $1 \mathrm{~L} / \mathrm{min} / \mathrm{m}^{2}$ in favor of Bosentan). Pulmonary vascular resistance was decreased in the Bosentan group while it was increased in the placebo group, and functional class improved in the Bosentan group as well. Asymptomatic increases in 
aminotransferases occurred in two Bosentan patients, but they normalized subsequently without discontinuing or decreasing the dose.

These encouraging results led to a larger RCT, which now enrolled 213 patients, equally randomized into $125 \mathrm{mg}$ b.i.d. or $250 \mathrm{mg}$ b.i.d. for a minimum of 16 weeks. ${ }^{232}$ Again patients with class III and IV and iPAH or scleroderma-PAH were eligible. The placebo and Bosentan groups were well matched, and after 16 weeks Bosentan improved the primary end point (the 6 -minute walk) by $36 \mathrm{~m}$, versus $-8 \mathrm{~m}$ deterioration seen in the placebo group. The improvement was more pronounced in the $250 \mathrm{mg}$ b.i.d. group compared to the $125 \mathrm{mg}$ b.i.d. group (+54 vs. $+35 \mathrm{~m}$ ). Abnormal liver function tests, syncope, and flushing were more frequent in the Bosentan group. The increase in the liver function tests was dose dependent $14 \%$ vs. $5 \%$ in the 250 vs. $125 \mathrm{mg}$ dose, respectively). Two patients in the $125 \mathrm{mg}$ group and five patients in the $250 \mathrm{mg}$ group were found to have increased liver enzymes to more than eight times the normal levels. These abnormalities were not reversible in three of the patients in the $250 \mathrm{mg}$ group, and these patients had to be withdrawn from the study. Three patients died during the study: two in the placebo group and one in the $125 \mathrm{mg}$ Bosentan group.

Based on this trial Bosentan was approved by the FDA for the target dose of $125 \mathrm{mg}$ po b.i.d. However, the FDA requires that liver function tests be performed monthly for patients taking the drug. Strict precautions for pregnancy have to be followed due to the teratogenic effects of Bosentan. Young males have to carefully consider the use of the drug, given the concerns that endothelin blockers as a class cause testicular atrophy with prolonged use.

\section{SitAXSENTAN}

In contrast to Bosentan, which is a nonselective ETA and ETB receptor, sitaxsentan is a selective ETA receptor. In theory, this could be advantageous since the vasoconstrictive and mitogenic signaling comes from the ETA receptor in the smooth muscle cells. In contrast the ETB receptor in the endothelial cells is mainly responsible for a NO-mediated vasodilatation and clearance of the circulating ET-1. In 2004, the first placebo-controlled RCT on sitaxsentan was reported, ${ }^{233}$ in which 178 patients with class II, III, and IV and with $\mathrm{PAH}$, scleroderma $\mathrm{PAH}$, or congenital heart diseasePAH were randomized into placebo versus sitaxsentan $100 \mathrm{mg}$ versus $300 \mathrm{mg}$ po qd for 12 weeks. Sitaxsentan improved the 6-minute walk by $35 \mathrm{~m}$ (100 mg group) and $33 \mathrm{~m}$ (300 mg group). The NYHA class improved in $29 \%$ of the patients in the $100 \mathrm{mg}$ group and in $30 \%$ of the patients in the $300 \mathrm{mg}$ group. The PVR and cardiac index improved in a similar manner in both groups. This trial suggested that the 300-mg dose was associated with a saturation of the receptors and, furthermore, was associated with higher incidence of abnormal liver function tests (10\% versus $2 \%$ for the $100-\mathrm{mg}$ dose). Interestingly, in an earlier pilot study, even higher doses of sitaxsentan (500 mg b.i.d.) were associated with two fatal cases of hepatitis. ${ }^{234} \mathrm{~A}$ significant increased in INR occurs in patients taking sitaxsentan, due to inhibition of the CYP2C9 P-450 enzyme that metabolizes warfarin. A larger double-blind placebocontrolled RCT has just been completed and the results are expected to be announced within a few months.

\section{Discussion}

A recent Cochrane review concludes that in the short term (16 weeks) there is evidence that these drugs improve hemodynamics, dyspnea, and exercise capacity in PAH. ${ }^{235}$ The endothelin antagonists offer benefits to patients with moderate $\mathrm{PAH}$ but are not curative and suffer from a relative lack of efficacy. They have no proven benefit on mortality and have not been adequately studied in class II or class IV PAH. It is noteworthy that hepatotoxicity is a class effect, possibly related to bile salt accumulation, and careful observation is required as the liver toxicity can be fatal. ${ }^{234}$ In another cautionary note, these agents were unsuccessful as therapy for congestive heart failure and systemic hypertension, although endothelin levels are increased in these conditions, as they are in $\mathrm{PAH}$.

\section{Phosphodiesterase Inhibitors}

In the pulmonary circulation, $\mathrm{NO}$ causes vasodilatation in part by the opening of large conductance, $\mathrm{Ca}^{2+}$-sensitive $\mathrm{K}^{+}$ channels and $\mathrm{BK}_{\mathrm{Ca}}$ channels via a cGMP-dependent kinase mechanism. ${ }^{236}$ At any given time, the cGMP levels in the PASMCs reflect the balance between production (due to the tonic effects of the endothelium-derived or exogenous NO) and breakdown [by phosphodiesterase type 5 (PDE-5), which is relatively specifically expressed in the pulmonary and the penile/clitoral circulation]. Therefore, there is synergism between both endogenous and exogenous NO and the PDE-5 inhibitors. This synergism occurs at all levels of the cGMP pathway, from the electrophysiology (opening of $\mathrm{BK}_{\mathrm{Ca}}$ channels) to the final vasodilatation.

The oral PDE-5 inhibitor sildenafil (Viagra ${ }^{\circledR}$, Pfizer) is a very attractive drug to be tested in $\mathrm{PAH}$ because of extensive prior clinical use and good safety profile. Sildenafil's most important side effect (systemic hypotension) is largely restricted to patients who ignore the absolute contraindication and concomitantly use systemic nitrates for the treatment of angina. The use of sildenafil for the treatment of conditions other than erectile dysfunction is not complicated by inappropriate erections since it only facilitates erections when arousal increases the levels of NO in the penile tissue..$^{237}$ In a cohort of 13 patients with $\mathrm{PAH}$, a single dose of sildenafil $(75 \mathrm{mg})$ decreases PVR to a similar extent as the maximal doses of iNO (80ppm) ${ }^{238}$ (Fig. 105.19). Most importantly, sildenafil significantly increases cardiac output and, in contrast to iNO, decreases pulmonary artery wedge pressure. ${ }^{238}$ Like iNO, sildenafil does not decrease systemic arterial pressure. Finally, the combination of iNO and sildenafil is well tolerated acutely and is superior to iNO in reducing PVR. This suggests that PDE-5 inhibitors might be safe alternatives to iNO in the evaluation of patients with PAH.

In a small iPAH cohort, chronic therapy with sildenafil $50 \mathrm{mg}$ po t.i.d. was well tolerated and resulted in improved PVR, right ventricular hypertrophy as well as in a significant increase in the 6-minute walk $(+110 \mathrm{~m}$ increase from baseline $)^{156}$ (Fig. 105.20). We have been following these patients for almost 2 years now. While several have a sustained improvement, some patients slowly returned to their baseline level of hemodynamics, although almost all maintain the improvement in the 6-minute walk that they showed at 


\section{$\% \Delta$ PVR index}

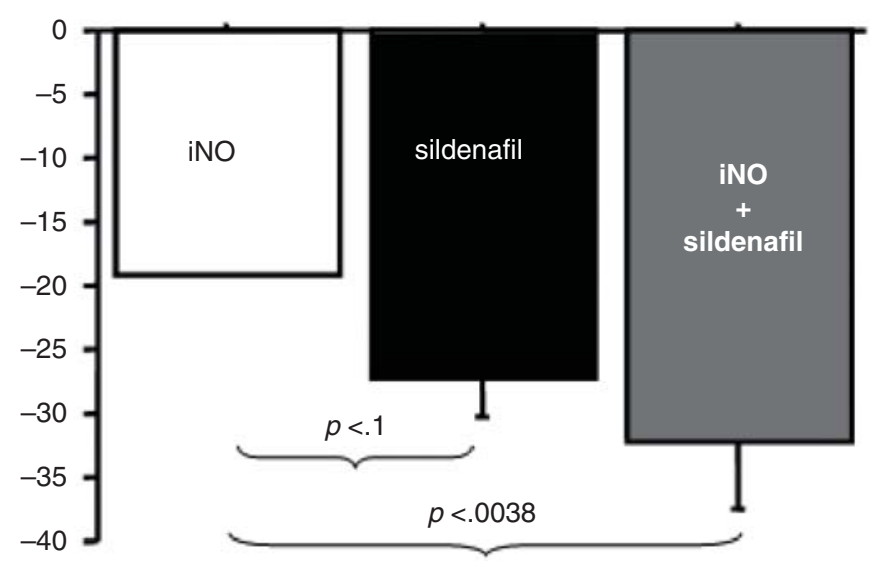

A

$p<.03$

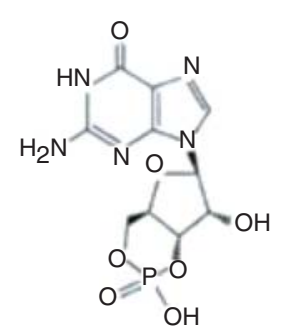

B

cGMP

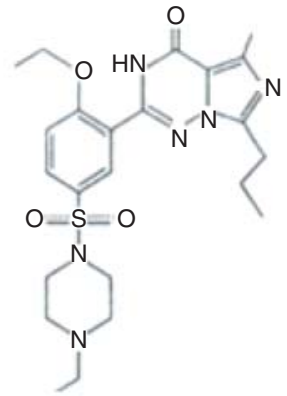

Vardenafil

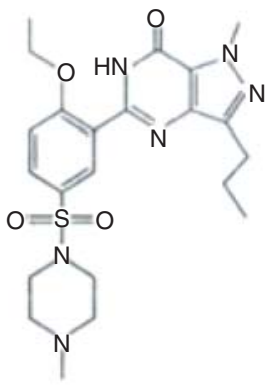

Sildenafil<smiles>CN1CC(=O)N2C(CC3c4ccccc4NC3C2c2ccc3c(c2)OCO3)C1=O</smiles>

Tadalafil

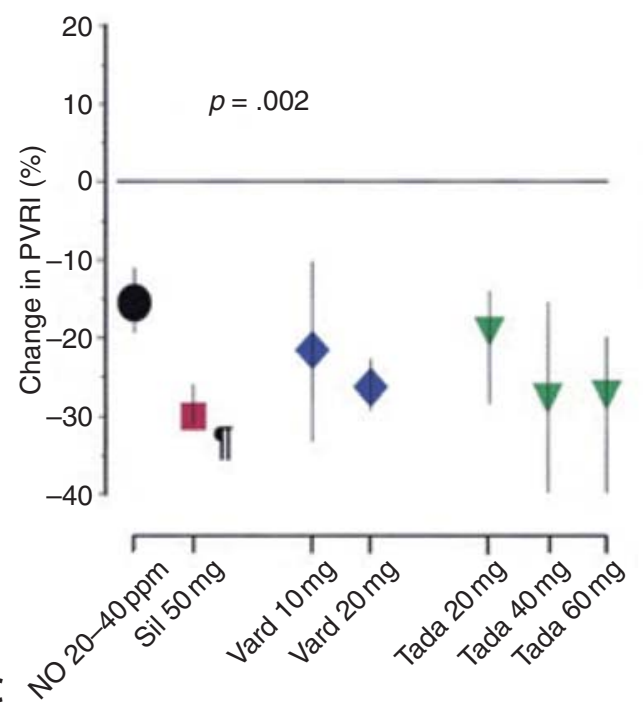

FIGURE 105.19. The acute effects of Phosphodiesterase- 5 inhibitors in PAH. (A) A single dose of sildenafil $(75 \mathrm{mg}$ po) is as effective as iNO $(80 \mathrm{ppm})$ in patients with iPAH. (B) The structures of cyclic guanosine monophosphate (cGMP) and the three currently used

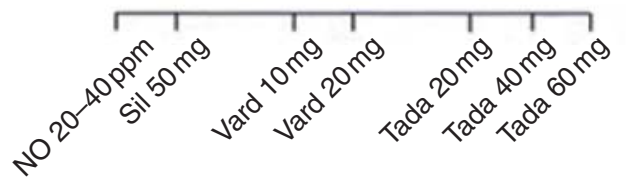

PDE-5 inhibitors. (C) Direct comparison of all the PDE-5 inhibitors in patients with PHT. Note that vardenafil is much less selective that the other inhibitors, since it fails to decrease the PVR/SVR ratio. 

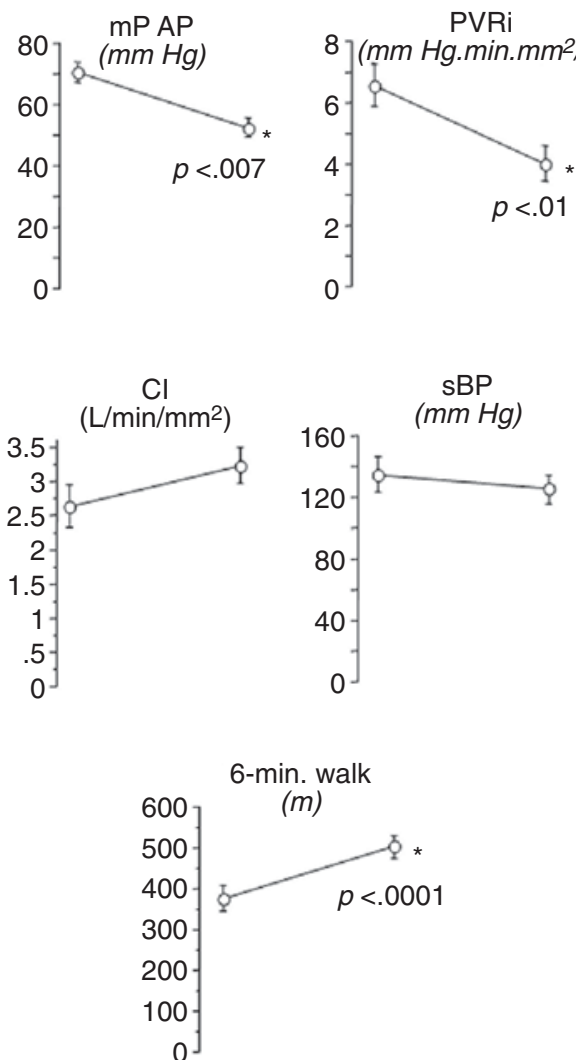

FIGURE 105.20. Chronic (3-month) treatment of iPAH patients with sildenafil $(50 \mathrm{mg}$ po t.i.d.) leads to improvements in the 6-minute walk and hemodynamics, without affecting system arte- transverse
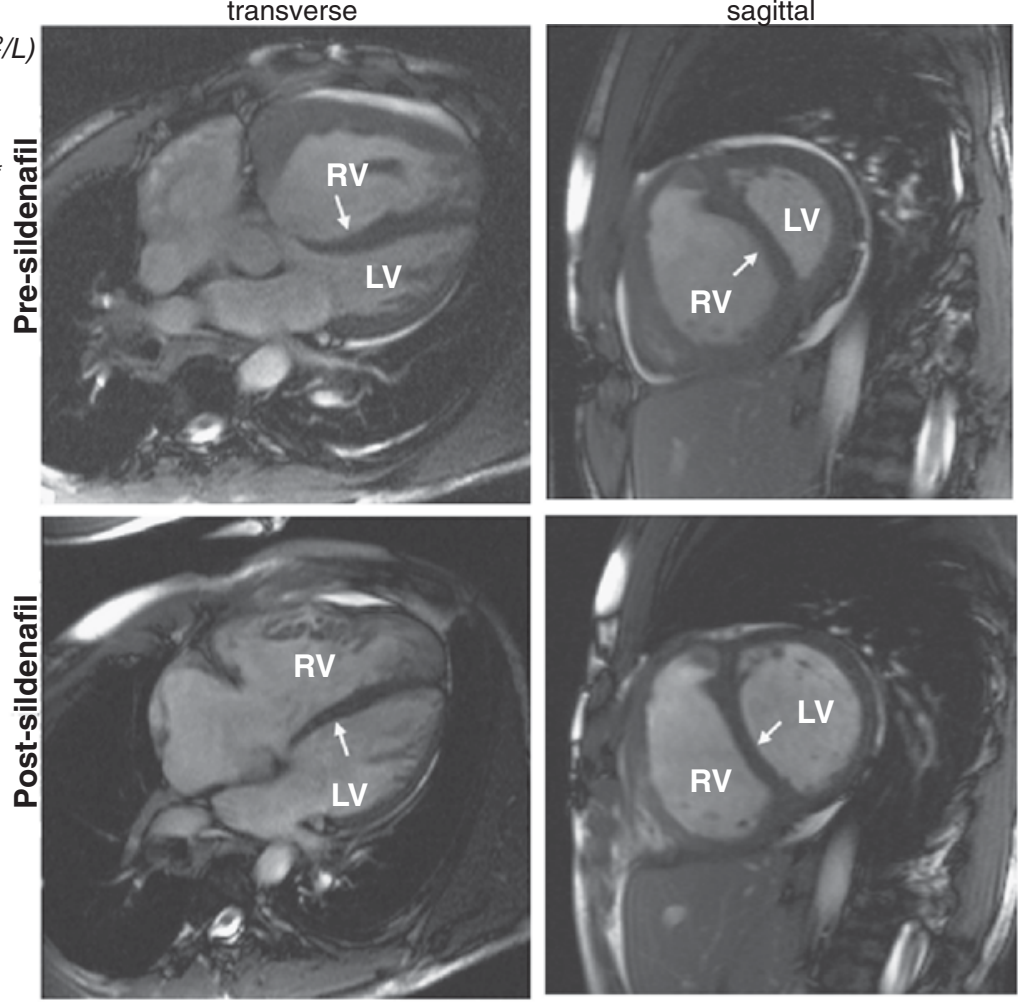

rial pressure. In the MRI example shown, note that the abnormal septum position due to the RV pressure overload is normalized after sildenafil therapy (arrows).
6 months. The significance of this observation as well as the role of possible tolerance to this drug is unknown at this point. A large industry-sponsored placebo-controlled 3month trial has been completed and will soon be published. Although this trial will give a more definitive answer on the safety and efficacy of sildenafil, more trials extending to 12 or more months will be needed in the future. Of course, this is true for all RCTs in PAH, most of which have been quite short ( 3 to 4 months). Sildenafil has already found an "offlicense" role in the treatment of patients with PAH. A recent study prospectively compared sildenafil (50 mg po t.i.d.) with Bosentan in 26 patients with iPAH and scleroderma-PAH (NYHA class III) in a double-blind fashion. ${ }^{157}$ Patients on sildenafil improved their 6-minute walk by $116 \mathrm{~m}$ while the patients on Bosentan improved only by $59 \mathrm{~m}$ (Fig. 105.21). Most importantly, sildenafil caused a significant reduction in the RV mass, measured by MRI, while Bosentan failed to improve RV mass ${ }^{157}$ (Fig. 105.21). During the study period (16 weeks) there was one death in the sildenafil group that the authors did not associate with sildenafil. This important trial was sponsored by the British Heart Foundation and did not have any industry support.

The newer PDE-5 inhibitors might also prove to be useful in PAH. Ghofrani et al. ${ }^{239}$ recently compared the acute hemodynamic effects of sildenafil, tadalafil, and vardenafil in iPAH patients undergoing right heart catheterizations (Fig.
105.19). Their research indicates that not all PDE-5 inhibitors are selective to the pulmonary circulation. For example, vardenafil caused a much higher systemic vasodilatation and, in comparison to sildenafil or tadalafil, failed to decrease the PVR to systemic vascular resistance (SVR) ratio. ${ }^{239}$ In small series, sildenafil has also been suggested to be beneficial in preventing rebound in $\mathrm{PAH}$ patients treated with inhaled $\mathrm{NO},{ }^{240} \mathrm{PHT}$ associated with pulmonary fibrosis, ${ }^{241}$ $\mathrm{PAH}$ due to veno-occlusive disease, ${ }^{242}$ and $\mathrm{PAH}$ in children. ${ }^{243}$

Although PDE5 inhibitors have promise in therapy for $\mathrm{PAH}$, further study is required, and there is not currently an FDA-approved PAH indication for this therapy. Nonetheless, the PDE5 inhibitors appear to be well tolerated and, if one excludes patients with connective tissue disease, may offer relatively larger increases in functional class and 6-minute walk than other therapies. In addition, phosphodiesterase inhibitors are significantly less expensive and less toxic than endothelin antagonists, the only other oral therapy available, and are less difficult to administer than Flolan or Iloprost.

\section{Transplantation}

Patients with severe PAH may be considered for either combined heart-lung or lung transplantation. Although there is no consensus at present regarding the preferred procedure for 
6-minute walk distance

A
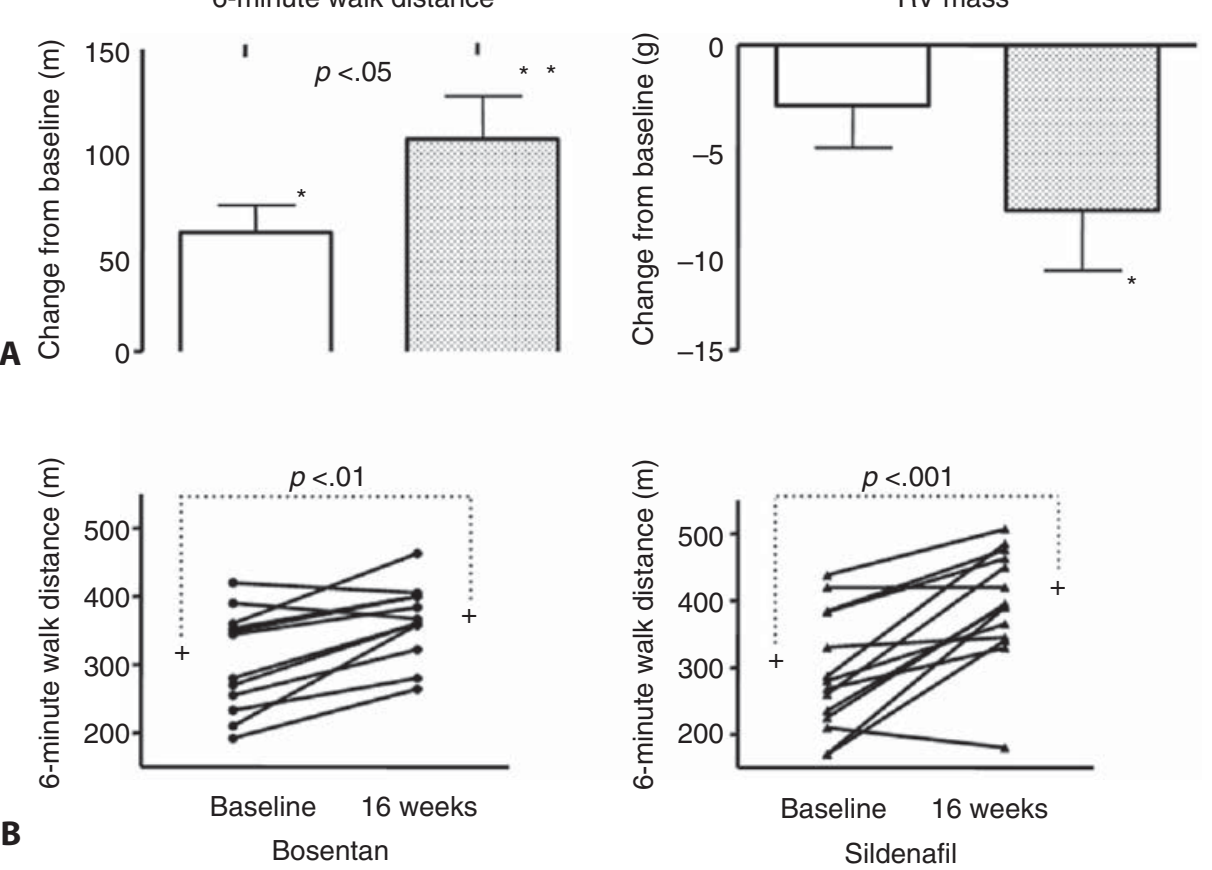

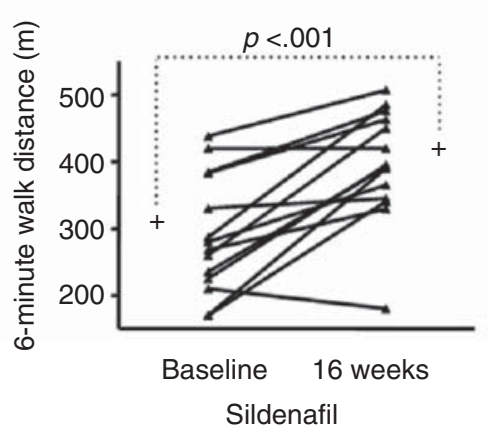

FIGURE 105.21. A head-to-head blinded comparison of sildenafil versus bosentan in $\mathrm{PAH}$. (A) Following 3 months of treatment the sildenafil groups showed a significant increase in the 6-minute walk and a reduction in RV mass, measured by MRI. The bosentan group had a smaller improvement in the 6-minute walk and did not show any regression of right ventricular hypertrophy. (B) The two group performances in the 6-minute walk are shown. most patients with pulmonary vascular disease, patients with PAH due to complex congenital heart disease should undergo combined heart-lung transplantation. Single lung transplantation has been performed successfully in patients with iPAH and PHT due to chronic obstructive pulmonary disease and fibrotic lung disease. ${ }^{244}$ The major complications of transplantation surgery for pulmonary vascular disease are organ rejection and opportunistic infection. Bronchiolitis obliterans occurs in $25 \%$ to $40 \%$ of transplant patients, and may result in serious respiratory embarrassment or death. Data from the International Society for Heart and Lung transplantation (1990-2001) show that the 3-year survival for iPAH after transplantation is approximately 54\% for lung transplantation (total 691 patients) and 50\% for heart-lung transplantation (total 302 patients). ${ }^{245}$

Access to this therapy is, and will remain, severely limited by the availability of donors. In addition, as therapy for PAH improves, there will be reluctance to transplant patients before all medical options are exhausted, as the 5year survival for patients following lung transplantation is not substantially better than the prognosis of patients with class II to III PAH on medical treatment.

\section{Multidisciplinary Pulmonary Arterial Hypertension Clinics}

Because of the diverse conditions that lead to $\mathrm{PAH}$ and the often complicated and expensive therapies, patients with PAH should be referred to multidisciplinary clinics in tertiary care centers. As an example, in our PAH clinic at the University of Alberta (www.pulmonaryhypertension.ca), patients are evaluated by teams that include cardiologists, congenital heart disease specialists, pulmonologists, rheu- matologists, and endocrinologists. Cases are discussed by teams that include radiologists and pharmacologists, and patients are often also seen by social workers and psychologists. The grim prognosis and the predisposition of young women of reproductive age for this disease explain the often severe social and psychological challenges in the management of these patients. In this model, patient care is coordinated by a highly trained nurse practitioner.

\section{An Evidence-Based Approach to the Patient with Pulmonary Arterial Hypertension}

Figure 105.22 is an evidence-based algorithm for the treatment of PAH, based on the discussion above. Since class I or II patients have not been studied in the PAH RCTs, no evidence-based recommendations can be made for these patients. Several RCTs are also currently under way, and within the next 5 years additional short-term as well as long-term trials will be available to strengthen this algorithm.

Although Flolan and Iloprost offer major benefits in $\mathrm{PAH}$ and are the current drugs of choice in North America and Europe, respectively, for class IV PAH, they are not curative and have major adverse effects and cost implications. Unfortunately, the new oral and subcutaneous analogues suffer from a relative lack of efficacy. Currently sildenafil and Bosentan are useful for class III patients, although the sildenafil therapy must be viewed as an "off-label" indication at the time of writing. It is likely that as with HIV-AIDs or tuberculosis, combination therapy for PAH will be required. This presumably would be targeted to optimize function, PVR, and BNP levels. All PAH patients should be followed in a multidisciplinary PAH clinic. 


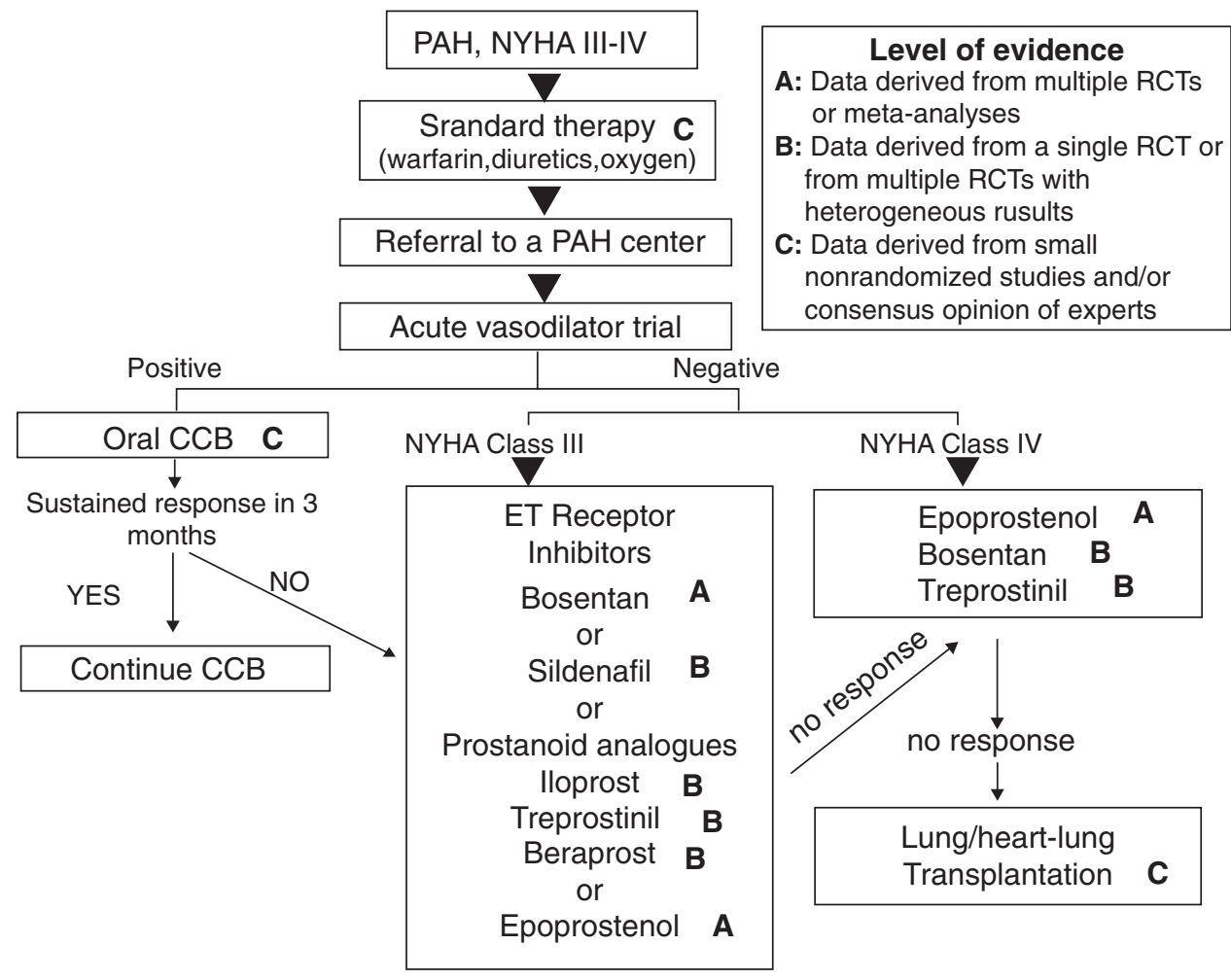

FIGURE 105.22. An evidence-based algorithm for the treatment of patients with New York Heart Association (NYHA) class III and IV PAH. CCB, calcium channel blocker.

\section{Acknowledgments}

Drs. Michelakis and Archer are supported by ABACUS, the Alberta Cardiovascular and Stroke Research Centre, Canada Foundation for Innovation, the Canada Research Chair Program, the Alberta Heart and Stroke Foundation, and the Canadian Institutes for Health Research. Dr. Archer is supported by National Institutes of Health grant RO1-HL071115. Dr. Michelakis is supported by the Alberta Heritage Foundation for Medical Research.

\section{References}

1. Bittar E. A study of Ibn Nafis. Bull Hist Med 1955;29:363.

2. Fulton J. Selected Readings in the History of Physiology. Springfield, IL: Charles C. Thomas, 1966.

3. Comroe J. Harvey's 1651 perfusion of the pulmonary circulation of man. Circulation 1982;65:1-3.

4. Young JT. DePulmonibus observations anatomiae; Bologna, 1661. Proc R Soc Med 1929;23(pt 1):7-11.

5. Forssmann W. Catheterization of the right heart. Klin Wochenschr 1929;45:2085-2089.

6. Romberg E. Ueber slerose der lungenarterien. Dtsch Arch Klin Med 1891;48:197.

7. Monckeberg JG. Uber die genuine arteriosklerose der lungenarterie. Dtsch Med Wochenschr 1907;33:1243-1246.

8. Dresdale D, Schultz M, Michtom R. Primary pulmonary hypertension. Clinical and hemodynamic study. Am J Med 1951;11: 686-705.

9. Archer S, Rich S. Primary pulmonary hypertension: a vascular biology and translational research "work in progress." Circulation 2000;102(22):2781-2791.
10. Michelakis ED, Weir EK, Wu X, et al. Potassium channels regulate tone in rat pulmonary veins. Am J Physiol Lung Cell Mol Physiol 2001;280(6):L1138-1147.

11. Haissaguerre M, Jais P, Shah DC, et al. Spontaneous initiation of atrial fibrillation by ectopic beats originating in the pulmonary veins. N Engl J Med 1998;339(10):659-666.

12. D'Alonzo G, Barst R, Ayres S. Survival in patients with primary pulmonary hypertension. Results from a national prospective registry. Ann Intern Med 1991;115:343-349.

13. Reeves J, Dempsey J, Grover R. Pulmonary Circulation During Exercise. New York: 1989.

14. Fishman A. Clinical classification of pulmonary hypertension. Clin Chest Med (Pulmon Hypertens) 2001;22(3):385-391.

15. Rich S, Chomka E, Hasara L, et al. The prevalence of pulmonary hypertension in the United States. Chest 1989;96:236241.

16. Appelbaum L, Yigla M, Bendayan D, et al. Primary pulmonary hypertension in Israel: a national survey. Chest 2001;119(6): 1801-1806.

17. The International Primary Pulmonary Hypertension Study (IPPHS). Chest 1994;105(2 suppl):37S-41S.

18. Rich S, Dantzker DR, Ayres SM, et al. Primary pulmonary hypertension: a national prospective study. Ann Intern Med 1987; 107:216-223.

19. Rajasekhar D, Balakrishnan KG, Venkitachalam CG, et al. Primary pulmonary hypertension: natural history and prognostic factors. Indian Heart J 1994;46(3):165-170.

20. Okada O, Tanabe N, Yasuda J, et al. Prediction of life expectancy in patients with primary pulmonary hypertension. A retrospective nationwide survey from 1980-1990. Intern Med 1999;38(1):12-16

21. Lilienfeld DE, Rubin LJ. Mortality from primary pulmonary hypertension in the United States, 1979-1996. Chest2000;117(3): 796-800. 
22. Michelakis ED, Thebaud B, Weir EK, Archer SL. Hypoxic pulmonary vasoconstriction: redox regulation of $\mathrm{O}_{2}$-sensitive $\mathrm{K}+$ channels by a mitochondrial $\mathrm{O}_{2}$-sensor in resistance artery smooth muscle cells. J Mol Cell Cardiol 2004;37(6):1119-1136.

23. Stenmark KR, Abman SH. Lung vascular development: implications for the pathogenesis of bronchopulmonary dysplasia. Annu Rev Physiol 2005; 67:623-661.

24. Stenmark KR, Gebb SA. Lung vascular development: breathing new life into an old problem. Am J Respir Cell Mol Biol 2003; 28(2):133-137.

25. Parera MC, van Dooren $M$, van Kempen $M$, et al. Distal angiogenesis: a new concept for lung vascular morphogenesis. Am J Physiol Lung Cell Mol Physiol 2005;288(1):L141-149.

26. Han RN, Post M, Tanswell AK, Lye SJ. Insulin-like growth factor-I receptor-mediated vasculogenesis/angiogenesis in human lung development. Am J Respir Cell Mol Biol 2003;28(2): 159-169.

27. Gebb S, Stevens T. On lung endothelial cell heterogeneity. Microvasc Res 2004;68(1):1-12.

28. Madden JA, Vadula MS, Kurup V. Effects of hypoxia and other vasoactive agents on pulmonary and cerebral artery smooth muscle cells. Am J Physiol 1992;263:L384-L393.

29. Archer SL, Huang JMC, Reeve HL, et al. Differential distribution of electrophysiologically distinct myocytes in conduit and resistance arteries determines their response to nitric oxide and hypoxia. Circ Res 1996;78:431-442.

30. Archer SL, Wu XC, Thebaud B, et al. Preferential expression and function of voltage-gated, $\mathrm{O}_{2}$-sensitive $\mathrm{K}+$ channels in resistance pulmonary arteries explains regional heterogeneity in hypoxic pulmonary vasoconstriction: ionic diversity in smooth muscle cells. Circ Res 2004;95(3):308-318.

31. Archer SL, Souil E, Dinh-Xuan AT, et al. Molecular identification of the role of voltage-gated K+ channels, Kv1.5 and Kv2.1, in hypoxic pulmonary vasoconstriction and control of resting membrane potential in rat pulmonary artery myocytes. J Clin Invest 1998;101(11):2319-2330.

32. Archer S, Will J, Weir E. Redox status in the control of pulmonary vascular tone. Herz 1986;11:127-141.

33. Archer SL, Huang J, Henry T, Peterson D, Weir EK. A redox based oxygen sensor in rat pulmonary vasculature. Circ Res 1993; 73:1100-1112.

34. Mohazzab KM, Fayngersh RP, Kaminski PM, Wolin MS. Potential role of NADH oxidoreductase-derived reactive $\mathrm{O}_{2}$ species in calf pulmonary arterial $\mathrm{PO} 2-$ elicited responses. Am J Physiol $1995 ; 269(5$ pt 1):L637-644.

35. Michelakis ED, Hampl V, Nsair A, et al. Diversity in mitochondrial function explains differences in vascular oxygen sensing. Circ Res 2002;90(12):1307-1315.

36. Yuan JX, Aldinger AM, Juhaszova M, et al. Dysfunctional voltage-gated $\mathrm{K}+$ channels in pulmonary artery smooth muscle cells of patients with primary pulmonary hypertension. Circulation 1998;98(14):1400-1406.

37. Pozeg ZI, Michelakis ED, McMurtry MS, et al. In vivo gene transfer of the $\mathrm{O}_{2}$-sensitive potassium channel Kv1.5 reduces pulmonary hypertension and restores hypoxic pulmonary vasoconstriction in chronically hypoxic rats. Circulation 2003; 107(15):2037-2044.

38. McMurtry MS, Bonnet S, Wu X, et al. Dichloroacetate prevents and reverses pulmonary hypertension by inducing pulmonary artery smooth muscle cell apoptosis. Circ Res 2004;95(8): 830-840.

39. Rich S, Kaufmann E, Levy PS. The effect of high doses of calcium-channel blockers on survival in primary pulmonary hypertension. N Engl J Med 1992;327(2):76-81.

40. McMurtry S, Archer S, Altieri D, et al. Gene therapy targeting survivin selectively induces pulmonary vascular apoptosis and reverses pulmonary arterial hypertension. J Clin Invest 2005; 115:1479-1499.
41. Chazova I, Loyd JE, Zhdanov VS, Newman JH, Belenkov Y, Meyrick B. Pulmonary artery adventitial changes and venous involvement in primary pulmonary hypertension. Am J Pathol 1995;146(2):389-397.

42. Mason NA, Springall DR, Burke M, et al. High expression of endothelial nitric oxide synthase in plexiform lesions of pulmonary hypertension. J Pathol 1998;185(3):313-318.

43. Tuder RM, Groves B, Badesch DB, Voelkel NF. Exuberant endothelial cell growth and elements of inflammation are present in plexiform lesions of pulmonary hypertension. Am J Pathol $1994 ; 144(2): 275-285$.

44. Cool CD, Stewart JS, Werahera P, et al. Three-dimensional reconstruction of pulmonary arteries in plexiform pulmonary hypertension using cell-specific markers. Evidence for a dynamic and heterogeneous process of pulmonary endothelial cell growth. Am J Pathol 1999;155(2):411-419.

45. Budhiraja R, Tuder RM, Hassoun PM. Endothelial dysfunction in pulmonary hypertension. Circulation 2004;109(2):159-165.

46. Christman B, McPherson C, Newman J, et al. An imbalance between the excretion of thromboxane and prostacyclin metabolites in pulmonary hypertension. N Engl J Med 1992;327: 70-75.

47. Giaid A, Saleh D. Reduced expression of endothelial nitric oxide synthase in the lungs of patients with pulmonary hypertension. N Engl J Med 1995;333(4):214-221.

48. Archer SL, Djaballah K, Humbert M, et al. Nitric oxide deficiency in fenfluramine- and dexfenfluramine-induced pulmonary hypertension. Am J Respir Crit Care Med 1998;158(4): 1061-1067.

49. Forrest IA, Small T, Corris PA. Effect of nebulized epoprostenol (prostacyclin) on exhaled nitric oxide in patients with pulmonary hypertension due to congenital heart disease and in normal controls. Clin Sci (Colch) 1999;97(1):99-102.

50. Bogdan M, Humbert M, Francoual J, et al. Urinary cGMP concentrations in severe primary pulmonary hypertension. Thorax 1998;53(12):1059-1062.

51. Archer S, Djaballah K, Humbert M, et al. Nitric oxide deficiency in fenfluramine- and dexfenfluramine-induced pulmonary hypertension. Am J Respir Crit Care Med 1998;158(4): 1061-1067.

52. Stelzner TJ, O'Brien RF, Yanagisawa M, et al. Increased lung endothelin-1 production in rats with idiopathic pulmonary hypertension. Am J Physiol 1992;262(5 pt 1):L614-620.

53. Stewart D, Levy R, Cernacek P, Langlehben D. Increased plasma endothelin-1 in pulmonary hypertension: marker or mediator of disease? Ann Intern Med 1991;114:464-469.

54. Giaid A, Yanagisawa M, Langleben D, et al. Expression of endothelin-1 in the lungs of patients with pulmonary hypertension. N Engl J Med 1993;328(24):1732-1739.

55. Rich S, McLaughlin VV. Endothelin receptor blockers in cardiovascular disease. Circulation 2003;108(18):2184-2190.

56. Packer M, McMurray J, Massie BM, et al. Clinical effects of endothelin receptor antagonism with bosentan in patients with severe chronic heart failure: results of a pilot study. J Card Fail $2005 ; 11(1): 12-20$.

57. Petkov V, Mosgoeller W, Ziesche R, et al. Vasoactive intestinal peptide as a new drug for treatment of primary pulmonary hypertension. J Clin Invest 2003;111(9):1339-1346.

58. Lee SD, Shroyer KR, Markham NE, Cool CD, Voelkel NF, Tuder RM. Monoclonal endothelial cell proliferation is present in primary but not secondary pulmonary hypertension. J Clin Invest $1998 ; 101(5): 927-934$.

59. Archer SL, Rusch NJ, eds. Potassium Channels in Cardiovascular Biology, 1st ed. New York: Kluwer Academic/Plenum, 2001.

60. Post J, Hume J, Archer S, Weir E. Direct role for potassium channel inhibition in hypoxic pulmonary vasoconstriction. Am J Physiol 1992;262:C882-C890. 
61. Weir EK, Archer SL. The mechanism of acute hypoxic pulmonary vasoconstriction: the tale of two channels. FASEB J 1995; 9(2):183-189.

62. Platoshyn O, Golovina VA, Bailey CL, et al. Sustained membrane depolarization and pulmonary artery smooth muscle cell proliferation. Am J Physiol Cell Physiol 2000;279(5):C15401549.

63. Remillard CV, Yuan JX. Activation of K+ channels: an essential pathway in programmed cell death. Am J Physiol Lung Cell Mol Physiol 2004;286(1):L49-67.

64. Yuan XJ, Wang J, Juhaszova M, Gaine SP, Rubin LJ. Attenuated $\mathrm{K}+$ channel gene transcription in primary pulmonary hypertension [letter]. Lancet 1998;351(9104):726-727.

65. Michelakis ED, Weir EK. Anorectic drugs and pulmonary hypertension from the bedside to the bench. Am J Med Sci 2001;321(4):292-299.

66. Weir EK, Reeve HL, Huang J, et al. Anorexic agents Aminorex, Fenfluramine and Dexfenfluramine inhibit potassium current in rat pulmonary vascular smooth muscle and cause pulmonary vasoconstriction. Circulation 1996;94:2216-2220.

67. Michelakis ED, McMurtry MS, Wu XC, et al. Dichloroacetate, a metabolic modulator, prevents and reverses chronic hypoxic pulmonary hypertension in rats: role of increased expression and activity of voltage-gated potassium channels. Circulation $2002 ; 105(2): 244-250$.

68. Salvesen GS, Duckett CS. IAP proteins: blocking the road to death's door. Nat Rev Mol Cell Biol 2002;3(6):401-410.

69. Altieri DC. Validating survivin as a cancer therapeutic target. Nat Rev Cancer 2003;3(1):46-54.

70. Dohi T, Beltrami E, Wall NR, Plescia J, Altieri DC. Mitochondrial survivin inhibits apoptosis and promotes tumorigenesis. J Clin Invest 2004;114(8):1117-1127.

71. Xu Y, Fang F, Ludewig G, Jones G, Jones D. A mutation found in the promoter region of the human survivin gene is correlated to overexpression of survivin in cancer cells. DNA Cell Biol 2004;23(9):527-537.

72. Voelkel NF, Cool C, Lee SD, Wright L, Geraci MW, Tuder RM. Primary pulmonary hypertension between inflammation and cancer. Chest 1998;114(3 suppl):225S-230S.

73. Zhao YD, Campbell AI, Robb M, Ng D, Stewart DJ. Protective role of angiopoietin-1 in experimental pulmonary hypertension. Circ Res 2003;92(9):984-991.

74. Herve P, Drouet L, Dosquet C, et al. Primary pulmonary hypertension in a patient with a familial platelet storage pool disease: role of serotonin. Am J Med 1990;89(1):117-120.

75. Herve P, Launay JM, Scrobohaci ML, et al. Increased plasma serotonin in primary pulmonary hypertension. Am J Med 1995; 99(3):249-254.

76. Egermayer P, Town GI, Peacock AJ. Role of serotonin in the pathogenesis of acute and chronic pulmonary hypertension. Thorax 1999;54(2):161-168.

77. MacLean MR. Endothelin-1 and serotonin: mediators of primary and secondary pulmonary hypertension? J Lab Clin Med 1999;134(2):105-114.

78. Eddahibi S, Humbert M, Fadel E, et al. Serotonin transporter overexpression is responsible for pulmonary artery smooth muscle hyperplasia in primary pulmonary hypertension. J Clin Invest 2001;108(8):1141-1150.

79. MacLean MR, Deuchar GA, Hicks MN, et al. Overexpression of the 5-hydroxytryptamine transporter gene: effect on pulmonary hemodynamics and hypoxia-induced pulmonary hypertension. Circulation 2004;109(17):2150-2155.

80. Morecroft I, Heeley RP, Prentice HM, Kirk A, MacLean MR. 5 -hydroxytryptamine receptors mediating contraction in human small muscular pulmonary arteries: importance of the 5-HT1B receptor. Br J Pharmacol 1999;128(3):730-734.

81. Keegan A, Morecroft I, Smillie D, Hicks MN, MacLean MR. Contribution of the 5-HT(1B) receptor to hypoxia-induced pulmonary hypertension: converging evidence using 5-HT(1B)receptor knockout mice and the 5-HT(1B/1D)-receptor antagonist GR127935. Circ Res 2001;89(12):1231-1239.

82. Launay JM, Herve P, Peoc'h K, et al. Function of the serotonin 5 -hydroxytryptamine $2 \mathrm{~B}$ receptor in pulmonary hypertension. Nat Med 2002;8(10):1129-1135.

83. Weir EK, Reeve HL, Johnson G, Michelakis ED, Nelson DP, Archer SL. A role for potassium channels in smooth muscle cells and platelets in the etiology of primary pulmonary hypertension. Chest 1998;114(3 suppl):200S-204S.

84. Wang J, Juhaszova M, Conte JV Jr, Gaine SP, Rubin LJ, Yuan JX. Action of fenfluramine on voltage-gated $\mathrm{K}+$ channels in human pulmonary-artery smooth-muscle cells [letter]. Lancet 1998; 352(9124):290.

85. Rabinovitch M. It all begins with EVE (endogenous vascular elastase). Isr J Med Sci 1996;32(10):803-808; discussion 809_ 810.

86. Cowan KN, Jones PL, Rabinovitch $\mathrm{M}$. Elastase and matrix metalloproteinase inhibitors induce regression, and tenascin- $\mathrm{C}$ antisense prevents progression, of vascular disease. J Clin Invest $2000 ; 105(1): 21-34$.

87. Fernandez-Patron C, Martinez-Cuesta MA, Salas E, et al. Differential regulation of platelet aggregation by matrix metalloproteinases-9 and -2. Thromb Haemost 1999;82:1730-1735

88. Fernandez-Patron C, Radomski M, Davidge S. Vascular matrix metalloproteinase-2 cleaves big endothelin-1 yielding a novel vasoconstrictor. Circ Res 1999;85:906-911.

89. Dorfmuller P, Perros F, Balabanian K, Humbert M. Inflammation in pulmonary arterial hypertension. Eur RespirJ $2003 ; 22(2)$ : 358-363.

90. Gonzalez-Lopez L, Cardona-Munoz EG, Celis A, et al. Therapy with intermittent pulse cyclophosphamide for pulmonary hypertension associated with systemic lupus erythematosus. Lupus 2004;13(2):105-112.

91. Groen H, Bootsma H, Postma DS, Kallenberg CG. Primary pulmonary hypertension in a patient with systemic lupus erythematosus: partial improvement with cyclophosphamide. J Rheumatol 1993;20(6):1055-1057.

92. Balabanian K, Foussat A, Dorfmuller P, et al. CX(3) C chemokine fractalkine in pulmonary arterial hypertension. Am J Respir Crit Care Med 2002;165(10):1419-1425.

93. Yu AY, Shimoda LA, Iyer NV, et al. Impaired physiological responses to chronic hypoxia in mice partially deficient for hypoxia-inducible factor 1alpha. J Clin Invest 1999;103(5): 691-696.

94. Shimoda LA, Manalo DJ, Sham JS, Semenza GL, Sylvester JT. Partial HIF-1alpha deficiency impairs pulmonary arterial myocyte electrophysiological responses to hypoxia. Am J Physiol Lung Cell Mol Physiol 2001;281(1):L202-208.

95. Tuder RM, Flook BE, Voelkel NF. Increased gene expression for VEGF and the VEGF receptors KDR/Flk and Flt in lungs exposed to acute or to chronic hypoxia. Modulation of gene expression by nitric oxide. J Clin Invest 1995;95(4):1798-1807.

96. Tuder RM, Chacon M, Alger L, et al. Expression of angiogenesis-related molecules in plexiform lesions in severe pulmonary hypertension: evidence for a process of disordered angiogenesis. J Pathol 2001;195(3):367-374.

97. Nichols WC, Koller DL, Slovis B, et al. Localization of the gene for familial primary pulmonary hypertension to chromosome 2q31-32. Nat Genet 1997;15(3):277-280.

98. Loyd JE, Butler MG, Foroud TM, Conneally PM, Phillips JA, 3rd, Newman JH. Genetic anticipation and abnormal gender ratio at birth in familial primary pulmonary hypertension. Am J Respir Crit Care Med 1995;152(1):93-97.

99. Loyd JE, Slovis B, Phillips JA 3rd, et al. The presence of genetic anticipation suggests that the molecular basis of familial primary pulmonary hypertension may be trinucleotide repeat expansion. Chest 1997;111(6 suppl):82S-83S. 
100. Deng Z, Haghighi F, Helleby L, et al. Fine mapping of PPH1, a gene for familial primary pulmonary hypertension, to a 3-cM region on chromosome 2q33. Am J Respir Crit Care Med 2000; 161(3 pt 1):1055-1059.

101. Morse JH, Jones AC, Barst RJ, Hodge SE, Wilhelmsen KC, Nygaard TG. Mapping of familial primary pulmonary hypertension locus (PPH1) to chromosome 2q31-q32. Circulation 1997;95(12):2603-2606.

102. Lane KB, Machado RD, Pauciulo MW, et al. Heterozygous germline mutations in BMPR2, encoding a TGF-beta receptor, cause familial primary pulmonary hypertension. The International PPH Consortium. Nat Genet 2000;26(1):81-84. taf/ dynapage.taf?file=/ncb/genetics/v26/n81/full/ng0900_0981. html taf/dynapage.taf?file=/ncb/genetics/v0926/n0901/abs/ ng0900_0981.html.

103. Machado RD, Pauciulo MW, Thomson JR, et al. BMPR 2 haploinsufficiency as the inherited molecular mechanism for primary pulmonary hypertension. Am J Hum Genet 2001; 68(1): 92-102.

104. Thomson JR, Machado RD, Pauciulo MW, et al. Sporadic primary pulmonary hypertension is associated with germline mutations of the gene encoding BMPR-II, a receptor member of the TGF-beta family. J Med Genet 2000;37(10):741-745.

105. Wozney JM, Rosen V, Celeste AJ, et al. Novel regulators of bone formation: molecular clones and activities. Science 1988; 242(4885):1528-1534.

106. Hogan BL. Bone morphogenetic proteins: multifunctional regulators of vertebrate development. Genes Dev 1996;10(13):15801594.

107. Bellusci S, Henderson R, Winnier G, Oikawa T, Hogan BL. Evidence from normal expression and targeted misexpression that bone morphogenetic protein (Bmp-4) plays a role in mouse embryonic lung morphogenesis. Development 1996;122(6): 1693-1702.

108. De Caestecker M, Meyrick B. Bone morphogenetic proteins, genetics and the pathophysiology of primary pulmonary hypertension. Respir Res 2001;2(4):193-197.

109. Massague J, Wotton D. Transcriptional control by the TGFbeta/Smad signaling system. EMBO J 2000;19(8):1745-1754.

110. Sekelsky JJ, Newfeld SJ, Raftery LA, Chartoff EH, Gelbart WM. Genetic characterization and cloning of mothers against dpp, a gene required for decapentaplegic function in Drosophila melanogaster. Genetics 1995;139(3):1347-1358.

111. Beppu H, Kawabata M, Hamamoto T, et al. BMP type II receptor is required for gastrulation and early development of mouse embryos. Dev Biol 2000;221(1):249-258.

112. Thomas A, Gaddipati R, Newman J, Loyd J. Genetics of primary pulmonary hypertension. Clin Chest Med (Pulmon Hypertens) $2001 ; 22(3): 477-491$.

113. Morrell NW, Yang X, Upton PD, et al. Altered growth responses of pulmonary artery smooth muscle cells from patients with primary pulmonary hypertension to transforming growth factor-beta(1) and bone morphogenetic proteins. Circulation 2001;104(7):790-795.

114. West J, Fagan K, Steudel W, et al. Pulmonary hypertension in transgenic mice expressing a dominant-negative BMPRII gene in smooth muscle. Circ Res 2004;94(8):1109-1114.

115. Reeves JT, Groves BM. Approach to the patient with pulmonary hypertension. In: Weir EK, Reeves JT, eds. Pulmonary Hypertension. Mt. Kisco, NY: Futura, 1984:1-44.

116. Yuceoglu YZ, Dresdale DT, Valensi QJ, Narvas RM, Gottlieb NT. Primary pulmonary hypertension with hoarseness and massive (fatal) hemoptysis. Review of the literature and report of a case. Vasc Dis 1967;4(5):290-304.

117. Saha A, Balakrishnan KG, Jaiswal PK, et al. Prognosis for patients with Eisenmenger syndrome of various aetiology. Int J Cardiol 1994;45(3):199-207.
118. Kambe T, Hibi N, Fukui Y, et al. Clinical study on the rightsided Austin Flint murmur using intracardiac phonocardiography. Am Heart J 1979;98(6):701-707.

119. Peres JE, Smith CA, Meltzer VN. Pulmonic valve insufficiency: a common cause of transient diastolic murmurs in renal failure. Ann Intern Med 1985;103(4):497-502.

120. Paciocco G, Martinez FJ, Bossone E, Pielsticker E, Gillespie B, Rubenfire M. Oxygen desaturation on the six-minute walk test and mortality in untreated primary pulmonary hypertension. Eur Respir J 2001;17(4):647-652.

121. Nagaya $N$, Nishikimi $T$, Uematsu $M$, et al. Plasma brain natriuretic peptide as a prognostic indicator in patients with primary pulmonary hypertension. Circulation 2000;102(8):865870.

122. Lehtonen J, Sutinen S. Electrocardiographic criteria for the diagnosis of right ventricular hypertrophy verified at autopsy. Chest 1988;93:839-842.

123. Schiller NB, Sahn DJ. Pulmonary pressure measurement by Doppler and two-dimensional echocardiography in adult and pediatric populations. In: Weir EK, Archer SL, Reeves JT, eds. The Diagnosis and Treatment of Pulmonary Hypertension. Mt. Kisco, NY: Futura, 1992:41-59.

124. Missri J. Evaluation of pulmonary hypertension by Doppler echocardiography. J Cardiovasc Ultrason 1988;7:277282.

125. Nanda N, Gramiak R, Robinson T, Shah P. Echocardiographic evaluation of pulmonary hypertension. Circulation 1974;50: 575.

126. Acquatella H, Schiller N, Sharpe D, Chatterjee K. Lack of correlation between echocardiographic pulmonary valve morphology and simultaneous pulmonary arterial pressure. Am J Cardiol 1979;43:946-950.

127. Okamoto M, Miyatake K, Kinoshite N, Sakakibara H, Nimura Y. Analysis of blood flow in pulmonary hypertension with the pulsed Doppler flowmeter combined with cross-sectional echocardiography. Br Heart J 1984;51:407-415.

128. Bauman W, Wann L, Childress R, Weyman A, Feiganbaum H, Dillon J. Mid systolic notching of the pulmonary valve in the absence of pulmonary hypertension. Am J Cardiol 1979;43: 1049-1052.

129. Tsuda T, Sawayama T, Kawai N, Katoh T, Nezuo S, Kikawa K. Echocardiographic measurement of right ventricular wall thickness in adults by anterior approach. Br Heart J 1980;44: $55-61$.

130. Gottdiener J, Gay J, Maron B, Fletcher R. Increased right ventricular wall thickness in left ventricular pressure overload: Echocardiographic determination of hypertrophic response of the "nonstressed" ventricle. J Am Coll Cardiol 1985;6:550555.

131. Goerke RJ, Carlsson E. Calculation of left and right ventricular volumes; methods using standard computer equipment and biplane angiograms. Invest Radiol 1967;2:360.

132. Starling MR, Crawford MH, Sorenson SG, O'Rourke RA. A new two-dimensional echocardiographic technique for evaluating right ventricular size and performance in patients with obstructive lung disease. Circulation 1982;66:612.

133. Schimada R, Takeshita A, Nakamura M. Noninvasive assessment of right ventricular systolic pressure in atrial septal defect: analysis of the end-systolic configuration of the ventricular septum by two-dimensional echocardiography. Am J Cardiol 1984;53:1117-1123.

134. Park B, Dittrich H, Polikar R, Olson L. Echocardiographic evidence of pericardial effusion in severe chronic pulmonary hypertension. Am J Cardiol 1989; 63:143-145.

135. Wilson N, Goldberg SJ, Dickinson DF. Normal intracardiac and great artery blood velocity measurements by pulsed Doppler echocardiography. Br Heart J 1985;53:451-458. 
136. Kitabatake A, Inoue M, Asao M, et al. Noninvasive evaluation of pulmonary hypertension by a pulsed Doppler technique. Circulation 1984;68:302-309.

137. Mahan G, Dabestani A, Gardin J, Allfie A, Burn C, Henry W. Estimation of pulmonary artery pressure by pulsed Doppler echocardiography. Circulation 1983;68(suppl III):III-367(abstr).

138. Berger M, Haimowitz A, Van Tosh A, Berdoff R, Goldberg E. Quantitative assessment of pulmonary hypertension in patients with tricuspid regurgitation using continuous wave doppler ultrasound. J Am Coll Cardiol 1985;6:359-365.

139. Yock P, Popp R. Noninvasive estimation of right ventricular systolic pressure by Doppler ultrasound in patients with tricuspid regurgitation. Circulation 1984;70:657-662.

140. Currie P, Seward J, Chan K-L. Continuous wave Doppler determination of right ventricular pressure: a simultaneous Dopplercatheterization study in 127 patients. J Am Coll Cardiol 1985; 6:750-756.

141. Kircher B, Himelman R, Schiller N. Right atrial pressure estimation from respiratory behavior of the inferior vena cava. Circulation 1988;78:2196.

142. Simonson J, Schiller N. Sonospirometry: a new method for noninvasive estimation of mean right atrial pressure based on two dimensional echographic measurements of the inferior vena cava during measured inspiration. Am Coll Cardiol 1988;11:557-564.

143. Epler GR, McLoud TC, Gaensler EA, Mikus JP, Carrington CB. Normal Chest Roentgenograms in chronic diffuse infiltrative lung disease. N Engl J Med 1978;298:934-939.

144. Pruszczyk P, Torbicki A, Pacho R, et al. Noninvasive diagnosis of suspected severe pulmonary embolism: transesophageal echocardiography vs spiral CT. Chest 1997;112(3): 722-728.

145. Perloff JK, Hart EM, Greaves SM, Miner PD, Child JS. Proximal pulmonary arterial and intrapulmonary radiologic features of Eisenmenger syndrome and primary pulmonary hypertension. Am J Cardiol 2003;92(2):182-187.

146. Hull RD, Hirsh J, Carter C, et al. Diagnostic value of ventilation-perfusion lung scanning in patients with suspected pulmonary embolism. Chest 1985;88:819-828.

147. Child J, Wolfe J, Tashkin D, Nakano F. Fatal lung scan in a case of pulmonary hypertension due to obliterative pulmonary vascular disease. Chest 1975;67:308-309.

148. Hayashino Y, Goto M, Noguchi Y, Fukui T. Ventilationperfusion scanning and helical CT in suspected pulmonary embolism: meta-analysis of diagnostic performance. Radiology 2005;234(3):740-748.

149. Thistlethwaite PA, Auger WR, Madani MM, Pradhan S, Kapelanski DP, Jamieson SW. Pulmonary thromboendarterectomy combined with other cardiac operations: indications, surgical approach, and outcome. Ann Thorac Surg 2001;72(1):13-17; discussion 17-19.

150. Schrijen F, Jezek V. Hemodynamic and pulmonary wedge angiography findings in chronic bronchopulmonary disease. Scand J Respir Dis 1977;58:151-158.

151. Rabinovitch M, Keane JF, Fellows KE, Castenada AR, Reid L. Quantitative analysis of the pulmonary wedge angiogram in congenital heart defects: correlation with hemodynamic data and morphometric findings in lung biopsy tissue. Circulation 1981;63:152-164.

152. Nicod P, Peterson K, Levine M, et al. Pulmonary angiography in severe chronic pulmonary hypertension. Ann Intern Med 1987; 107:565-568.

153. Stein P, Athanasoulis C, Alavi A, et al. Complications and validity of pulmonary angiography in acute pulmonary embolism. Circulation 1992;85:462-468.

154. Mukerjee D, St George D, Coleiro B, et al. Prevalence and outcome in systemic sclerosis associated pulmonary arterial hypertension: application of a registry approach. Ann Rheum Dis 2003; 62(11):1088-1093.

155. Bogren H, Klipstein R, Mohiaddin R, et al. Pulmonary artery distensibility and blood flow patterns: a magnetic resonance study of normal subjects and of patients with pulmonary arterial hypertension. Am Heart J 1989;118:990-999.

156. Michelakis ED, Tymchak W, Noga M, et al. Long-term treatment with oral sildenafil is safe and improves functional capacity and hemodynamics in patients with pulmonary arterial hypertension. Circulation 2003;108(17):2066-2069.

157. Wilkins MR, Paul GA, Strange JW, et al. Sildenafil versus Endothelin Receptor Antagonist for Pulmonary Hypertension (SERAPH) Study. Am J Respir Crit Care Med 2005;171:12921297.

158. Kuehne T, Yilmaz S, Steendijk P, et al. Magnetic resonance imaging analysis of right ventricular pressure-volume loops: in vivo validation and clinical application in patients with pulmonary hypertension. Circulation 2004;110(14):2010-2016.

159. Ohno Y, Hatabu H, Murase K, et al. Quantitative assessment of regional pulmonary perfusion in the entire lung using threedimensional ultrafast dynamic contrast-enhanced magnetic resonance imaging: preliminary experience in 40 subjects. J Magn Reson Imaging 2004;20(3):353-365.

160. Kruger S, Haage P, Hoffmann R, et al. Diagnosis of pulmonary arterial hypertension and pulmonary embolism with magnetic resonance angiography. Chest 2001;120(5):1556-1561.

161. Laffon E, Vallet C, Bernard V, et al. A computed method for noninvasive MRI assessment of pulmonary arterial hypertension. J Appl Physiol 2004;96(2):463-468

162. Salerni R, Rodnan GP, Leon DF, Shaver JA. Pulmonary hypertension in the CREST syndrome variant of progressive systemic sclerosis (scleroderma). Ann Intern Med 1977;86(4): 394-399.

163. Stupi AM, Steen VD, Owens GR, Barnes EL, Rodnan GP, Medsger TA, Jr. Pulmonary hypertension in the CREST syndrome variant of systemic sclerosis. Arthritis Rheum 1986; 29(4):515-524.

164. Silver RM. Scleroderma. Clinical problems. The lungs. Rheum Dis Clin North Am 1996;22(4):825-840.

165. Hoffman JI, Rudolph AM. The natural history of ventricular septal defects in infancy. Am J Cardiol 1965;16(5):634-653.

166. Craig RJ, Selzer A. Natural history and prognosis of atrial septal defect. Circulation 1968;37(5):805-815.

167. Kidd L, Driscoll DI, Gersony WM, et al. Second natural history study of congenital heart defects. Results of treatment of patients with ventricular septal defects. Circulation 1993; 87(2 suppl):I38-51.

168. Vogel M, Berger F, Kramer A, Alexi-Meshkishvili V, Lange PE. Incidence of secondary pulmonary hypertension in adults with atrial septal or sinus venosus defects. Heart 1999;82(1):30-33.

169. Hopkins WE, Ochoa LL, Richardson GW, Trulock EP. Comparison of the hemodynamics and survival of adults with severe primary pulmonary hypertension or Eisenmenger syndrome. J Heart Lung Transplant 1996;15(1 pt 1):100-105.

170. Castro M, Krowka MJ, Schroeder DR, et al. Frequency and clinical implications of increased pulmonary artery pressures in liver transplant patients. Mayo Clin Proc 1996;71(6):543-551.

171. Yang YY, Lin HC, Lee WC, et al. Portopulmonary hypertension: distinctive hemodynamic and clinical manifestations. J Gastroenterol 2001;36(3):181-186.

172. Robalino BD, Moodie DS. Association between primary pulmonary hypertension and portal hypertension: analysis of its pathophysiology and clinical, laboratory and hemodynamic manifestations. J Am Coll Cardiol 1991;17(2):492-498.

173. Krowka MJ, Frantz RP, McGoon MD, Severson C, Plevak DJ, Wiesner RH. Improvement in pulmonary hemodynamics during intravenous epoprostenol (prostacyclin): a study of 15 
patients with moderate to severe portopulmonary hypertension. Hepatology 1999;30(3):641-648.

174. Krowka MJ, Plevak DJ, Findlay JY, Rosen CB, Wiesner RH, Krom RA. Pulmonary hemodynamics and perioperative cardiopulmonary-related mortality in patients with portopulmonary hypertension undergoing liver transplantation. Liver Transpl 2000;6(4):443-450.

175. Kim KK, Factor SM. Membranoproliferative glomerulonephritis and plexogenic pulmonary arteriopathy in a homosexual man with acquired immunodeficiency syndrome. Hum Pathol 1987; 18(12):1293-1296.

176. Himelman RB, Dohrmann M, Goodman P, et al. Severe pulmonary hypertension and cor pulmonale in the acquired immunodeficiency syndrome. Am J Cardiol 1989; 64(19):13961399.

177. Speich R, Jenni R, Opravil M, Pfab M, Russi EW. Primary pulmonary hypertension in HIV infection [see comments]. Chest 1991;100(5):1268-1271.

178. Opravil M, Pechere M, Speich R, et al. HIV-associated primary pulmonary hypertension. A case control study. Swiss HIV Cohort Study. Am J Respir Crit Care Med 1997;155(3):990995.

179. Mette SA, Palevsky HI, Pietra GG, et al. Primary pulmonary hypertension in association with human immunodeficiency virus infection. A possible viral etiology for some forms of hypertensive pulmonary arteriopathy. Am Rev Respir Dis 1992; 145(5):1196-1200.

180. Morse JH, Barst RJ, Itescu S, et al. Primary pulmonary hypertension in HIV infection: an outcome determined by particular HLA class II alleles. Am J Respir Crit Care Med 1996;153(4 pt 1):1299-1301.

181. Petitpretz P, Brenot F, Azarian R, et al. Pulmonary hypertension in patients with human immunodeficiency virus infection. Comparison with primary pulmonary hypertension. Circulation 1994;89(6):2722-2727.

182. Nunes H, Humbert M, Sitbon O, et al. Prognostic factors for survival in human immunodeficiency virus-associated pulmonary arterial hypertension. Am J Respir Crit Care Med 2003;167(10):1433-1439.

183. Cool CD, Rai PR, Yeager ME, et al. Expression of human herpesvirus 8 in primary pulmonary hypertension. $\mathrm{N}$ Engl J Med 2003;349(12):1113-1122.

184. Gurtner HP. Pulmonary hypertension, "plexogenic pulmonary artericopathy" and the appetite depressant drug aminorex: post or propter? Bull Eur Physiopathol Respir 1979;15:897-923.

185. Abenhaim L, Moride Y, Brenot F, et al. Appetite-suppressant drugs and the risk of primary pulmonary hypertension. International Primary Pulmonary Hypertension Study Group. N Engl J Med 1996;335(9):609-616.

186. Archer SL, Djaballah K, Humbert M, et al. Nitric oxide deficiency in fenfluramine- and dexfenfluramine-induced pulmonary hypertension. Am J Respir Crit Care Med 1998;158(4): $1061-1067$.

187. Connolly HM, Crary JL, McGoon MD, et al. Valvular heart disease associated with fenfluramine-phentermine. N Engl J Med 1997;337:581-588.

188. Michelakis ED, Weir EK, Nelson DP, Reeve HL, Tolarova S, Archer SL. Dexfenfluramine elevates systemic blood pressure by inhibiting potassium currents in vascular smooth muscle cells. J Pharmacol Exp Ther 1999;291(3):1143-1149.

189. Perchenet L, Hilfiger L, Mizrahi J, Clement-Chomienne OP. Effects of anorexinogen agents on cloned voltage-gated $\mathrm{K}(+)$ channel hKv1.5. J Pharmacol Exp Ther 2001;298(3):1108-1119.

190. Patel AJ, Lazdunski M, Honore E. Kv2.1/Kv9.3, a novel ATP-dependent delayed-rectifier $\mathrm{K}+$ channel in oxygensensitive pulmonary artery myocytes. EMBO J 1997;16(22): 6615-6625.
191. Swensen SJ, Tashjian JH, Myers JL, et al. Pulmonary venoocclusive disease: CT findings in eight patients. AJR Am J Roentgenol 1996;167(4):937-940.

192. Humbert M, Maitre S, Capron F, Rain B, Musset D, Simonneau G. Pulmonary edema complicating continuous intravenous prostacyclin in pulmonary capillary hemangiomatosis. Am J Respir Crit Care Med 1998;157(5 pt 1):1681-1685.

193. Wagenvoort CA, Beetstra A, Spijker J. Capillary haemangiomatosis of the lungs. Histopathology 1978;2(6):401-406.

194. Langleben D, Heneghan JM, Batten AP, et al. Familial pulmonary capillary hemangiomatosis resulting in primary pulmonary hypertension. Ann Intern Med 1988;109(2):106-109.

195. Dufour B, Maitre S, Humbert M, Capron F, Simonneau G, Musset D. High-resolution CT of the chest in four patients with pulmonary capillary hemangiomatosis or pulmonary venoocclusive disease. AJR Am J Roentgenol 1998;171(5):13211324.

196. Masur Y, Remberger K, Hoefer M. Pulmonary capillary hemangiomatosis as a rare cause of pulmonary hypertension [published erratum appears in Pathol Res Pract 1996;192(6):646]. Pathol Res Pract 1996;192(3):290-295; discussion 296-299.

197. Almagro P, Julia J, Sanjaume M, et al. Pulmonary capillary hemangiomatosis associated with primary pulmonary hypertension: report of 2 new cases and review of 35 cases from the literature. Medicine (Baltimore) 2002;81(6):417-424.

198. Cornfield DN, Resnik ER, Herron JM, Abman SH. Chronic intrauterine pulmonary hypertension decreases calciumsensitive potassium channel mRNA expression. Am J Physiol Lung Cell Mol Physiol 2000;279(5):L857-862.

199. Grover TR, Parker TA, Balasubramaniam V, Markham NE, Abman SH. Pulmonary hypertension impairs alveolarization and reduces lung growth in the ovine fetus. Am J Physiol Lung Cell Mol Physiol 2005;288(4):L648-654.

200. Roberts JD, Jr., Fineman JR, Morin FC, 3rd, et al. Inhaled nitric oxide and persistent pulmonary hypertension of the newborn. The Inhaled Nitric Oxide Study Group. N Engl J Med 1997; 336(9):605-610.

201. Trembath RC, Thomson JR, Machado RD, et al. Clinical and molecular genetic features of pulmonary hypertension in patients with hereditary hemorrhagic telangiectasia. N Engl J Med 2001;345(5):325-334.

202. Grisaru D, Rachmilewitz EA, Mosseri M, et al. Cardiopulmonary assessment in beta-thalassemia major. Chest 1990;98(5): $1138-1142$

203. Gladwin MT, Sachdev V, Jison ML, et al. Pulmonary hypertension as a risk factor for death in patients with sickle cell disease. N Engl J Med 2004;350(9):886-895.

204. Reiter CD, Wang X, Tanus-Santos JE, et al. Cell-free hemoglobin limits nitric oxide bioavailability in sickle-cell disease. Nat Med 2002;8(12):1383-1389.

205. Thurnheer R, Jenni R, Russi EW, Greminger P, Speich R. Hyperthyroidism and pulmonary hypertension [see comments]. J Intern Med 1997;242(2):185-188.

206. Lozano HF, Sharma CN. Reversible pulmonary hypertension, tricuspid regurgitation and right-sided heart failure associated with hyperthyroidism: case report and review of the literature. Cardiol Rev 2004;12(6):299-305.

207. Curnock AL, Dweik RA, Higgins BH, Saadi HF, Arroliga AC. High prevalence of hypothyroidism in patients with primary pulmonary hypertension. Am J Med Sci 1999;318(5):289-292.

208. Badesch DB, Wynne KM, Bonvallet S, Voelkel NF, Ridgway C, Groves BM. Hypothyroidism and primary pulmonary hypertension: an autoimmune pathogenetic link? [see comments]. Ann Intern Med 1993;119(1):44-46.

209. Ojamaa K, Sabet A, Kenessey A, Shenoy R, Klein I. Regulation of rat cardiac Kv1.5 gene expression by thyroid hormone is rapid and chamber specific. Endocrinology 1999;140(7):3170-3176. 
210. Nocturnal Oxygen Therapy Trial Group. Continuous or nocturnal oxygen therapy in hypoxemic chronic obstructive lung disease. Ann Intern Med 1980;93:391-398.

211. Sandoval J, Aguirre JS, Pulido T, et al. Nocturnal oxygen therapy in patients with the Eisenmenger syndrome. Am J Respir Crit Care Med 2001;164(9):1682-1687.

212. Fuster V, Steele P, Edwards W. Primary pulmonary hypertension: Natural history and the importance of thrombosis. Circulation 1984;70:580-585.

213. Barst RJ, Rubin LJ, Long WA, et al. A comparison of continuous intravenous epoprostenol (prostacyclin) with conventional therapy for primary pulmonary hypertension. The Primary Pulmonary Hypertension Study Group. N Engl J Med 1996; 334(5):296-302.

214. Badesch DB, Tapson VF, McGoon MD, et al. Continuous intravenous epoprostenol for pulmonary hypertension due to the scleroderma spectrum of disease. A randomized, controlled trial. Ann Intern Med 2000;132(6):425-434.

215. Barst RJ, Rubin LJ, McGoon MD, Caldwell EJ, Long WA, Levy PS. Survival in primary pulmonary hypertension with longterm continuous intravenous prostacyclin. Ann Intern Med 1994;121(6):409-415.

216. Shapiro SM, Oudiz RJ, Cao T, et al. Primary pulmonary hypertension: improved long-term effects and survival with continuous intravenous epoprostenol infusion. J Am Coll Cardiol 1997;30(2):343-349.

217. McLaughlin VV, Genthner DE, Panella MM, Rich S. Reduction in pulmonary vascular resistance with long-term epoprostenol (prostacyclin) therapy in primary pulmonary hypertension. N Engl J Med 1998;338(5):273-277.

218. McLaughlin VV, Shillington A, Rich S. Survival in primary pulmonary hypertension: the impact of epoprostenol therapy. Circulation 2002;106(12):1477-1482.

219. Kim NH, Channick RN, Rubin LJ. Successful withdrawal of long-term epoprostenol therapy for pulmonary arterial hypertension. Chest 2003;124(4):1612-1615.

220. Sitbon O, Humbert M, Nunes $H$, et al. Long-term intravenous epoprostenol infusion in primary pulmonary hypertension: prognostic factors and survival. J Am Coll Cardiol 2002;40(4): 780-788.

221. Rich S, McLaughlin VV. The effects of chronic prostacyclin therapy on cardiac output and symptoms in primary pulmonary hypertension. J Am Coll Cardiol 1999;34(4):1184-1187.

222. Robbins IM, Cuiper LL, Stein CM, et al. Angiotensin II mediates systemic rebound hypertension after cessation of prostacyclin infusion in sheep. J Appl Physiol 1998;85(2):731737.

223. Califf RM, Adams KF, McKenna WJ, et al. A randomized controlled trial of epoprostenol therapy for severe congestive heart failure: the Flolan International Randomized Survival Trial (FIRST). Am Heart J 1997;134(1):44-54.

224. Simonneau G, Barst RJ, Galie N, et al. Continuous subcutaneous infusion of treprostinil, a prostacyclin analogue, in patients with pulmonary arterial hypertension: a double-blind, randomized, placebo-controlled trial. Am J Respir Crit Care Med $2002 ; 165(6): 800-804$.

225. Gessler T, Schmehl T, Hoeper MM, et al. Ultrasonic versus jet nebulization of iloprost in severe pulmonary hypertension. Eur Respir J 2001;17(1):14-19.

226. Olschewski H, Ghofrani HA, Schmehl T, et al. Inhaled iloprost to treat severe pulmonary hypertension. An uncontrolled trial. German PPH Study Group. Ann Intern Med 2000;132(6): 435-443.

227. Hoeper MM, Schwarze M, Ehlerding S, et al. Long-term treatment of primary pulmonary hypertension with aerosolized iloprost, a prostacyclin analogue. N Engl J Med 2000;342(25): $1866-1870$.
228. Olschewski H, Simonneau G, Galie N, et al. Inhaled iloprost for severe pulmonary hypertension. N Engl J Med 2002;347(5): 322-329.

229. Galie N, Humbert M, Vachiery JL, et al. Effects of beraprost sodium, an oral prostacyclin analogue, in patients with pulmonary arterial hypertension: a randomized, double-blind, placebocontrolled trial. J Am Coll Cardiol 2002;39(9):1496-1502.

230. Barst RJ, McGoon M, McLaughlin V, et al. Beraprost therapy for pulmonary arterial hypertension. J Am Coll Cardiol 2003;41(12):2119-2125.

231. Channick RN, Simonneau G, Sitbon O, et al. Effects of the dual endothelin-receptor antagonist bosentan in patients with pulmonary hypertension: a randomised placebo-controlled study. Lancet 2001;358(9288):1119-1123.

232. Rubin LJ, Badesch DB, Barst RJ, et al. Bosentan therapy for pulmonary arterial hypertension. N Engl J Med 2002;346(12): 896-903.

233. Barst RJ, Langleben D, Frost A, et al. Sitaxsentan therapy for pulmonary arterial hypertension. Am J Respir Crit Care Med 2004;169(4):441-447.

234. Barst RJ, Rich S, Widlitz A, Horn EM, McLaughlin V, McFarlin J. Clinical efficacy of sitaxsentan, an endothelin-A receptor antagonist, in patients with pulmonary arterial hypertension: open-label pilot study. Chest $2002 ; 121(6): 1860-1868$

235. Liu C, Cheng J. Endothelin receptor antagonists for pulmonary arterial hypertension. Cochrane Database Syst Rev 2005(1): CD004434.

236. Archer SL, Huang JM, Hampl V, Nelson DP, Shultz PJ, Weir EK. Nitric oxide and cGMP cause vasorelaxation by activation of a charybdotoxin-sensitive K channel by cGMP-dependent protein kinase. Proc Natl Acad Sci U S A 1994;91(16):7583-7587.

237. Michelakis E, Tymchak W, Archer S. Sildenafil: from the bench to the bedside. Can Med Assoc J 2000;163(9):1171-1175.

238. Michelakis E, Tymchak W, Lien D, Webster L, Hashimoto K, Archer S. Oral sildenafil is an effective and specific pulmonary vasodilator in patients with pulmonary arterial hypertension: comparison with inhaled nitric oxide. Circulation 2002; 105(20):2398-2403.

239. Ghofrani HA, Voswinckel R, Reichenberger F, et al. Differences in hemodynamic and oxygenation responses to three different phosphodiesterase-5 inhibitors in patients with pulmonary arterial hypertension: a randomized prospective study. J Am Coll Cardiol 2004;44(7):1488-1496.

240. Lepore JJ, Maroo A, Pereira NL, et al. Effect of sildenafil on the acute pulmonary vasodilator response to inhaled nitric oxide in adults with primary pulmonary hypertension. Am J Cardiol $2002 ; 90(6): 677-680$.

241. Ghofrani HA, Wiedemann R, Rose F, et al. Sildenafil for treatment of lung fibrosis and pulmonary hypertension: a randomised controlled trial. Lancet 2002;360(9337):895-900.

242. Barreto AC, Franchi SM, Castro CR, Lopes AA. One-year follow-up of the effects of sildenafil on pulmonary arterial hypertension and veno-occlusive disease. Braz J Med Biol Res $2005 ; 38(2): 185-195$.

243. Karatza AA, Bush A, Magee AG. Safety and efficacy of Sildenafil therapy in children with pulmonary hypertension. Int J Cardiol 2005; 100(2):267-273.

244. Pasque MK, Trulock EP, Cooper JD, et al. Single lung transplantation for pulmonary hypertension. Single institution experience in 34 patients. Circulation 1995;92(8):2252-2258.

245. Hertz MI, Taylor DO, Trulock EP, et al. The registry of the international society for heart and lung transplantation: nineteenth official report-2002. J Heart Lung Transplant. 2002; 21(9):950-970.

246. Dabestani A, Mahan G, Gardin J, et al. Evaluation of pulmonary artery pressure and resistance by pulsed Doppler echocardiography. Am J Cardiol 1987;59:662-668. 
247. Hatle L, Angelsen B. Doppler ultrasound in cardiology: physical principles and clinical applications. 1985.

248. D'Alonzo GE, Bower JS, Dantzker DR. Differentiation of patients with primary and thromboembolic pulmonary hypertension. Chest 1984;85:457-461.

249. Moser KM, Daily PO, Peterson K, et al. Thromboendarterectomy for chronic, major-vessel thromboembolic pulmonary hypertension. Ann Intern Med 1987;107:560-565.

250. Moser K, Spragg R, Utley J, Daily P. Chronic thrombotic obstruction of major pulmonary arteries. Ann Intern Med 1983;99:299-305.

251. Keller CA, Shepard JW, Chun DS, Vasquez P, Dolan GF. Pulmonary hypertension in obstructive pulmonary disease: multivariate analysis. Chest 1986;90:185-192.

252. Rubin LJ, Mendoza J, Hood M, et al. Treatment of primary pulmonary hypertension with continuous intravenous prosta- cyclin (epoprostenol). Results of a randomized trial. Ann Intern Med 1990;112(7):485-491.

253. Shirai M, Sada K, Ninomiya I. Effects of regional alveolar hypoxia and hypercapnia on small pulmonary vessels in cats. J Appl Physiol 1986;61(2):440-448.

254. Hampl V, Weir EK, Archer SL. Endothelium-derived nitric oxide is less important for basal tone regulation in the pulmonary than the renal circulation of the adult rat. J Vasc Med Biol $1994 ; 5: 22-30$.

255. Lawler LP, Askin FB. Pulmonary capillary hemangiomatosis: multidetector row CT findings and clinico-pathologic correlation. J Thorac Imaging 2005;20(1):61-63.

256. Skatchkov MP, Sperling D, Hink U, Anggard E, Munzel T. Quantification of superoxide radical formation in intact vascular tissue using a Cypridina luciferin analog as an alternative to lucigenin. Biochem Biophys Res Commun 1998;248(2):382-386. 